\title{
GENDER IDENTITY: EXPLORING STRUGGLES \& SCHOOL SUPPORT AMONG \\ NEW ZEALAND SENIOR SECONDARY STUDENTS
}

\author{
by Krishn Chandra
}
A thesis submitted to the Victoria University of Wellington
in fulfilment of requirements for the Degree
of Master of Arts
in Education

Victoria University of Wellington 



\section{DEDICATION}

"Somewhere over the rainbow, dreams do come true"

For my babies Timmy and Zinny

My partner, my parents and to someone who we lost on the way 



\section{ACKNOWLEDGEMENTS}

I sincerely wish to appreciate the following for their support, guidance and contribution throughout this research:

- Almighty for his undue blessing, courage and giving the strength at every stage of this research.

- Dr. Cherie Chu and Dr. Fuapepe Rimoni, for your positivity, guidance and believing in me and my abilities as a researcher.

- Mrs. Heather Tanner (Principal - Kelvin Road School), for her support and making this research a possibility

- Staff of Kelvin Road School for their continuous encouragement.

- John Rohs (Principal), Kelly Patterson (Deputy Principal-Pastoral Care) and Josy Whittaker (Social Services officer) of the school as part of this study for their approval, time, commitment and flexibility.

- My friends, family and partner for their love, support and encouragement.

- The participants of this research. 

ABSTRACT

\section{CHAPTER 1 INTRODUCTION AND ORIENTATION}

$\begin{array}{lll}1.1 & \text { Background } & 1\end{array}$

$\begin{array}{lll}1.2 & \text { Research Paradigm } & 10\end{array}$

$\begin{array}{lll}1.3 & \text { Rationale for the Research } & 13\end{array}$

$\begin{array}{lll}1.4 & \text { Problem Statement } & 15\end{array}$

$\begin{array}{lll}1.5 & \text { Research Questions } & 16\end{array}$

$\begin{array}{lll}1.6 & \text { Research Aims } & 16\end{array}$

$\begin{array}{lll}1.7 & \text { Assumptions } & 16\end{array}$

$\begin{array}{lll}1.8 & \text { Glossary of Terms } & 17\end{array}$

$\begin{array}{lll}1.9 & \text { Outline of Chapters } & 18\end{array}$

\section{CHAPTER 2 LITERATURE REVIEW}

$\begin{array}{lll}2.0 & \text { Introduction } & 20\end{array}$

2.1 Gender Diversity or LGBTQIA 20

2.2 Gender Diversity in Secondary Schools 23

2.3 Attitude towards Gender Diverse students in Schools 25

2.4 Effects of Abuse and Bullying in Schools 32

2.5 School Environment 36

2.6 School’s Support for Struggling Gender Diverse Students 39

2.7 Curriculum and Gender Diversity 44

$\begin{array}{lll}2.8 & \text { Conclusion } & 46\end{array}$

\section{CHAPTER 3 RESEARCH METHODOLOGY}

$\begin{array}{lll}3.0 & \text { Introduction } & 47\end{array}$ 
$\begin{array}{lll}3.1 & \text { Context of the Study } & 47\end{array}$

3.2 The Research Method 48

3.3 Research Approach - Phenomenology 49

$\begin{array}{lll}3.4 & \text { Sample } & 50\end{array}$

3.5 Method 53

3.6 Data Analysis $\quad 55$

$\begin{array}{lll}3.7 & \text { Ethical Consideration } & 58\end{array}$

$\begin{array}{lll}3.8 & \text { Conclusion } & 61\end{array}$

\section{CHAPTER 4 RESULTS}

$\begin{array}{lll}4.0 & \text { Introduction } & 62\end{array}$

4.1 The Analysis of the Participants 62

$\begin{array}{lll}4.2 & \text { Discussion } & 67\end{array}$

$\begin{array}{lll}4.3 & \text { Conclusion } & 91\end{array}$

\section{CHAPTER 5 DISCUSSION}

$\begin{array}{lll}5.0 & \text { Introduction } & 92\end{array}$

$\begin{array}{lll}5.1 & \text { Finding of the Study } & 92\end{array}$

5.2 Recommendations for Student Support in New Zealand Schools 106

5.3 Recommendations for Future Research 107

$\begin{array}{lr}\text { CONCLUSION } & 109\end{array}$

$\begin{array}{ll}\text { BIBLIOGRAPHY } & 111\end{array}$

$\begin{array}{ll}\text { APPENDICES } & 133\end{array}$

Appendix A Letter of Ethics Approval 135

Appendix B Information Sheet for the Participants 136

$\begin{array}{lll}\text { Appendix C } & \text { Information Sheet for Principal }\end{array}$

$\begin{array}{lll}\text { Appendix D } & \text { Interview Questions } & 148\end{array}$ 


\section{ABSTRACT}

This research was undertaken with an intention to contribute to the existing literature and research on issues related to struggles and support for gender diverse students in New Zealand secondary schools. Gender diversity is a classification of individuals who do not see themselves as just male or female. LGBTQIA [lesbians, gays, bisexual, transgender and Queer] has been an acronym used to describe individuals of alternative lifestyles. The main objective of this study was to investigate in-depth to understand the positive and negative experiences of gender diverse students in New Zealand Secondary schools. A qualitative research approach was utilised and pragmatics as the research paradigm, as the focus was on the experiences of the learners and view of the teachers. Semi-structured interviews were used as this is regarded as a process of in-depth inquiry which has generated detailed descriptions. The outcomes of this research have been in line with the current and existing literature related to the experiences of gender diverse students in secondary schools in New Zealand. A review of existing literature indicates that gender diverse students are subjected to negative academic and social experiences such as verbal slurs, emotional harassment and abuse. Further, the disengagement of the curriculum and the support of the teachers in schools. The positive indication of this research was the support of the heterosexual students and teachers in the school however, there is a need for more support. It is recommended from this research that the school needs to provide professional development for its teachers and design their curriculum to create equality in the school. 


\section{CHAPTER 1 INTRODUCTION AND ORIENTATION}

\subsection{BACKGROUND}

Diversity among human beings is natural and normal with several variations which undergoes goes various milestones and adolescence is one of the most crucial phases. Adolescence (Fonagy, 2001; Fonagy, Gergely, Jurist, \& Target, 2004; Smart 2012) is a phase marked by social, biological, physiological and psychological changes. Dynamism of social and political climate related to lesbians, gays, bisexual, transgender, queer and recently added intersex and asexual (LGBTQIA) communities has brought about an increased visibility towards equality for those individuals who do not identify themselves as the traditional male or female gender found in Western Civilisation. The issues related LGBTQIA and specifically issues related to gender diversity and inclusiveness are included in this study. The society is experiencing a major shift in helping the way that individuals are now preceding their gender outside their historical binary of male and female. Various studies working on gender diversity and gender identity and expression indicates that gender diversity is not universally viewed as a diagnosable mental illness.

However, the issues related to gender diversity have been an intriguing concept for educators for its controversial history that the sensitiveness of the concepts and its implication on an individual and society at large. Furthermore, the classroom is one of the most common places to study differences in identities and it is where children learn the appreciation for others way of lives. For children to be fully prepared to lead a complete life more issues of diversity should be part of the teaching and learning process. According to the Rainbow Youth (2012) Report, it is stated that an aspect not often prioritised in New Zealand schools are the Gay, Lesbian, Bi-sexual, Transgender, Queer, Intersex and Asexual (LGBTQIA) issues. There are no exact statistics on the number of LGBTQIA's in New Zealand (NZ), but it is believed that 
there is at least one student in every NZ classroom (Post Primary Teachers' Association Report, 2017).

The following chapter outlines the concept of gender diversity, homophobia and abuse of gender diverse students, school support and curriculum related to sexuality and gender diversity. This chapter further sets up the research paradigm, the research aims and objectives, research questions and the rationale of this study.

\subsubsection{EQUALITY, RIGHTS AND GENDER DIVERSITY}

Diversity among human beings is natural and normal with several variations. According to Morgan et at., (2011), in Western societies where friendships are pretentious, and core values challenged, expression of sexuality and gender may be explored, and its independence is encouraged. Smart (2012) states, as most of the students achieve their milestones of the developmental stages, the process can be an additional burden on gender diverse students (Payne \& Smith, 2010). As more individuals begin to identify themselves as being sexually diverse, society can become more acceptable. However, the gender diverse students are still not given equal rights which they deserve as any other individuals.

New Zealand has made significant changes in the policies and regulations pertaining to the rights and freedom of all individuals and has been recognised for being more inclusive. This has been reflected in legislation such as Crimes Amendment Bill in 1974, the Homosexual Law Reform Act in 1986 and Human Rights Act of 1993. Also, “The Civil Union Act was passed in April 2005 and provided couples, either of the same sex or opposite sex, to have their relationships formalised through a civil union ceremony officially registered in New Zealand. Following on the Civil Union Act, the Relationships (Statutory References) Act of 2005 included amendments to a series of Acts to allow the same legal protection of civil union partners as spouses or de facto partners” (Statistics New Zealand, 2016). The 2013 Census 
Quick Stats (Statistics NZ, 2016) suggests that there has been an increase in more diverse families, also more individuals who have openly classified themselves as diverse. The 2013 Census recorded 8,328 same-sex couples; 0.9 percent of all couples (3,672 were male couples and 4,656 were female couples) (Statistics NZ, 2016). The report indicated that as more individuals were accepting themselves as LGBTQIA, there were also many more who were to identify as LGBTQIA. The reports further indicated that the most gender diverse families are relatively young. Reports of studies conducted in NZ secondary schools found $92 \%$ of secondary students were exclusively attracted to the opposite sex, while a significant $4 \%$ were attracted to the same sex or both sexes and $4 \%$ were not sure or were attracted to neither sex while $1 \%$ of students reported being transgender, while the other $3 \%$ were unsure (The Ministry of Social Development, New Zealand, 2016).

The issue of gender diversity has been (and continues to be) discussed internationally at major world leadership gatherings. In 2011 the United Nations Educational, Scientific and Cultural Organisation (UNESCO) held the First International Consultation on Gay, Lesbian, Bisexual, Transgender, Intersex and Queer (GLBTIQ) issues in Educational Institutions in Rio de Janeiro, Brazil (Jones, 2015), where it was asserted that the right to education must not be 'curtailed by discrimination on the basis of sexual orientation or gender identity'. The United Nations Secretary General stated that such bullying is a violation of human rights and to an extent it is a health crisis. Over the decades, the Lesbian, Gay, Bisexual, Transgender, Queer, Intersex and Asexual (LGBTQIA) group have seen significant changes with more individuals being acceptive of their sexual orientation and coming out about their sexuality. They are trying to embrace and 'come out' at a younger age, to live openly with the support of the families, communities and society at large as based on the report the most affected are teenagers aged between 15 to 18-year olds who are going through phases of change and were struggling to identify their sexual orientation (Jones, 2015). 
This research focuses on the perceptions and understanding of the participants and their experiences of being an LGBTQIA or gender diverse student in New Zealand secondary schools which makes this research qualitative in nature.

\subsubsection{HOMOPHOBIA AND ABUSE}

Although there have been some evidence of change and progress, it is still extremely difficult for many individuals from the LGBTQIA community, and especially for young individuals who are 'closeted' or confined or those who cannot openly accept their sexual orientation and those who are not supported by their family, schools and society. This notion is closely supported by Hoffman (2001) that children need to feel safe in school and learn to feel good about themselves and value differences. Hoffman (2001) further suggests, educators need to learn to handle difficult and sensitive issues in a fair and positive manner. The need for positive acceptance for any individual is the key for any individual's growth and active participation in the society. With current societal trends, more individuals are 'coming out' and openly accepting their orientation which has led to more gender diverse families living freely in the society. Making School Safe (1993) report indicates, at least 97\% of students in secondary school's report regularly of hearing such homophobic remarks in schools (Gay Lesbian Education Network 1999). As safety of students is important thus, Teachers in schools require on going professional development and support to handle increasingly sensitive issues for their students.

While many gender diverse students are going through identity challenges, they are also exposed to many forms of physical or verbal abuses. Bullying is another form of discrimination and backlash experienced by homosexual individuals. This important issue was highlighted in the Action Plan on Bullying, published by the Department of Education and Skills, Ireland in January, 2013 in which the Action Plan acknowledges, while there is a variation in the rates of 
bullying reported in studies, it is clear from the available data how many children and young people will encounter some form of bullying behaviour. Unfortunately for a minority the forms of bullying will have a negative impact on the lives of the gender diverse students (UNESCO Report, 2016, p. 220). A combined study by Rubert, Healey, Refferes and Scarlet (2016) revealed that New Zealand has one of the world's highest suicide rates for young men, and research links this to NZ culture's narrow limitations on what is acceptable masculine and male behaviour. According to the 2017 -2018 suicide report released by Mental Health NZ (2018) the highest rate of suicide was among youth aged 15-24 years (19.1 per 100,000). There could be many reasons for this, and many New Zealand schools have taken steps to address bullying. However, the problem continues for students. Bullying in schools has been faced by gender diverse students. Incidents involving physical violence, verbal abuse, emotional attacks, and psychological abuse are common for gender diverse students. This is further supported by the Auckland University’s Youth 2000 survey which indicates of 8166 secondary students surveyed report highlighted gay and bi-sexual young people were three times more likely hurt or bullied at school and transgender participants were 4.5 times when compare to their heterosexual peers (Stopbullying.gov).

In New Zealand, Mental health issues has been an area of concern and discussion. Christchurch Health and Development Study (2005) found that predominantly homosexual men had over five times the rate of mental health problems compared with exclusively heterosexual men, including suicide attempts and suicidal ideation. Sadly, 28.6\% of gay men reported attempting suicide compared with $1.6 \%$ of straight men and $76.4 \%$ reported suicidal ideation (planning or having thoughts of committing suicides) compared with $10.9 \%$ of straight men (mentalhealth.org.nz). The report further stated that the risk of suicide had been mainly caused by discrimination and social exclusion Sexual orientation, gender identity and intersex status are not the cause of the elevated risk of mental health problems and suicidality among the 
rainbow population. Rather, the increased risk is due to discrimination and exclusion (mentalhealth.org.nz).

\subsubsection{CURRICULUM}

It is evident that New Zealand, as a society has tried to pave a way for the acceptance of gender diverse individuals, in the legislation. However, discriminative attitudes from the public has resulted in general non-acceptance, suicidal attempts, and a rise in sexually transmitted diseases such as HIV and AIDS among the LGBTQIA group. The New Zealand AIDS Foundation (2018) report states that, 197 people were diagnosed with HIV of which 89\% of the infections acquired in NZ were men who have sex with men (MSM) in 2017- this remains unchanged from 2016. Therefore, there is a need for the education system to help address these issues. Johanna et al., (2016) stated that conversations about sexuality and gender identity are being encouraged. This is about the encouragement of school personnel to question gender stereotypes and assumptions about sexuality, including discussions of culturally appropriate practices and processes for working with Māori and Pasifika students. The New Zealand curriculum is well supported with ideologies of diversity, respect and gives importance to human rights but the curriculum should also reflect support in terms of one's self-expression, support and to realise one's sexual orientation (NZ Health Curriculum, 2017). A positive learning environment is a key factor to support students and this could be achieved through school environments. It will only be possible if schools amend their school charters and establishes frameworks to support student diversity of identities in the school system.

Sex education or sexuality education is one of the important components of the New Zealand Curriculum. It is aimed at contributing to the overall health, wellbeing and resilience of young people (Education Review Unit, 2017). Although the units on Sex Education are part of the curriculum from Years 1 to 13, Sex Education is only compulsory from Year 9 and the 
gender related topics are only introduced and from Years 11 to 13. These topics include approaches to analysing gender and sexuality, exploring and critiquing how sexuality and gender are viewed in society and culture, researching positive sexual health behaviours, working across the school to affirm human rights to be inclusive of everybody (Education Review Unit, 2017).

As an educator, I have realised that sexual education related topics are only taught from Year 6 (age 12 upwards) however, students tend to use words such as 'gay' and 'that's so gay' to describe students who portray feminine characteristics. I agree with Culpan (2004) highlighting sex education and homosexuality inclusion has been a cause for controversy such as religious beliefs, whether this is an appropriate age and some groups in society deeming this a social issue rather than as an educational issue. Students below the age of 16 years require consent from their parents to attend such classes and these classes are not greatly supported and well-studied in depth. According to the Education Review Report (2017) the sexuality education only became part of the Health and Physical Education curriculum in 1999.

Moreover, according to research, the age range of students who are mostly affected by homophobic abuse are aged 16 years and over. Despite sex education being a compulsory topic, this still does not require teachers to teach or include this in their teaching. The absence of such issues is detrimental to sexuality education and some teachers assume that it is not relevant in mainstream teaching (McAullam, 2015). There is no explicit requirement for the teachers to inculcate such topics in their classroom subjects. The exclusion of such material denies the basic rights of gender diverse students from information and development about their personal identity.

Jackson and Weatherall (2010) claim that moral conservatism has a strong influence on the content of New Zealand sexuality education. This research also investigated the role of the school in supporting gender diverse students. Support was offered in the form of regular 
counselling and encouraging students to be active in their schools. The question that has remained unanswered by the schools, Ministry of Education and the curriculum itself, despite educational policies, gender diverse students remain victimised or are the ones who are challenged in their homes, schools and in society. This has led to the need for discussions to happen on the nature of educational settings and an analysis of how policies are being implemented as well as the roles of schools in policy implementation. Jones (2015) further highlights a case in Australia where the lack of educational policies for LGBTQIA student support to support them in schools. Despite many reforms such as Homosexual Law Reform Act in 1986 and Human Rights Act of 1993 and the 2005 civil union reforms the New Zealand education system and the Health and Physical Education curriculum focusing on sexuality and sexual orientation has not progressed much for LGBTQIA students. Generally, documents such as the curriculum and the education system or policies does not cater for the gender diverse students, as most schools and teachers still treat students as heterosexual (Jones, 2015).

The Education Review Office's (2007) investigation into the sexuality education programmes in 100 New Zealand secondary schools revealed that $80 \%$ of schools were unable to show evidence that their "sexuality education programmes provided opportunities for students to explore and challenge issues such as homophobia, diversity and acceptance”. The 2017 evaluation, the Education Review Office still found that overall, curriculum coverage was inconsistent. The 2017 Report further indicated schools not meeting minimum standards of compliance with current requirements and those meeting minimum standards, but many have significant gaps in curriculum coverage. Furthermore, the groups identified as being disadvantaged (LGBTQIA) in the 2007 report remain less well catered for, despite being at higher risk of negative wellbeing outcomes (ERO Report, 2017).

McAllum (2015) further discusses that according to the 2007 ERO report, many schools assume their students to be of heterosexual orientation. During this research, it was highlighted 
that some teachers treated gender diverse students differently and these pretended to be 'normal'. This also suggests that the teachers contribute to the students' negative experiences in schools. Sexuality education as described by Munro (2003) is a contentious area of the New Zealand Curriculum. There have been a lot of debates in education and in society, about how to teach sex education and who the most suitable teacher to teach these topics is. It is evident that some the teachers are challenged by their personal morals, principles beliefs and their abilities to address issues related to gender diverse students.

Due to limited literature which examines how gender diversity is taught, integrated and addressed in educational institutions, this study utilises one to one interview that asks specific questions related to teachers, administration and other staff members are, policies and guidelines, if at all, using information related to gender diversity in guidelines set by the Ministry of Education, New Zealand (ERO, 2018).

\subsubsection{SUPPORT AND SAFETY}

McInnes and Davies (2008) describes safety as social spaces where sexually diverse young people are free from physical and/or emotional challenges. Schools need to provide its leaners with a conducive environment regardless of their gender, sexual orientation or race. As stated earlier, bullying has been one of the common issues that affects students throughout the country. Nansel et al, (2001) stipulates that approximately 30\% of LGBTQIA students have reported being bullied by their peers.

Furthermore, this research investigated how these individuals could obtain support for their identity changes. Growing up as teenagers is already challenging but LGBTQIA students are confronted with the additional challenges of being accepted. Learning facilities such as schools play an instrumental role in providing comprehensive support through education and enable them to feel safe and supported. Jones (2015) highlighted that the Ministry of Education, 
together with other Government agencies, needed to continue to support schools to deliver educational programmes in a safe and supportive environment to meet the needs of the range of students in the community. The research further analysed the views of the teachers on the curriculum content, their abilities to deliver the content, their personal feelings and their recommendations in order to cater to gender diversity.

This research is aimed to explore students' understanding of gender diversity through self-realisation and identification which further investigates the misrecognition of gender diverse students in schools. Through this it is hoped that teachers are made aware of the issues pertaining in their schools and addressing the learning needs and presence of LGBTQIA students in the classroom. It is aimed to contribute to available research and literature by having a closer look into school contexts and health education classes in school.

This topic is relevant to teaching and education in relation to the impact of teachers, students, administration and school as perpetuating the status quo. Furthermore, the impact they may have in the teaching and learning of students related to issues of gender and gender diversity. It is hoped that this study of the secondary education system will lead to greater understandings to advocate respect, equality, support and recognition for those students who identify as either lesbian, gay, bisexual, transgender, queer, intersex or asexual. It is also hoped that the findings of this study may inform the issues related to gender diverse students in secondary schools in New Zealand and policies and issues that may need attention in school environments.

\subsection{RESEARCH PARADIGM}

This research focused on the qualitative research approach due to the complexity of responses through open-ended questions. Qualitative research methodologies over time have become an increasingly important mean of obtaining data for social sciences and applied fields 
such as education. According to Leedy and Ormrod (2005) this approach focuses on the phenomena that occur in the natural setting - that is in the "real world" and studying these phenomena in all their complexity.

Focusing on the complexity of responses permissible in open ended questions in a qualitative approach justified the research (Leedy and Ormrod, 2005). A small sample of participants' voices are illuminated to provide an appreciation of their experiences. These details are central to understanding the experiences of participants who may have faced homophobia. This approach allows a description of events with an attempt to understand and explain them in-depth. This research focuses on the perceptions of the participants, giving insights of what they are thinking and what affects their actions. This approach allows the researcher to seek explanations and interpret feelings rather that measurement of evidence. As Leedy and Ormrod (2005) and Kothari (2004) state that qualitative research is normally conducted in its natural environment and the researcher becomes the part of the research process. Variables are normally not controlled, and the problems are constantly refined. This research intends to record and analyse necessary facts and values through the perspectives of the participants. Thus, through this research I was able to understand and analyse the challenges of the gender diverse students in the New Zealand secondary schools.

This research focuses on the perceptions and understanding of the participants and their experiences of being an LGBTQIA or gender diverse students in New Zealand secondary schools which makes this research qualitative in nature. I was interested in the experiences of the participants and their world. In addition to this, there are various paradigmatic frameworks that can be utilised in order to gain qualitative data according to De Vos et al. (2005) who further describe paradigms as a way of understanding reality.

To set the search paradigm, this research has been based on the Pragmatic approach. Pragmatists believe that reality is constantly renegotiated, debated, interpreted, and therefore 
one of the suitable methods to use as it solves the problem (Patel, 2015). I believe that this research is based on the constant debate as to how the gender diverse students are catered for. The reality concept is important here because the issue being studied here, is understood considering different experiences and perceptions. Pragmatists link the choice of approach directly to the purpose of and the nature of the research questions posed (Creswell, 2003). Pragmatism is a philosophical movement that includes those who claim that an ideology or proposition is true if it works satisfactorily, that the meaning of a proposition is to be found in the practical consequences of accepting it, and that unpractical ideas are to be rejected (McDermid, 2017).

The pragmatic paradigm has what Tashakkori and Teddlie (1998) and Creswell (2003) identify as intuitive appeal, permission to study areas that are of interest, embracing methods that are appropriate and using findings in a positive manner with the value system held by the researcher. For these reasons, it can be argued that the pragmatic paradigm can adopted for the purpose of social and management research endeavours as this is congruent with the mixed quantitative and qualitative approach taken within the predisposition of "practitioner-based" research.

The research process has enabled a systematic and cumulative composition knowledge from New Zealand classrooms that has constantly allowed me to renegotiate the issue and ideas. There are not many New Zealand educators and researchers who have reported on the issue of gender diversity. I believe my research study will challenge and broaden research areas as well as aim to improve and, on the status, and policies pertaining the LGBTQIA groups in school. This study is designed in order to provide learning experiences for the participant's reflections on a dilemma that is troubling them. The active conversation engagement acts as a catalyst in bringing up the issues. 
The pragmatic approach works on a philosophical movement that includes those who claim that an ideology or proposition is true if it works satisfactorily and the meaning of a proposition is to be found in the practical consequences of accepting it, and that unpractical ideas are to be rejected (McDermid, 2017). With this it is intended to derive theories that could provide school leaders to re-examine the school policies and the curriculum at large. This would make way for diverse gender identities, leading to paradigm shift which can address issues within school's curriculum. With this research, it is intended that teachers can learn about the complexities of identities from queer theory and that labels have a damaging impact on children that is felt well into their adulthood (Morris, 2000).

\subsection{RATIONALE FOR THE RESEARCH}

A significant number of researches has been conducted over the years related to marginalised students to investigate their experiences in education, which are substantially different from the experiences of their counterparts (Sanlo et al., 2002). As research, further states most of the minority students might be less satisfied than their counterparts with school experiences (Sanlo et al., 2002). It is rather unfortunate that gender diverse students are stereotypically being ignored as marginalised students in most educational institutions. Therefore, this research is taken up with an intention to investigate the issues pertaining to gender diverse students in school and more specifically in secondary schools and to scrutinise the issues that is affecting the educational experiences of gender diverse students. This research may bring out some strategies and results that may improve the personal, academic and professional development of gender diverse students in New Zealand secondary schools. The data may be used to improve best practices in schools to improve the conditions of the gender diverse students and can lead to future avenues of research. 
Furthermore, this topic has always been close to my heart as a researcher and educator, while I also classify myself a bi-sexual. There were incidences where I was called derogatory names. My friendships were usually with the opposite gender and these were more feminine friendships rather than relationships or sexual courtships. After moving to New Zealand from Fiji, I had some personal encounters, where I was not considered for jobs for which I was suitably qualified for due to my sexual preferences. After successful interviews and being promised a teaching position, it was later withdrawn due to speaking openly about my sexuality and ideologies regarding homosexuality.

As an experienced teacher and educator, I have been open to issues related to gender diversity in my teaching career and it is surprising that the New Zealand Curriculum and the school system does not fully support gender diverse students. I come from a background and country where homosexuality is legal, but the general society is conservative in their thoughts and actions and in religious terms homosexuality is still seen as wrongdoing. While being a teacher for almost 10 years I have experienced changes in gender and family life. Reading various articles and statistics related to New Zealand I have developed more interest in this issue and how it has prepared me to face issues, personally and for students in New Zealand schools. My desire is to contribute to existing researches. I am keen to explore the perceptions of the students and teachers. I wish to increase awareness of issues related to gender diversity and to contribute to an increasing the wellbeing of the gender diverse students in New Zealand secondary schools. One of the reasons that drove me to investigate this issue is that, this research could increase the knowledge of LGBTQIA students' experiences. This study can also contribute to helping schools develop policies to protect the rights, freedom and dignity of the LGBTQIA students.

Apart from my personal viewpoint as a researcher, the literature related to the experiences of gender diverse students shows a clear deficiency in research and data related to 
the experiences of students in secondary schools (Walso, 1998; Sanlo, 2004). According to the Education Review Report (2017) there is still no concrete evidence on exact number LGBTQIA students in secondary schools. While scrutinising literature I noted a significant gap related to how the issue is dealt with and lack of policies in secondary schools to equally recognise and give the equal status in the school system. It is apparent that gender diverse student's continually face discrimination and abuse at universal level as well as in schools. Sanlo et at, (2002) suggests that it is due to underlying heterosexist views in the education system that gender diverse students remain ignored. This research is conducted with a belief that it is an obligation of all educators and leaders to educate students to function effectively in a contemporary global community and to provide students with a rich environment which is inclusive and equitable for gender diverse students.

\subsection{PROBLEM STATEMENT}

Research students have indicated that gender diverse students in secondary schools are experiencing homophobic abuse. Olweus (1991) stated that physical bullying such as hitting, kicking, grabbing toys, from other children, and engaging in very rough and intimidating play while psychological bullying included name calling, teasing, taunting, making faces, and making threats or verbally such as name calling. Horowitz and Loehnig, (2005) reported that students are subjected to verbal abuse and derogatory comments. The LGBTQIA community have identified that being called "fag”, "homo” or "gay” are common everyday occurrences. The report also outlined that teachers have looked the other way when such terms were used, and some did not provide any punishment which further led to the continuation of the issue. As the results show, these comments could cause distress to the gender diverse students. Bullock (2002) suggested that victims of bullying can suffer from feelings of loneliness and low selfesteem in addition to developing anxiety and fears about school. 
According to the Youth '12 (2013), the gender diverse students were negatively affected by their school environment as most of them were afraid that someone might hurt or bother them while $20 \%$ students indicated being bullied on a weekly basis and $46.1 \%$ were being bullied mainly because they were gender diverse. This has been one of the core reasons for high rates of suicide among gender diverse students as according to the Suicide Mortality Review Committee (2016, p. 32) noted that "the stigma associated with homosexuality appeared to be particularly significant for the males in this population who were bullied about their sexual orientation”.

\subsection{RESEARCH QUESTIONS}

Through this research I answered the following questions:

- To what extent does the New Zealand curriculum and secondary schools support gender diversity?

- What are the key issues for LGBTQIA young people in NZ schools?

\subsection{RESEARCH AIMS}

- To study and scrutinize the New Zealand (NZ) education curriculum and policies in relation to gender diversity and the struggles faced by senior secondary students.

- To investigate the issues faced by gender diverse students in NZ schools.

- To make recommendations as to how the education system and schools support gender diversity for their optimum growth.

\subsection{ASSUMPTIONS}

I approached this study with the following assumptions in order to find clarity throughout the process of this study: 
- Being gender diverse does not determine an individual and his or her capabilities and not their worth as a human.

- Gender diversity is not given the same acceptance and support as heterosexual individuals and the state of change towards homosexuality is still slow.

- Sexual orientation is inborn human trait which cannot changed or altered and for some it is a deliberate choice.

- The prejudice nature of the society towards the homosexuality is the key reason for unacceptance.

\subsection{GLOSSARY OF TERMS AND KEY CONCEPTS}

As clarity is imperative in any research, the following list are some of the basic terms as they are used for the purpose of this research.

Bisexual is noted as sexual attraction towards both male and female whereby an individual has a coexistence of birth heterosexuality and homosexuality (Baker, 1999).

Bullying is an unwanted aggressive and repetitive behaviour due to imbalance of power. (dictionary.com, 2019)

Discrimination is any form of negative or unequal treatment due to race, religion, sexual orientation and so on (Baker, 1999).

Experience refers to an event that one has lived through or undergone.

Gay is a term used to represent homosexual males.

Gender Diversity is an individual's gender identity, role or expression which may differ from the cultural norms related to a sex.

Gender identity is an individual's identify of oneself as male, female or something else.

Gender is an individual's biological sex. 
Heterosexism according to Baker (1999, p. 214) is “The belief that Gay men and Lesbians are deviant, abnormal or inferior to heterosexual people” (Barker, 1999, p. 214).

Homophobia is stated as hatred or unreasonable fear of homosexuals (Barker, 1999, p. 214). Homosexuality is noted as an attraction towards the same gender.

Lesbian is an attraction of a woman towards another woman.

LGBTQIA - Lesbian, Gay, Bi-sexual, Transgender, Queer, Intersex, and Asexual. Acronym used to address gender diverse group.

Sex refers to an individual's biological status categorised as male, female or intersex.

Sexual minority is noted as individual whose sexuality is considering to be other than heterosexual.

Sexual Orientation is a person's sexual identity in relation to the gender to which they are attracted.

Transgender is where in gender identity one's assigned gender does not match their felt identity.

\subsection{OUTLINE OF CHAPTERS}

\section{CHAPTER 1: INTRODUCTION AND RATIONALE}

Chapter 1 outlines the research study which will include a brief discussion on the motivation for undertaking this study, the aims and objectives of the study and the research paradigm which this research is based upon.

\section{CHAPTER 2: LITERATURE REVIEW}

Chapter 2 discusses the relevant literature that underpins the study and the experiences of the gender diverse students in New Zealand and across the world will be reviewed. 


\section{CHAPTER 3: RESEARCH DESIGN AND METHODOLOGY}

Chapter 3 discusses the research design used as well as the methods employed to facilitate participant selection, data collection and data analysis in this study.

\section{CHAPTER 4: ANALYSIS OF RESEARCH FINDINGS}

Chapter 4 discusses the finding and interpretation of the research in detail.

\section{CHAPTER 5: SUMMARY, RECOMMENDATIONS AND CONCLUSIONS}

Conclusions are drawn in this chapter through integration of collected data and conclusions drawn and recommendations made from the findings of this research. 


\section{CHAPTER 2 LITERATURE REVIEW}

\subsection{INTRODUCTION}

This review focuses on the notion of sexuality including the struggles of gender identity and the support provided by schools and the education system. In terms of evidence, a limited range of research has been conducted focusing specifically on the senior secondary LGBTQIA students in New Zealand. While scrutinising for literature, it is evident that the main sources of literature appear as selected reports locally by organisations. Therefore, I have extended my interest focusing on the diverse groups at different schooling levels more specifically secondary schools aged 16 to 18-year olds, internationally.

Gender diverse students not only are faced with personal challenges, but researchers believe that it also impacts their educational experiences and also in some cases their academically. This literature elaborates number of issues such as the gender diversity in schools, abuse and bullying they face, its effects on gender diverse students, school support and the role of schools and curriculum in recognising and catering for gender diversity among them.

\subsection{GENDER DIVERSITY OR LGBTQIA (LESBIAN, GAY, BI-SEXUAL, TRANSGENDER, QUEER, INTER-SEX AND ASEXUAL)}

Fone's (2000) research stated that issues of discrimination against sexual minority or gender diverse people was evident almost hundred years ago by Magnus Hirschfeld. However, in New Zealand the LGBTQIA society has been given equal importance through legislation but these changes have been enacted very recently. According to Laurie (2005) the United Nations made significant changes to the Human Rights Act in 1977 but the Government of New Zealand refused to recognise sexuality and gender diversity as reasons to provide protection against harassment and discrimination. In 1985 the Government of New Zealand introduced the 
Homosexual law reform bill which decriminalised sexual relationships between males (Laurie and Evans, 2009). According to Laurie (2004) despite the Bill being voted to bring about the changes, the discrimination clause was rejected in the parliament as the oppositions felt that homosexuality is not human rights issue and the discrimination against the LGBTQIA were acceptable until 1993 when reforms were made to the bill that outlaw the discrimination on the basis of sexual orientation or HIV (Ua, 2005). Further changes were proposed over time such as changes into the Civil Union Act allowing the same-sex couple to marry came into effect in 2013 (New Zealand Government, 2013).

Being gender diverse or being homosexual in the 1950's to early 1970's was considered a mental illness. However, in 1973 the American Psychologist Association removed homosexuality from the list of mental illnesses. Loftus (2001) suggested that this shift was prompted by recognition through education of civil liberties associated with homosexuality. According to Griffin and Ouellet (2003), in the late 1980's homosexuality was included as part of sex education, incorporating it with Human Immune Virus (HIV) and Acquired Immune Deficiency Syndrome (AIDS). Jones (2013) stated that this was negatively associating homosexuality with disease, illness and death.

Further elaborating, on the concept of gender identity, Shine et al. (2018) describes gender as a person's deeply-felt, inherent sense of being a boy, a man, or male; a girl, a woman, or female, or an alternative gender (e.g. genderqueer, gender nonconforming, gender neutral) that may or may not correspond to a person's sex assigned at birth or to a person's primary or secondary sex characteristics is referred to as gender identity. Since gender identity is internal, a person's gender identity is not necessarily visible to others. 'Affirmed gender identity’ refers to a person's gender identity after coming out as transgender or undergoing a social and/or medical transition process (Shine et al. 2018). The author explains that sexual orientation is a component of identity that includes a person's sexual and emotional attraction to another person 
and the behaviour and/or social affiliation that may result from this attraction. A person may be attracted to men, women, both, neither, or to people who are genderqueer, androgynous, or have other gender identities (APA Online, 2003). Individuals may identify as lesbian, gay, heterosexual, bisexual, queer, pansexual, or asexual, among others (Shine et al., 2018). Behaviourists believe that some sexual and gender identification differences result from roles imposed by family and friends upon children, such as the masculine and the feminine stereotypes. However, Richard (2003) states that the problems with this is that there is no evidence, social or biological, to support that homosexual children were raised differently than were the heterosexual children. Also, with reinforcement of gender identification norms, one would be led to logically deduce that all the stereotype reinforcement would ensure a heterosexual outcome.

While in many cultures' homosexuality is considered as 'wrongdoing', with modern changes in conceptualisations and understanding, there has been an influx of more individuals 'coming out'. 'Coming out' is the term used to describe the process through which a person realises that they are lesbian, gay, bisexual or transgender and begins to disclose their sexual orientation or gender identity to others (Gay Lesbian Equality Network (GLEN), 2016). As prominent researchers have noted, the 'coming out' process is tantamount with segregation, vulnerability, indistinctness and concealment (McCunne, 2008; Walters, 2014) while researchers such Orne (2011) challenge their audience while social scientists such as Kus et al., (1985) to embrace a wider understanding of meaning potentially held by gender diverse individuals as it is related to self-discourse and sexual orientation exploration process. The process of 'coming out' is as indicated is a lifelong process (Orne, 2011) than a single episode of disclosure (Walters, 2014) and it is likely to begin with recognition of one's gender identity with many individuals sharing their status with others (Cohne et al., 2010; Orne, 2011). 
Even though gender diversity is natural, and these youths are more vulnerable, many countries infer that same-sex relationships are a negative thing (Bass \& Kaufman, 1996). The process of coming out also involves developing a positive identity as an LGBTQIA person. Rofes (1989) states that there has been resistance in dealing with sexual minority youth due to the perception that sexual orientation is developed late in adolescence and therefore sees youth as sexually neutral. The level of support available to young people from family, friends and school is a major determinant of how easy or difficult it is for them to navigate this process (Higgins et al, 2016; Mayock, et al, 2009). The authors further state that the period between accepting their orientation and realisation is one of the most difficult phases of any individual's life which leads to traumatisation, and more for the fear of rejection (Mayock et al, 2009). The researcher further states that the age of 16 years is a significant age to realise their homosexual identity thus, this Master of Arts study has selected students in senior secondary schools who are 16 years and over in line with literature.

\subsection{GENDER DIVERSITY IN SECONDARY SCHOOLS}

Around New Zealand, thousands of LGBTQIA students walk through the school gates; of theses about $4 \%$ of New Zealand secondary school students are unsure of their gender (Faculty of Medical and Health Sciences, 2012). A report released by Bullying Free NZ (2017) suggests that around $10 \%$ of the secondary school students are likely to be gender diverse. Harassment and various forms of sexism disseminate gender inequalities in prominence and supremacy the society. The report published by GLSEN 2009 titled the National School Climate Survey, it was stated that $62.6 \%$ of the participants claimed being negatively labelled about their gender expression such as not being ‘masculine or feminine enough' frequently at school (Kosciw et al., 2011). 
Whilst there has been an increase in public knowledge related to gender issues in the last decade, many educationists are not exposed to the needs for gender diverse students and how to cater for those who are struggling to open about their sexuality. Thus, as Rubert et al. (2016) states that that teachers, principals and schools need to be equipped to support the wellbeing and success of diverse gendered young people. The longer a LGBTQIA student is not affirmed in their identity, the more significant and long-lasting the negative consequences can become. These consequences can include the loss of interest in school, heightened risk for alcohol and drug abuse, poor mental health and suicide (Faculty of Medical and Health Sciences, 2012). Such issues become an imperative for all educationists and individuals to conceptualise themselves on issues of gender identity.

Further, Mayock et al., (2009) urges that the individuals need to be supported, understood and respected. Craig et al. (2008) indicates that secondary schools are thought to be unsafe environments for many sexual or gender diverse youth. The LGBTQIA students in most cases are not able to accept or have self-realisation of their sexuality. These unsafe environments create significant barriers to learning and wellbeing. New Zealand based research such as Rossen et al. (2009) indicate that twice as many homosexual individuals have been abused in comparison to heterosexual students. The researchers reported incidences of bullying, victimisation, harassment and assaults, with levels of suicide and self-harm well above and beyond those of their heterosexual peers (Rossen et al., 2009).

This literature highlights that in New Zealand, a higher prevalence of violence is evident against LGBTQIA students than other students. A 2014 report suggested that lesbian, gay and bisexual students are three times more likely to be bullied than their heterosexual peers, and transgender students are five times more likely to be bullied than non-transgender students (UNESCO Report, 2016). Therefore, this literature highlights the issues of bullying and 
discrimination of gender diverse students. It further highlights the struggles of gender diverse students and finally the slack of support through school for them to lead an equal life.

Evidence has surfaced that peer victimisation due to gender diversity (Collier et al., 2013) is largely associated with a deteriorating sense of belonging in schools and levels of disruptions and depression. According to Craig et al., (2008, p. 239) "school officials and lawmakers at the local, state, and federal are accountable for refusing to dismantle the policies or eliminate the practices that permit the continual victimization of these students” (Craig et al., 2008, p. 239). Research conducted by Johnston (2005) 18\% of gender diverse students indicated the LGBTQIA issues were discussed in the physical education or sex education classes. Moreover $68 \%$ of students indicated that such issues were not discussed in schools at all. Wright and Cullen (2001) stated that homophobic attitudes related to sex education being taught in class school inequalities and people with more homophobic views were less well informed about homosexuality. Coming out to other people is a sensitive moment for gender diverse students and the students tend to be vulnerable and likely to suffer from mood disorders, substance abuse or risky behaviours and suicides rates and self-harm are alarmingly high among the gender diverse students (Hooper, 2004).

\subsection{ATTITUDES TOWARDS GENDER DIVERSE STUDENTS IN SECONDARY SCHOOLS}

Secondary schooling is an exciting part of the education system, on the contrary can be challenging for some as well. While it is already difficult for any individual to deal with the period of adolescence, gender diverse students are faced with even more difficulties. In addition to discomfort and discrimination, gender diverse student's homophobic attitudes and oppression in their daily lives and thus create a social climate that is detrimental to gender diverse students. This leads to many gender diverse students to live and study under depression 
(May\&Cochran, 2001) and often leads to individuals to experience "greater vulnerability to depressive distress and anxiety” (Mays \& Cochran, 2001, p. 1870). The process of advocating for LGBTQIA students began with the recognition of schools as sites of bullying, harassment and victimisation and then led to programmes being designed specifically to address gay and lesbian student needs in schools (Griffin \& Ouellett, 2003; Rofes, 1989). The GLSEN (1999) research stipulates that majority of the LGBTQIA students surveyed that $69 \%$ of the total students surveyed of which $61.1 \%$ stated being verbally harassed; $46.4 \%$ informed of being sexually assaulted such as having suggestive comments made, being touched inappropriately and so on, and $27 \%$ experienced physical assault such as being kicked and pushed. Some LGBTQIA students also experience rejection from their friends, peers and family in most cases (Bulter, 2008). Butler (2008) further states that this includes students being ignored, excluded, ostracised and disregarded mainly for reasons that they are different. Researchers (Garofalo \& Wolf, 1998; Hershberger \& Pilkington, 1997; Morrison \& L’ Heureux, 2001) have always outlined that adolescents are extremely vulnerable to homophobic abuse and are mostly regarded as high risk of psychological health issues. Most gender diverse students find themselves being exposed to homophobic verbal abuses throughout their course of education and sadly, many of these remarks ignored by teachers and other staff members (Morrison \& L' Heureux, 2001). Mortison and L'Heureux (2001) further state the act of oppression and damaging remarks leads to the LGBTQIA students finding themselves isolated and feeling at risk.

A LGBTQIA teen may encounter vague feelings of being different, or experience feelings of isolation and it is important for these teens to gain a sense of universality, to not feel alone but to feel accepted and understood (Bass \& Kaufman, 1996). They further discuss that in order to gain universality in a classroom ample support and open discussions are mandatory (Bass \& Kaufman, 1996). Among various challenges a gender diverse student is exposed to 
various forms of discrimination and bullying at school. Jones (2015) states that the discrimination young gender diverse people face in their lives can be harsh and pervasive, affecting them in every facet of their lives. The impact is established where there is a direct relationship between discrimination and the health and wellbeing of LGBTQIA students (Rossen et al, 2009). Further documented in Gywn (2006) a Health and Wellbeing survey documented that 40 percent of transgender students had significant depressive symptoms and one in five had attempted suicide in the past year. Gruber and Fineran (2008) and McCormack, (2011) expresses, not many gender diverse students proceed to higher education institutions since it is difficult for them to succeed scholastically in schools’ due to abuse and exclusion. Russell et al. (2011) that this limits the LGBTQIA students for further opportunities to achieve their career goals.

The mind-set of heterosexual educators and students towards sexual minorities needs to be attended to and changed (Birkett et al., 2009). This can be achieved through professional development on sexuality and including this as part of the teacher training program (Butler et al., 2003). Educators need to understand that all types of oppression whether it depends on race, sexual orientation should to be addressed and countered, with a similar urgency (Francis and Msibi, 2011). According to D’Augelli and Hershberger (1993) gay and lesbian students selfrealise their sexual orientation as young as 10 years old. Therefore, when considering this age group this could be students’ young as Year 4. With self-realisation students are exposed to various emotions and feelings. To be able to accept their feelings and changes requires courage as the young mind goes through various inner conflicts (Bass and Kaufman, 1996). Thurlow (2001) asserts that the light-hearted way derogatory words are used by secondary school learners indicates that they have little concern for the harmful consequences of their actions. Thurlow (2001) further explains teachers and other heterosexual peers did not see the use of derogatory words to refer to homosexuals as serious as it was not their intention to cause harm. 
Though the heterosexual learners indicated that it was not their intention, their disregard for the feelings of sexual minority groups came through strongly.

Moreover, there are hopes to address homosexuality and gender identity related issues but there is also a need for more awareness and understanding of bullying around sexuality and gender diversity. As noted, sociologists have traditionally categorised gender, sexual orientation and sex as separate variables (Ward \& Schneider, 2009). According to "experts," everyone is born with a male or female body, and one's disposition in terms of gender and behaviour is either masculine or feminine, and sexuality falls into either a heterosexual or a homosexual classification (Valocchi, 2005).

On the contrary, there have been some countries that have shown initiatives in addressing the issue of homosexuality. For example, Australia’s 2013 Sex Discrimination Act (Sexual Orientation, Gender Identity and Intersex Status) provides protection against discrimination based on sexual orientation, gender identity or expression and intersex status (UNSECO, 2016). Similarly, New Zealand's the Ministry of Education published a Guide for Sexuality Education (Burford, 2013) stating that school anti-bullying procedures should directly address bullying related to sexual orientation and gender identity/expression and that these incidents should be recorded as such and monitored. The Report further discusses the comprehensive guidance also touches upon the curriculum, school uniforms, restroom facilities, procedures and policies in sports and extra-curricular activities (Burford, 2013).

The research further notes that in recent years bullying in New Zealand has risen to prominence in the national media and education policy debates (Ministry of Education, 2011). Bullying and other forms of anti-social behaviour are becoming a challenge for all educational institution and relevant stakeholders. It has been noted that for one in five transgender students in New Zealand have had experiences of bullying at school on a weekly (or more frequent) basis (Rubert et al, 2016). Jones (2015) states that bullying can include physical attacks, verbal 
bullying, gossip, name calling, being shamed in front of others, and being excluded socially. Bullying Prevention and Response: a guide for schools is a Ministry of Education publication (Post Primary Teachers Association, 2017) where it outlines what bullying is, what safe and positive school environments looks like, bullying policies and processes and how schools can respond to bullying behaviour (Ministry of Education, 2011). However, as a researcher the question arises as to how closely this document is utilised for the betterment of the gender diverse students in schools and what facilities the schools have address the students' needs and educate all students on the issue to create equality.

Even though homosexual students have equal privileges and rights, the environment at times does not support the individuals well (Muižnieks, 2014). Regrettably, the Gay Lesbian Education Network (GLEN Report, 2016) documents that this has a negative impact on learning and achievements for all students, undermines students' trust in the staff and the institution, and can result in students disliking or feeling disconnected from school. Clift (1988) states that many educational institutions have ignored the issues of gender diverse students. While many students are still found to be suffering because of intolerance (Sanlo, 2004). Most of the gender diverse students find the school climate more negative than their counterparts (Brown et al., 2004). To investigate this issue, a survey conducted in Canada in 2009, found that 58 per cent of heterosexual students expressed emotional distress over homophobic comments overheard in school. It is proven that any form of violence or exclusion will achieve adverse effects on individuals such as performance, attendance, interaction with others and this not only affect the homosexual individuals but has negative effects on the heterosexual students as well (UNSECO Report, 2016). This has been noted by Jones (2015) who reiterated the adverse effects on heterosexual students as well. It is imperative to highlight the issues surrounding the LGBTQIA in the classrooms and to create an understanding of diversity. Nearly all classrooms have 
someone who are struggling with their sexuality or who have gay parents, or some may realise their sexuality in future.

Wyss (2004) suggested teachers and school administrators often directly or indirectly participated in homophobic verbal abuse by allowing homophobic words and remarks to be used without reprimand. Robinson (2005) states that students are reluctant to discuss sexuality, as it is considered inappropriate to discuss such topics thus, gender diverse issue are greatly ignored by teachers. Gunn (2003) further elaborates that teachers do not discuss sex and sexuality prior to secondary schools. Robinson $(2005,107)$ makes the point that even though teachers think of children as young and innocent, or asexual, the dominant discourse, heterosexuality, is an “integral part of children's every day educational experiences”.

Despite continuous interest in the issue and how the LGBTQIA youth, there has been limited literature available about how these students function in schools and specifically the classrooms. It is universally agreed that education is the key to eliminate homophobia through discussion and sharing of information (Bennett, 1997; Boyd, 1999; Marcus, 1999; Raymond, 1996). However, the agreement dwindles when these issues are pushed to be included in the curriculum and every day teaching as based on literature provided sexuality is always a touchy topic. Boyd's (1999) study highlights that educators and teachers need to clarify misunderstandings by openly discussing topics in the classroom and allowing all individuals to present their opinions. Gender diversity issues need to be openly discussed to as there are negative discourses related to LGBTQIA people is common in classrooms, schools, or even staffrooms (Chansnoff and Cohen, 1997). Educators should not ignore such issues and it is important that they explore these issues openly in the classroom. Boyd (1999) further discusses that educators should teach not to discriminate others but to accept and respect difference.

Many educators feel that the responsibility lies with the family to discuss issues pertaining LGBTQIA students. Boyd (1999) states that some teachers see these issues as 
immoral and they feel that such topics do not have a place in the classroom as goes against their religious beliefs. Schools based on the literature sees homosexuality as immoral and violate the religious beliefs as it is always assumed that all students are heterosexual (Boyd, 1999). It is believed that students need to be helped to become accepted from a very young age (Aronson, 1995). Littig and Long (1995) states inclusion of gender diverse issues in the curriculum will not only educate students but will eliminate the isolation of diverse students. However, Adams et al., (2016), suggest that there are many schools who are not well prepared to discuss these issues.

Hooper (2004) reports gay children who conceal their identity can feel isolated. Homophobic attitudes of Year 11 pupils in relation to the Sex Education they receive nothing in the school to promote positive homosexual role models. Stormbreak (2003) found that only one in ten LGBTQIA people knew an identifiably gay adult role model when they were at school. Koskiw (2003) found that LGBTQIA children who were at schools where staff were supportive of sexual minority youth had fewer school troubles. In addition, school environment, peers, teachers and other administrative staff tend to be less supportive towards the the gender diverse students therefore, these students find their school experience less fulfilling than their heterosexual counterparts (Koskiw, 2003). Sanlo (2004) also stated that apart from unsupportive environment the students also suffer from lack of representation among the leaders, staff and curriculum they engage with.

Over time New Zealand schools have become more affirmative towards sexual diversity hence, the experiences of the LGBTQIA students are slowly becoming more positive. This significant change in attitude towards homosexual minorities has contributed to the increased visibility of LGBTQIA youth in schools (McCormack, 2011). Over the years, researchers have found that gender diverse students can experience high levels of resilience. As Kosciw (2004) states educational resilience highlights probability of educational success regardless of the 
difficulties and personal vulnerabilities experienced by a learner (Kosciw, 2004). Moreover, Msibi (2012) believes that from his research that LGBTQIA students are no longer powerless, hopeless or passive as they reflect a greater sense of self-worth and confidence as they are proud of themselves, their choices and abilities. Kosciw et al. (2013) state that support from school staff, an inclusive curriculum, anti-homophobic bullying policies and Gay Straight Alliances (GSA) act as environmental influences that contribute to a positive school experience for gender diverse learners.

\subsection{THE EFFECTS OF ABUSE AND BULLYING IN SCHOOLS}

Oppression of LGBTQIA individuals have a long history globally. Educationist and Social Scientist (Tinto, 1975, 1982, 1988) strongly believes that is strong relationship between student's performance and abilities in connection to their educational experience and the students abilities to succeed academically; while Cornelius-White (2007) further believes that there is a sturdy connection among students and their teachers and student academic success. It could be further claimed that gender diverse students have a greater need to feel affianced with and recognised by the school as there only very few places gender diverse students feel safe. As per the GLSEN (1999) report many gay and lesbian students do not feel comfortable or safe in school, nor do they feel comfortable talking to school staff about their issues. In an earlier report by D’Augelli \& Hershberger (1993), they found that (on average) secondary school students hear anti-gay epithets 25 times a day. Studies over the years have shown that one's personal development, feeling safe and involvement in school are imperative to any student's ability to succeed (Cornelius-White, 2007) and if the gender diverse students does not open up one's sexuality it could be related to adverse consequences thus there is a very small chance of being connected or engaged in schools. Thus, schools need to provide productive, respectful, nurturing and strong relationships with their teachers (Cornelius-White, 2007; McCombs, 2004; 
McCombs \& Whisler, 2007). Educators play an important role however, 97\% of teachers failed to respond to the slurs as per the GLSEN (2009) report. A majority of the gay and lesbian youth surveyed (69\%) by the Gay, Lesbian and Straight Education Network reported experiencing some form of harassment or violence (GLEN, 1999). Of those 69\%, 61.1\% reported experiences of verbal harassment, $46.5 \%$ reported experiences of sexual harassment, and $27.6 \%$ reported experiences of physical harassment (being shoved, pushed, kicked, etc.). Wells and Polders (2005) research indicates $19 \%$ of the of the participants reporting being sexually harassed or being raped during the secondary school years. They (Wells and Polders, 2005) further report that the perpetrators were victimised by mostly students, the educators and non-teaching staff at their school.

Furthermore, according to their perpetrators the intention of their actions is to cure them from homosexuality based in the United States covering 3.2 million educator views across the country (Department of Education, 2008). Accordingly, it is common for homosexual youth to have higher levels of absenteeism (McCormack, 2011) and school dropouts than their peers (Mishna, Newman, Daley \& Solomon, 2009). Rivers (2000) suggested that homophobia is one the main reasons for the LGBTQIA student's absenteeism and disengagement in schools. Some students tend to develop a paratendinous nature by being ill to skip school and to avoid harassment and any form abuse (Rivers, 2000). Many LGBTQIA students who are exposed to hate crimes and remarks tend to drop out of schools (Grossman et al. 2009).

LGBTQIA learners also experience social, emotion and mental segregation mainly due to their physicality and sexual orientation Munoz- Plaza et al. (2002). The exclusion and isolation of LGBTQIA learners are exacerbated by their inability to form deep friendships with heterosexual girls because of a lack in common interest such sexuality, attraction towards a gender and perceptions about their partners or preferred gender (Payne, 2007). This leads to gender diverse students feeling excluded, isolated and feeling unacceptable in the society. 
Murdock and Bolch (2005), research denote that harassment and abuse at school leads to absenteeism and affecting the academic performance of the gender diverse students. This leads to emotional and mental isolation of gender diverse students which is a challenging problem for LGBTQIA learners (Williams et al., 2004). LGBTQIA learners find it difficult to concentrate in class because they are unable to prevent harmful thoughts and emotions from surfacing (Robinson, 2002).

Quinlivan (2002) further explains that as no coincidence that sexual orientation and gender diverse young people in New Zealand are positioned as ‘at-risk or vulnerable' as well as being at risk of slipping into depression which in turn affects individuals academically and socially. Many gender diverse students often become invisible in secondary schools when their homosexual romantic attractions and inclinations are not recognised due to the school culture. Akerlof \& Kranton, (2002) further states, students tend to withdraw from academic activities to the extent that they become invisible and disengaged from the learning process. Students do not feel that they belong or are a part of the school community. Some students prefer to be invisible mainly to safeguard themselves from any form of victimisation and harassment (Craig, Tucker and Wagner, 2008). In such scenario’s students need positive intervention and support by school workers, teachers, educators and counsellors for a higher level of engagement and increased academic achievement among sexual minority students (Seelman et al., 2012). Mallon (1996) writes that the student needs of the diverse community has to be understood and recognised by educators and others, especially their peers. Many educators struggle when discussing same sex families in class and any issues related to LGBTQIA as they believe the responsibility lies with the parents to discuss these issues such as sex, sex education, social justice and inclusion (Gunn, 2003b; Robinson, 2002; Robinson, 2005a; Sumara, 2008; Surtees, 2008). 
In a strong argument by researcher's homophobic verbal abuse cements heterosexist and pathologizes homosexuality (Francis and Msibi, 2011). Rubert et al. (2016) states that given the high incidence of mental distress experienced by transgender students as a result of exposure to discrimination, and a school's obligations under legislation such as the 2015 Health and Safety at Work Act and 1993 Human Rights Act of New Zealand (Post Primary Teachers association, 2017), it would be prudent for schools to proactively consider school policies across the board to ensure school is a space free from discrimination, and safe for all students. Robinson and Ferfolja’s (2008) Australian based research indicated that participants thought that the younger the child was, the less relevant the topic of sexuality was highlighting ways in which teachers avoided engaging with the topics.

Thus, Jones (2015) highlights that more than half of LGBTQIA students have reported being afraid that someone at school would hurt or bother them, and approximately 40 percent suffer from significant depressive problems which can be caused or exacerbated by bullying. It was elaborated by the Post Primary Teachers’ Association in 2017 that being targeted by such bullying causes emotional distress and leads to academic difficulties, leading to substance abuse and affecting schooling. These lays the foundation of this MA research where many NZ students are at risk of drug abuse, alcohol, suicides, and unsafe sex. While many researchers over the years have categorised such individuals as 'troubled' few have addressed the issue. It is certainly true in the NZ context as the issue is apparent but hardly any effort has been made to address the issue. For instance, the report compiled by the Suicide Mortality Review Committee (2016) commenting on the deaths of Takatāpui (a traditional term meaning 'intimate companion of the same sex' in Maori language) young people between 2007 and 2011'the stigma associated with homosexuality appeared to be particularly significant for the males in this population, who were bullied about their sexual orientation' (Mentalhealth.org.nz, 2016, p16). The report further explains bullying of lesbian, gay and bisexual New Zealanders found 
that the effects of bullying can be lifelong and can include manifest in educational attainment, income and levels of satisfaction with LGBTQIA identity.

Discrimination according to Youth'12 (Bullyfreenz.org, 2017) study that 'the health and wellbeing of many same or both-sex-attracted and transgender students was negatively affected by their social environment as more than half were afraid that someone at school would hurt or bother them, and around 20 reported being bullied at school on a weekly or more frequent basis. $46.1 \%$ of those same and both-sex attracted students who were bullied reported that they were targeted because they were gay or because people thought that they were gay'. While Pasco (2007) in his research indicated that the gender diverse students who were bullied mostly for their sexual orientation or identity rather than not maintaining the appropriate masculinity and femininity.

Furthermore, The GLEN Report (1999) suggest several individuals find it shocking to realise the LGBTQIA individuals are four times likely to attempt suicide than the heterosexual counterparts. Instead of being able to be themselves and feel good about who they are, these youth deal with isolation, fear, and harassment (Hyde \& Forsyth, 1994). The victimisation of gender diverse students is often highlighted in homes, schools or on social media which affects their well-being and lowers self-esteem and ability to come forth and accept their individuality. A 2015 report of New Zealand's support sector for rainbow people across New Zealand found that $76 \%$ gender diverse students were suicidal and a further $65 \%$ lost friends to suicide (Mentalhealth.org, 2017).

\subsection{SCHOOL ENVIRONMENT}

Birkett et al., (2009) recognises the significant elevation of bullying among gender diverse students who are questioning their sexuality compared to their heterosexually identified peers. Espelage et al. (2008) states that gender diverse students are likely to report depression, 
suicidality, truancy and substance abuse in comparison to their heterosexual counterparts, apart from those LGBTQIA students who perceive their environment to be positive. The findings from the literature suggests that teachers and play a significant role in creating a positive and safe environment through addressing homophobic abuse and engendering the perceptions of the teachers by realising that they need to be empathic towards gender diverse students. Teachers are also responsible for reducing bullying. The Education Council's Code of Ethics places an ethical obligation on teachers to "promote the physical, emotional, social, intellectual and spiritual wellbeing of learners” (Post Primary Teachers Association Report, 2017, 23). This means that students must not bully or harass students, and that they should respond to bullying by other students (Post Primary Teachers Association Report, 2017, 23).

Research supported by the Government of New Zealand (since 2001), addressed the health and well-being of secondary school students every six years. The 2014 Bully Free NZ report found that 17 per cent of LGBTQIA respondents declared being bullied at school weekly or more frequently (Burford, 2013). Among them, $46 \%$ reported that the violence was due to the victim's actual or perceived sexual orientation. While LGBTQIA students were three times more likely to be bullied than their heterosexual peers, transgender students were five times more likely to be bullied than their non-transgender peers' (UNSECO, 2016). A positive experience of coming out to others and where they are met with acceptance is critical to safeguarding the young person's mental health and well-being and it can also lessen the young person's fear of disclosing to their family and friends (Mayock et al, 2009). Most young people come out to a friend or another trusted individual before 'coming out' to family. Sometimes this trusted individual is a teacher or a Guidance Counsellor (GLEN Report, 2016). Thus, in doing so schools play instrumental roles in moulding a student's behaviour and must cater for their needs and allow them to lead themselves more positively and this where education and educational institution are extremely important. According to the Rainbow Youth Report 
(2013), schools should communicate a message to all students that diversity is welcomed and respected. Mayock et al., (2009) states that LGBTQIA young people and other minority groups should be clear that they are valued, and that school leadership will ensure their safety and support. It is critical that a young LGBTQIA person discovering their sexual orientation or gender identity feels supported and valued, regardless of whether they come out.

In addition, the UNESCO Report, (2016) explains how schools reflect wider societal trends and it is unsurprising that homophobic and transphobic violence also exists in educational settings in all regions of the world. In a report by Kosciw (2004) states that ninetyone percent of LGBTQIA students reported hearing homophobic remarks often or frequently from other students, and 20\% reported hearing these same remarks from school faculty or staff some of the time (citied in Wyne, 2008). LGBTQIA youth were over three times more likely to report a suicide attempt in the previous year, and 49\% reported that they had considered suicide during the previous year (Massachusetts Department of Education, 1999) (citied in Wyne, 2008).

According to Beren (2013), teachers have not been adequately educated to address gender diverse issues as their training did not expose them to the issues. In an Australian research, participants believed that they did not feel confident in approaching issues with children (Robinson, 2002). It was found that hostile responses were common when people raised gay issues, resulting in the subject being dropped, because it was too difficult to pursue (Robinson 2002). Mishna et al. (2009) asserted that homophobia is a common occurrence in schools. Factors that contribute to homophobic abuse in schools is the inadequate training of teachers related to gender diversity, shortage of policies which could protect the sexual minorities and failure to hold heterosexual teachers and students accountable for any form of homophobia towards gender diverse students. 
Wilkinson and Pearson (2009) state that heterosexuality is regarded as the norm in many societies while other sexual orientations are regarded as "deviant". Chesir-Teran (2003) maintains that dominant heterosexist discourses are sustained in American schools by subtle practices that increase the invisibility of LGBTQIA learners. They further state that the occurrence of heterosexist and homophobia in schools can be addressed by means if inclusive programmes that supports LGBTQIA learners (Chesir-Teran, 2003). Practices of heterosexism in schools are counted as subtle practices due to the absences of general harassment policies, specific anti-discrimination polices and inclusive programs amid unconcealed antagonism towards the gender diverse students. Sadly, there are schools that create negative environments in which homosexuality is stigmatised (Pearson et al., 2007). A research by Kosciw (2009) on American school climates and its impact on gender diverse learners indicated that the school environment in which gender diverse students are most accepted, are in urban schools. It was interesting to note that gender diverse students in large urban schools that have high populations of low-income earning families and racial minority groups experience more tolerance and less homophobic abuse or harassment as more parents and students are exposed to issues related to gender diversity.

As it is noted not all schools can optimise the school environment for its LGBTQIA leaners and the schools are frequently pressured by religious organisations to endorse teaching homosexuality as unacceptable (Ream and Savin-Williams, 2005). Kosciw (2013) asserts that the strongest positive encouragement for LGBTQIA learners comes from supportive adults at school and a supportive curriculum as it predicts a less hostile school climate and increased sense of self-esteem amongst gender diverse students. Many teachers strongly disapprove of homosexuality because of their own religious views, perceiving that homosexuality as a sin that can only be cured through religious teaching (Msibi, 2012). 


\subsection{SCHOOLS AND SUPPORT OF GENDER DIVERSE STUDENTS}

In the developmental years of an individual a youth spends great deal of their years in schools which greatly impacts on their learning, yet this may not be the only context which may impact on identity development however it does to some extent. Education is the universal right of every individual it is also mandatory for the educational setting to be conducive for the individuals with safe and sound environment thus for effective learning the schools need to be more inclusive and accepting of every individual (UNSECO, 2016).

The NZ School Curriculum (2007) places considerable emphasis on schools catering for diversity of all kinds:

- curriculum to be inclusive, which is defined as "non-sexist, non-racist and nondiscriminatory” and to ensure that "students' identities ... are recognised and affirmed and that their learning needs are addressed”

- values, which include "diversity”, require that students learn to "respect themselves, others, and human rights

However, despite this commitment, the ERO report (2017) reflects only a few schools conducted regular evaluation of their sexuality education provision or undertook robust analysis of the perceptions and needs of their students in this learning area. The review further states that few schools real or perceived community opposition towards the sexuality due to cultural or religious reasons which leads to inadequate sexuality programmes in schools or did not address important aspects of the curriculum which leads to a variability in practices across schools and addressing to the needs of the gender diverse students. Only a few schools conducted regular evaluation of their sexuality education provision or undertook a robust analysis of the perceptions and needs of their students in this learning area (ERO Report, 2017). 
A fundamental tenet of contemporary learning theory is that different kinds of learning outcomes require different approaches to teaching (Post Primary Teachers Association Report, 2017). Although much of what people learn occurs without formal instruction, adults have a key role in helping learners make the connections between new situations and familiar experiences. This means that effective teachers require pedagogical content knowledge knowledge about how to teach in different disciplines which is quite different from knowledge of general teaching methods (Bransford et al. 1999). Page and Liston (2002) highlighted that only $9 \%$ of preservice high school teachers report receiving preparation to deal with homophobia.

Morrison and Heureux (2001) stated the suicide rate in The United States for the LGBTQIA students are three times higher than their heterosexual counterparts. Also, alarming researches in New Zealand has found the LBTQIA students more likely to attempted suicide several times over their period of coming out. Coming out to everyone is a complex process. In most cases students tend to keep their sexuality a secret and when they do so this can lead to 'depression, anxiety, fear, low self-esteem, self-blame, post-traumatic stress disorder' and other somatic symptoms (Hooper, 2004: 4). Risk factors for gender diverse students in secondary schools include disclosure of sexual orientation; exposure to homophobia and harassment; gender nonconformity. Hopper (2004) further suggest that these negativities often leads to self-hatred which leads to many psychological problems such as cultural stigma, poor self-concept and social isolation.

Intervention programmes need to be taken up by education departments to educate teachers about the ways in which heterosexual dominance operates in schools enabling them to recognise the negative and harmful experiences of homosexual learners (Msibi, 2012). Such programmes will enable the teachers or the learners with the knowledge and skills to appropriately deal with sexual diversity. The implementation of psychosocial education should be sustained future 
educators can learn to respect the rights of diverse people including sexual minorities (Butler et al., 2003).

The Human Rights Watch (2001) highlights the inclusive education all schools shall serve the educational needs of their learners without discriminating against any one in any way. Educators are instrumental in helping students and make them feel accepted in a classroom environment. However, according to Rivers (2000) gender diverse students receive very little support from their teachers and educators. Instead of supporting these students the researcher states that LGBTQIA students harassed and abused mainly due to their actual or perceived sexual identity. Bulter et al. (2003) in his research stated that participants reported that harassment of homosexual students and abuse experienced by these teachers are life threatening effect throughout their lives. Constant humiliation makes students vulnerable and are reluctant to open about their sexuality. Such are the cases where schools perceive homosexuality as a diseases or abnormality in sex and religious education and whereby homophobic behaviour and language are sanctions and left unattended to (Rivers, 2000) the teachers’ lack of knowledge regarding homosexuality, teacher unwillingness to intervene in instances of homophobic abuse as well as their fear of losing their employment denies sexual minority's access to appropriate support and all-inclusive information on human sexuality and alternative lifestyles (Butler et al., 2003). Many schools and administrators only focus on the prevention of bullying when school safety policies are developed. However, it is extremely important that they also focus on the prevention of homophobic bullying as a separate entity. As Kosciw et al., (20030 stated in his research that implementation of harassment and anti LGBTQIA bullying policies are related to higher levels of self-esteem among the gender diverse students as it makes them feel accepted and being part of the policy. According to Mikulsky (2005) a zero-tolerance policy should be followed to eradicate homophobia in schools. The researcher further states that if this does not materialise LGBTQIA learners' rights to equal and quality education in an inclusive 
and safe environment will continue to be denied (Mikulsky, 2005). The research of Toomey et al. (2012) indicated that harassment would continue in school settings where policies only address bullying based on sexual orientation without accommodating the problematic policy of gender normativity. Valenti et al (2009) further suggests having policies in place as a source for students to being the role to disrupt the normative postulated reaction to safety and can empower gender diverse students to be more aware of the disorderly actions which are tied to harassment, in other words inclusive policies may help students to be more aware of their roles and take steps to confront issues related to intolerance. Inclusive policies can also be inestimable by virtue of having a structures procedure through which gender diverse students could report incidents related to harassment and bullying and these policies also provide guidelines for the schools and its team to create 'safe places' however it is not enough the schools had a policy.

Addressing further, Kosciw et al., (2013) in his research indicates that educators who are supportive make all possible means to intervene in order to ensure the safety of the gender diverse students by creating safer school environment and have a strong positive influence on the gender diverse students. He further asserts that through increased teacher support school and classroom environment becomes less hostile for the students, it decreases the victimisation of the LGBTQIA students, increases self-esteem, increases attendance and improved academic performance (Kosciw et al., 2013). Teachers many cases can be life changing catalyst for many students and for the gender diverse students by supporting in their struggle by being caring and strategizing the what they teach that the message is put across the other students in the class. Teachers who are willing to act as guides and advisors to LGBTQIA youth increase their educational resilience (Gastic \& Johnson, 2009; Msibi, 2012). Gastic and Johnson (2009) states that teachers are able to create conditions that can help LGBTQIA youth realize their full potential through positive affirmation, role modelling and respect. Peer support and friendships 
are some of the aspects which makes things easy for the any individuals in schools. However, in cases of gender diverse students this plays an instrumental role for being someone who is support when needed the most. However, in most instance the relationships with friends become sour when LGBTQIA students open up about their sexuality. As Robinson (2000) supports that friends and peers are important as it acts as a shield against harassment and gives gender diverse students the strength to confront those are victimised.

\subsection{CURRICULUM AND GENDER DIVERSITY}

The curriculum also plays an important role in addressing these issues and this includes the content and the way it is delivered in the educational setting. According to the European Union’s Fundamental Right Agency (2013) research states that only some countries have been inclusive. In practice, this is often apparent in in-service training, is small-scale and not mandatory. As a result, educational staff lack the resources to genuinely understand and address

sexual orientation and gender identity/ expression issues, particularly when it comes to homophobic and transphobic violence (Burford, 2013). The dynamics of including gender diversity in teacher education are perhaps the most delicate," when surrounded by the rest of the content in multicultural contexts, but "it is imperative to link sexism, racism, anti-semitism, and heterosexist in our anti-oppression courses” (Lipkin, 2002, 67).

An analysis of the New Zealand Health Curriculum (2017) suggests that efforts are made to include diversity in sexuality as part of the curriculum at the junior level and at the senior level. However, there has not been any consistency in the curriculum to address the issue and how to support such individuals. As Slater (2000) states most national curriculums focuses on the human reproductive system and the emotional and physical changes that an individual's goes through during puberty. He further states that anything beyond this is left for the schools to decide upon such as contraception, safe sex and access to local advice and treatment services. 
In most cases the curriculum could only be linked with gender diversity if the educators could the link and emphasise on the curriculum themselves. Gender diversity of homosexuality is hardly evident in the curriculum for schooling.

In discussing educational policies, the process has begun to extend the points of diversity. Terms must now include race, language, ethnicity, ability, disability and sexual orientation and must be accommodated in all schools. New Zealand curriculum has been of no exception which gives a great emphasis on issues related to gender diversity, but many schools choose not to discuss homosexuality or even give importance to gender diverse students. McCormack (2012) discusses that there is a lack of relevant information related to the LGBTQIA society in school libraries and teachers and educators who are openly homosexual and role models simply state that homosexuality in most schools are regarded as unacceptable concept.

Munoz-Plaza et al. (2002) in his research suggested that participants informed that they experienced denial and uncertainty when they were going through the process of coming out to acknowledge their sexuality and their choices to the society. Acceptance and admitting being gender diverse was difficult and led many to experience inner turmoil. Many students accept their feelings and inner conflict to deny their choices and supressing their feelings from others. Internal conflict experienced by the participants was exacerbated by a lack of information on homosexuality (Munoz-Plaza et al., 2002). Many researchers have indicated that students undergo abuse, and this decreases their self-esteem (Munoz-Plaza et al., 2002). Low self-esteem has negative impact on an individual of confidence which makes it difficult to socialise with other students in order to gain social acceptance (Butler, 2008).

Gender diverse students in most cases seek to confine their status to other gender diverse students; sharing the incidents and stories with friends of the same sexual orientation at meetings, presentations, and so on. Sharing their stories allows them to experience a sense of 
collective empowerment and relief for they learn that they are not alone (Craig et al., 2008). A gender sensitive curriculum addresses homophobia and victimisation in schools, which increases the self-esteem of these students (Kosciw et al., 2013). There are high chances that an inclusive curriculum could possibly increase the student participation especially the LGBTQIA students in their classroom and schoolwork at large thus leading to academic excellence. Apart from inclusive curriculum, inclusive policies are extremely important. As Kosciw et al. (2003) suggest that positive and inclusive policies contribute to the wellbeing of the students as it leads to a sense of self and belonging. With having such policies, it is an indication that schools acknowledge and support the LGBTQIA learners by providing protection and catering for their needs. Bulter et al. (2003) stating school's curriculum should reflect a celebration of being diverse and equal, thus, educating learners on their human and civil rights and respect for those who feel that they are different should be the core component of all educational aspects.

\subsection{CONCLUSION}

This literature analysis reveals that the LGBTQIA students or gender diverse learners in high schools are subjected to negative academic and social experiences. As the literature also suggests gender diverse students may experience or have experienced negative social encounters such as in form of harassment and abuse. The literature also suggests that there has been changes in the mind-set of the school management along with heterosexual educators and students towards the gender diverse students in the last 20 years. They have become more positive towards the gender diverse students which has led to more positive experience for gender diverse students. Chapter 3 further discuss the methodology used to obtained necessary data. 


\section{CHAPTER 3 RESEARCH METHODOLOGY}

\subsection{INTRODUCTION}

The following chapter focuses on the methodologies utilised in this study. Methodology is often referred as a general approach of studying an issue while methods are the techniques used by the researchers. This study focuses on qualitative approach being an integral part of the research. The pragmatic research paradigm was utilised in this research. The chapter discusses the research paradigm and its links to this study, the research methods, tools to obtain data and ethical consideration when conducting this research. This research further explores the personal experiences of the teachers and the students and their perceptions on gender diversity issues.

\subsection{CONTEXT OF THE STUDY}

The studied institution is a prominent high school (name not mentioned due to confidentiality) according to the school webpage is one of the southernmost secondary schools of the Auckland region. The high school is a culturally and gender diverse school with 64\% Maori, 8\% NZ European, 24\% Pacific students which includes Fijians and Fijians of Indian decent, while other minority students make up the remainder of the $4 \%$ of the student population (Patterson, 2018).

Established in 1954, the school has produced some notable alumni. The school is well established and technologically capable with teaching and learning conducted in a high technological environment. With rich diversity, the school has been participating regularly in the Auckland 'polyfest' and is committed to uphold the cultural values. Students at the institution are very enthusiastic about playing sport and all students are strongly encouraged to participate in either a winter or summer sports. 
Further, the school has a Social Service Centre for all students who are facing difficulties and one the very few schools in Auckland that widely accepts gender diverse students and have a very strong support system for them and have facilities such as full-time councillor, special pastoral care system and gender-neutral bathroom. The school has continuously organised Rainbow events for the students and the wider community to educate them on the gender diversity and support they can provide.

Students can engage in a wide range of programmes within the school and are ably supported with a team of guidance staff and health workers. The 'Kaiarahi' (Counselling) and Pastoral team are active in supporting behavioural and learning needs. The school has a nurse and special counsellor to support gender diverse students. The school in the past few years has made significant improvements to support and to properly engage gender diverse students and to create equality for all. The aspects of the school's support system are further discussed in the finding chapter of this research.

\subsection{THE RESEARCH METHODOLOGY}

As this research required students and teachers' views, a study of their experiences and feelings was important, allowing me to reach to conclusions through understanding details as it occurred. It was further noted that this approach allowed the recognition of issues studied into many dimensions. Qualitative researchers believe that the researcher's ability to interpret and make sense of what he or she sees is critical for understanding any social phenomenon (Leedy and Ormod, 2005). When little information exists on the topic, or when variables are unknown, or when relevant theory base is inadequate or missing, a qualitative study can help define what is important - that is, what is needs to be studied (Leedy and Ormod, 2005). 


\subsection{RESEARCH APPROACH - PHENOMENOLOGY}

In this research, I utilised phenomenology as an approach to obtain necessary information. Phenomenology is described as "a way of thinking and studying social reality" while method is "a set of procedures and techniques for gathering and analysing data” (Strauss and Corbin, 1998, 34). Bogdan and Biklen (2007) further described interpretive Phenomenology Analysis as an inductive process of exploring the narratives that individuals construct as a way of reflecting on and representing to others their lived experiences and describing it as entry to conceptual world. As Creswell (2009) states this as a process of identifying meaning related to individual experiences. The choice of this approach has enabled me to gain the insight of the gender diverse students; their experiences and situations of being a LGBTQIA student in secondary schools in New Zealand. As Merriam (2002) states this approach showed how complex meanings are built out of simple units of direct experience.

Lester $(1999,1)$ states 'in the human sphere phenomenology normally translates into gathering 'deep’ information and perceptions through inductive, qualitative methods such as interviews, discussions and participant observation, and representing it from the perspective of the research participant(s)'. As this approach is concerned with the study of experiences from the participant's viewpoint, this matches suitably with this research. As phenomenological approaches are based in a paradigm of personal knowledge and subjectivity and emphasises the importance of personal perspective and interpretation. These are powerful for understanding subjective experience, gaining insights into people's motivations and actions, and cutting through the clutter of taken-for-granted assumptions and conventional wisdom (Lester, 1999). Phenomenological studies leads to detailed comments about individual situations which however does not led to direct generalisation which according to Lester (1999) the development of general theories (i.e. which apply to situations beyond the participants or cases which have been studied) from phenomenological findings needs to be done transparently if it is to have 
validity; in particular, the reader should be able to work through from the findings to the theories and see how the researcher has arrived at his or her interpretations. This approach will enable me to derive themes effectively from the research and to provide a better analysis of the individuals’ experiences.

Experiences and narratives which are represented are rooted in and are impacted by social, historical, psychological and cultural occurrences (Caughey, 2006). Thus, I established the strategies that shaped the phenomenological analysis related studies with the sue of the semi-structured interviews, well detailed research goals and my position as a researcher (Bogdan et al., 2007) and my experiences as a gender diverse individual and embedded member of the community with attention to detail and insights of the informants who agree to take part in this study. Thus, a critical analysis of the problem made it a relevant approach in conducting this research and filled in the gaps left by the literature. As this research required the researcher to be more connected to the participants, interviews were one of the most suitable methods which allowed for both structured and informal conversations to understand the student's struggles. Interviews mostly opened the conversation and non-structured discussion created an eased environment with the interviewee. Documentation analysis further enhanced data collection and provided data which helped to fill gaps in the previously gathered data.

In sum, data has been collected through document analysis, and interviews. These are integral elements to phenomenology and by utilising descriptive approach as a research design to collect data it will give more relevant and well-informed data to make necessary conclusions and recommendations.

\subsection{SAMPLE}

For this research study, I utilised non-probability sampling called purposive sampling. This is also known as judgmental, selective or subjective sampling. Purposive 
sampling relies on the judgement of the researcher when it comes to selecting the units (e.g., people, cases/organisations, events, pieces of data) that are to be studied. Usually, the sample being investigated is quite small, especially when compared with probability sampling techniques (Dissertation.laerd.com.2018). Whilst the various purposive sampling techniques each have different goals, they can provide researchers with the justification to make generalisations from the sample that is being studied, whether such generalisations are theoretical, analytic and/or logical in nature (Dissertation.laerd.com.2018). This method seemed appropriate for my study as the predominant aim of nature of the research and not generalised but in-depth description of the data and information.

Being aware of the nature of participants I wished to include my research, I set to find suitable schools that were interested in taking up my research. I approached 30 secondary schools through emails and through personally approaching the schools however, only one school accepted the request. Due to the sensitive nature of my topic, it was difficult to get schools on board for research and one of the reasons to decline the invitation. Some indicated that they were heavily committed with other ongoing research and some did not respond to the invitation at all.

Purposive sampling allowed be to me to recruit individuals who were comfortable with providing information related to the issue. The following steps outline the recruitment procedures:

- After the approval was sought from the school, a day was allocated to meet with the Deputy Principal of Pastoral Care and later the School based Social worker was introduced.

- I started the sampling process by conducting meetings with the Deputy Principal of Pastoral Care and the School Social Worker as the school stated that since the school 
has been on board with creating equality and facilitating gender diversity the school based social works department has been an integral part of this and they felt that since this research will surely create improvement the school felt that they need to be part of this research to improve the quality of programme in the school.

- I discussed how the research process was going to take place with them and recruitment notices were to be put up around school.

- An orientation meeting was conducted after two weeks of the recruitment notice being displayed with the interested teachers and students along with the counsellor and deputy principal to request for the permission to include self -identified gender diverse students and to orientate them on the nature and the purpose of the study, the role of the participants, confidentiality and any possible risk that the participants may face during the process of the research.

At the end of the recruitment process six students and five teachers accepted the invitation to participate in the interview process regardless of their sexual orientation. The participants were both males and female students. The final signed up participants were two males and nine females. The major purpose of this study is to understand the participant's experiences and the school support the need for gender balance was not required. The student participants were aged 16-17 years old and the teacher participants ranged from 27 to 62 years old. All participants voluntarily participated in the research study. Despite being open for two weeks the number remained the same thus there was no requirement for any other selection process.

The students were randomly selected regardless of their ethnicity. The reasons for choosing students in Year 12 to 13, was that was the stage where many youths are beginning to understand their sexuality, need support and are who are more actively involved in homophobic bullying. 


\subsection{METHOD}

In order to collect my data, I utilised semi-structured interviews. I started with an orientation meeting at the school premises after the recruitment process whereby I introduced myself, to create an opportunity to know each other and to explain the process and nature of the research. My second visit to school was to obtain the necessary consents and to set the best date and time for the participants to meet. All interactions were made in person as it was one of the effective forms of communication. However, when it came to the time allocation for interviews and other research related correspondence was made through emails prior to visitation. Necessary arrangements were made with the deputy principals and the school counsellor who would make the arrangements so that the students and teachers were available and learning time was not lost. The interview process was spread over two weeks due to unavailability of the participants and time factor. As it was examination period, it was difficult to interview all participants on the same day. At least two interviews were conducted each day. Each interview last from 20 to 45 minutes depending on the participants' willingness to contribute. All the meetings were kept more informal to create an understanding of safety and maintaining confidentially of their identity and information. All the interviews were recorded with prior approval from the participants.

\subsubsection{DATA COLLECTION METHOD: SEMI-STRUCTURED INTERVIEWS}

Due to the high level of sensitivity of this research study I collected all the data myself. This meant that I was the main contact person and that the participants knew I kept their data safe. This has been one of the most important components of my research as Silverman (Leedy and Ormrod, 2005) has stated that interviews mainly bring about facts, feelings, motives, present and past behaviour and standards of behaviour. Further, as De Vos et al. (2005) states semi-structured interviews are organised around areas of interest, allowing considerable 
flexibility in scope and depth. Therefore, based on these points, I selected interviews as the primary mode of collecting data. The questions were semi- structured allowing the researcher to yield better information. Due to the sensitivity of the issue and information gathered all care was taken to keep the students and their experiences confidential.

Through the course of the interview it was evident that the participants went through various emotional stages such as sadness, anger, frustration, fear and so on in their everyday lives. With prior permission, all the interviews were recorded and were transcribed by me for better interpretation and understanding. The research interviews were conducted face to face in privacy and full confidentiality. I found the semi-structured interviews for data collection as the best choice as it provided me with the opportunity to have in-depth discussions as the interview progressed.

As I was the researcher who was solely responsible for the analysis and collection of data, I had to make sure that there was no researcher biasness, so I made use of member checking strategies to ensure credibility of the of the study and to eradicate possible researcher bias. Member checking, also known as participant or respondent validation, is a technique for exploring the credibility of results while data or results are returned to participants to check for accuracy and resonance with their experiences (Researchgate.com, 2019). After each interview, I went through the written materials or notes which I made during the interview session with the participants to validate the data provided by letting the participants check through the notes.

The following were the limitations to the study and data collection due to the nature of the project:

- The sample size of five teachers and six students being relatively low which does not allow the results to be generalised for all the schools in New Zealand. 
- The population selected does not represent all the cultural and socio-economic groups living in New Zealand which implicates that the study does not represent the difficulties and experiences of larger population of students in New Zealand secondary schools. The findings cannot be generalised though the purpose of this study was to get in-depth insights of the experiences of the LGBTQIA students in a school environment.

- I approached this research study from the viewpoint of an educational psychology master's student and assumed the role of researcher. Being employed by the Ministry of Education as a counsellor and inclusive education facilitator increased the possibility of role confusion. To prevent role confusion by myself, I constantly monitored my actions as I needed to act in accordance with my role as researcher. I must constantly remind myself of the boundaries and objective of this research to be successful.

\subsection{DATA ANALYSIS}

Examination of the data, categorisations, tabulation or recombination of evidence are the aspects of data analysis in order to address the initial proposing of a study. Data collection and analysis is a simultaneous process (Leedy and Ormrod, 2005). The research question is an important aspect of any research as they derive the processes of imperial research from data collection to reach conclusions by identifying themes that emerge from the analysis. Data from interviews were presented in the form of the narratives. According to Burton (2011, p. 147), presented in narrative, the qualitative research provides tones and a means of helping the reader to connect with the research that pure numerical data is unable to convey.

Data analysis in a qualitative research is a vigorous process whereby there are a continuous comparison which is a systematic process of selection, categorisation, synthesis and reflection of data in order to comprehend the challenges of the gender diverse students in New Zealand. 
To analyse data, a thematic analysis approach was utilised due to the nature of data collected. Thematic analysis is a method for identifying, analysing, and reporting patterns (themes) within data (Braun \&Clarke, 2010). However, it also often goes further than this, and interprets various aspects of the research topic (Boyatzis, 1998) (citied in Braun \&Clarke, 2010). This approach has been suitable for this research as it allows the researcher for more choices that not often made explicit. A theme captures something important about the data in relation to the research question and represents some level of patterned response or meaning within the data set (Braun \&Clarke, 2010).

To begin with the patterns of meaning and issues of potential interest in the data were identified as early as the data collection process. The objective of data collection and analysis in qualitative studies is to build a coherent interpretation of the phenomena under study (Marshall \& Rossman, 2011). The endpoint is the reporting of the content and meaning of patterns (themes) in the data, where themes are abstract (and often fuzzy) constructs the investigators identify [sic] before, during, and after analysis (Braun \&Clarke, 2010). With the nature of the research the analysis involved moving back and forth on the data collected, coding extracts of data that is being analysed and finally analysing the data is being produced. As writing is an integral part of this approach, I consistently took notes on the issue with potential coding schemes and continuing through the entire process.

The following steps outlined in the next section.

\subsubsection{ORGANISING THE DATA}

I began with organising the data and managing it by labelling the transcriptions from the interviews. I kept the data collected safely by storing it in a flash drive and making the copies of any original documentations collected and were safely stored as well. The transcripts 
and files were very helpful while I was analysing data thus could easily classify them under each theme that emerged while analysing the literature and the interviews which I conducted.

\subsubsection{UNDERSTANDING THE DATA}

As De Vos et. al (2005) recommended I, familiarised myself with the transcripts. I documented my interpretation in a summary of descriptive/interpretive note, recording my understanding of the available data.

\subsubsection{GENERATING THEMES}

After making notes where possible I decided to go through the interview questions and to cluster them with the themes emerged from the literature. As Biggam (2010) stated well designed data collection tools make collection and analysis of data much easier. This has occurred through themes and subs subthemes that transpired through literature. Thus, I included any new ideas or themes as they emerged through the analysis of the interview scripts.

Following the identification of the themes or headings in the literature used I colours to code themes that emerged from the semi-structured interviews. I did this in order to determine if the themes that emerged from my studies that I linked to themes correlated with the literature and the existing theories surrounding the LGBTQIA learners.

Then I interpreted single instance for specific meaning that is looking at the bits of important information which might be very useful which might have been missed out by the other two strategies. Then all the documents the interview transcripts, national curriculum and policies were analysed separately. Following which selective coding was used to show the interrelationships between the categories to describe the outcome in form of a report. The themes were continuously reviewed. 
Further, it is extremely important that all studies are trustworthy. It was always important to assess the reliability and that the validity of data analysis, findings and conclusions if the results are to be effective and meaningful to intended audience (Maree, 2010).

To ensure that a study is accepted by others it is imperative that that the researchers assesses and confirms the data and to draw conclusions (Bryman, 2004). This ensures that the research carried out are conducted according with good practices. By considering the perspective and experiences of all participants I increased the possibility of obtaining an indepth understanding of the gender diverse students in New Zealand secondary schools. I utilised and analysed the existing literature as reference to verify if the findings of the interviews were consistent or different from existing research.

Further, this research can be depended upon as Payne and Payne (2004) suggested that dependability refers to whether the findings of a study are applicable. To ensure that the findings of this research were applicable I audio taped the interviews and transcribed the interviews as it was relied during the interview.

Moreover, the conformability of this research findings as Bryman (2004) suggested that it refers to the researchers influences of his values to influence research findings. I to my best of the abilities tried achieving the conformability by being neutral and objective under all circumstances and situations. 


\subsection{ETHICAL CONSIDERATIONS}

In order to conduct this study, I adhered to all the guidelines set by the Ethics committee of the Victoria University of Wellington. I kept my conduct within the guidelines of the University and that of Aotearoa New Zealand such as democracy, confidentially, values and rights. This research followed the ethical guidelines as discussed to maintain the optimum outcome. Ethics in research is imperative to guide against fabrication, falsification of data, research procedures, data analysis, and annihilation of data for falsified purposes, plagiarism and abuse of confidentiality (Leedy and Ormrod, 2005). Researchers need to adhere to this to maintain professionalism, respect for their trade and each other. Physical or psychological harm will be taken into consideration and shall be protected and if any harm may arise will be justified and discussed with the participants. This implies that when conducting research with human beings, the researcher must consider the relevant scientific and moral values. Fieldman (2007), suggests that respecting people's humanity and dignity is of great importance even if it means that information may be lost.

In all circumstances, I tried to minimise harm of any form which may have caused physical or psychological form by only discussing, interviewing or sharing ideas of any form with participant only and in all confidence. The participants were very well informed of their rights to leave the research or exempt oneself from any part of the research which many do not feel comfortable with.

In carrying out a research study concerned with the wellbeing of the participants, the researcher sought informed consent from relevant stakeholders (Fieldman, 2007). No questions that could cause harm to participants were asked in the questionnaire. I obtained permission from the principals, teachers, and parents and selected for completing the study before which consent will be obtained from the relevant authorities such schools. Once the permission was obtained, I introduced myself and explained the issue of study and purpose of the study to the 
participants. The indentions were clearly explained so that any form of exploitation could be avoided. Allan (2008) states that the researcher must ensure that the research participants are fully informed about the nature, purpose, potential risks and limits to confidentiality involved before data collection commences. I also assured that due to the sensitivity of the research their names will be kept confidential and students and teachers will only be known as student A, B, $\mathrm{C}$ and so on. I clearly informed the contents of the information sheet to the participants and the consent was well spelled out to the participants with the aims and objectives of the research.

During this research I maintained confidentiality and privacy. Nolan (2006) mentioned that privacy is paramount, and that information provided were not forced from the participants and I respected their rights. For safety reasons, all the documentations such as recording, transcripts and any additional footnotes were locked away. No information was made know to another person due to the sensitivity and nature of research taking confidentiality was considered.

I maintained that the participants were free to provide as much information that they wished. I maintained honesty and accountability during interviews as well post interviews whereby I kept all the information and details with good care and where used for this research purpose only. I also maintained that no participant is deceived, or their privacy has been invaded in any way. All the information was kept were not disturbed or manipulated in any way.

I ensured that the participants were never placed in a situation where they could be harmed or embarrassed mainly due to the researcher's insensitive research practices (Denzin \& Lincoln, 2005). In order to protect the participants from any discomfort all interviews were conducted in student's free time and were it is more like a routine for students to visit the counsellors in their free time. Thus, a separate room was used to conduct the interviews. None of the information obtained were disclosed to any of the other participants or the school. However, they were discussed with my supervisor. 


\subsection{CONCLUSION}

This chapter described the methodological approach of my study. It provided a more detailed description of the selected research approach and design as well as the chosen methods of data collection and analysis. The results of the data analysis and the categorization of themes will be presented in Chapter 4 . 


\section{CHAPTER 4 RESULTS}

\subsection{INTRODUCTION}

In this chapter, I discuss the outcomes of my research by presenting the data which emerged during the analysis of the transcripts. I categorised the results under the themes that emerged in the literature and through the semi-structured interviews.

The issues/themes that emerged were as follows:

1. Understanding the concept of gender diversity

2. Struggles, discrimination and experiences of gender diverse students.

3. School environment and resources to accommodate the needs of gender diverse students.

4. The curriculum and the policies at school level

\subsection{THE ANALYSIS OF THE PARTICIPANTS}

The table below shows analysis of the interviewees. Due to confidently of information and nature research everyone is allocated a code.

\begin{tabular}{|c|c|c|c|c|}
\hline Code & Age & Ethnicity & Gender & Sexual Orientation \\
\hline \multicolumn{5}{|c|}{ Student } \\
\hline SA & 17 & NZ European & Female & Bisexual \\
\hline SB & 16 & Maori & Female & Bisexual \\
\hline $\mathrm{SC}$ & 17 & Maori & Female & Bisexual \\
\hline SD & 16 & Maori/Samoan & Female & Bisexual \\
\hline $\mathrm{SE}$ & 17 & Maori/Samoan & Female & Bisexual \\
\hline SF & 17 & Samoan/Niuean & Male & Bisexual \\
\hline \multicolumn{5}{|c|}{ Educators } \\
\hline TA & 39 & NZ European & Male & Straight \\
\hline TB & 56 & NZ European & Female & Straight \\
\hline
\end{tabular}




\begin{tabular}{|c|c|c|c|c|}
\hline TC & 59 & English & Female & Straight \\
\hline TD & 27 & NZ Maori & Female & $\begin{array}{c}\text { Straight (but in a relationship } \\
\text { with a transgender person) }\end{array}$ \\
\hline TE & 62 & NZ European & Female & Straight \\
\hline
\end{tabular}

\subsubsection{A BRIEF SYNOPSIS OF THE PARTICIPANTS}

\section{Student Participants}

\section{Student A (SA)}

A 17-year-old confident NZ European bi-sexual girl. SA has been open about her orientation with her family and as well as her friends and feels that she has been positively accepted by her family and friends. She is aware of the struggles of the gender diverse students in the school and feels that the school is very positive environment for her. She believes that the school is meeting the requirements of a very positive environment and recommends that all students need to accept gender diverse students equally though they cannot be forced to do so.

\section{Student B (SB)}

Bisexual, Maori, female who indicated that she is not yet out with her family however, she has shared with her friends. She deeply felt that there is a need for equality in terms of policies and resources in the school. She though felt that there is a sense of responsibility however, more could be done to create equality.

\section{Student C (SC)}

Maori/Indian Female, bisexual, indicated that she is also not out with her family. It is mainly due to her family being Christian and the fear of being "kicked out”. She mentioned that there are students who have called her names and she has been victimised at some point. She further mentioned that there are no policies in the school to safeguard her interests within their learning environment. Despite this she feels that the school is doing well in accommodating their needs as gender diverse students. 


\section{Student D (SD)}

This participant responded was extremely emotional while sharing her struggles of being a gender diverse student. She lost her friends when she came out and has encountered negative experiences. She felt there is hardly anything that accommodate them as gender diverse students at the school. She felt that there is hardly any information system that informs or educated other students. She also informed how she was ignored when she wanted to share her experiences. She also stated that some teachers did not approve of them being gender diverse and ignored them. According to student $\mathrm{D}$, some even discussed their choices such their sexual preferences, dressing and so on in the staffroom. She also felt that there is a discrepancy in the way issues are dealt with gender diverse students and heterosexual counterparts as they are more regressive for them.

\section{Student E (SE)}

The student was quite shy and did not respond in-depth to the question and her answers were mostly generic such as 'yes' or 'no' responses but informed that it was difficult for her family to accept her sexuality.

\section{Student F (SF)}

Male, bisexual student was quite informative about his experiences. He stated that it was quite difficult for him open to his family. They were not accepting initially due to their religious beliefs and he was told that he was not perfect. Coming out was one of the most difficult phases for him. Over time he was accepted by the family. He also indicated how he was ignored in the class by his teacher due to his sexuality in multiple incidences. He strongly believes that there is a need for intervention in the school policies and to inform the staff the difficulties they face. 


\section{Teacher Participants}

\section{Teacher A (TA)}

The teacher though straight is a strong advocate of the LGBTQIA movement and has been working closely with the students of the school. He has described his experience with gender diverse students and their difficulties within the school and with their family. He believes that all students should be given equal rights as gender diversity is a basic human right. He also stated that the school lack resources and there are no policies that accommodates the interest of the gender diverse students. He also stated that there is hardly anything in the curriculum that discusses the issues related to gender diverse groups. He believes that a lot needs to be improved in terms of teaching and policies.

\section{Teacher B (TB)}

Teacher B that she has seen students struggling with issues related to their sexuality. She believes the school has been doing well by providing facilities such as unisex washroom. However, she stated that there are no specific policies for gender diverse students, and she is not aware of any resources being available for gender diverse students. She further stated that due to her subject nature she does not teach on this issue. She also feels there is a need to educate all staff on the issue through professional development.

\section{Teacher C (TC)}

This teacher has been working very closely with the gender diverse students for a long time. She stated that she has seen difficulties and there was a moment that they had to intervene with their family and friends to support these students. She also informed of the activities run by the school and it is one of the few schools who is advocating the LGBTQIA movement. She stated that the everyone is quite accepting yet there are few who need to accept these students. There are facilities in school for gender diverse students and school allowing students to dress as they wish to. She did inform that there is a need to consider school policies and resources for 
the students. She also mentioned that the subject context does not integrate the issues. Finally, she stated that there is a need to educate everyone in school.

\section{Teacher D (TD)}

A strong advocate of the gender diverse students she indicated that though she is straight, but she is in a relationship with a transgender person. She mentioned that we should not label everything and everyone and felt that students need to be given privacy and respected for who they are. She mentioned that her group and she try their best to accommodate the students of all gender backgrounds and to accommodate their needs and to avoid biasness in her subject area. She shared her experience when teachers mistreated the students and she had to take matter to the authorities and there was no positive outcome. She also mentioned when she stated the need to include the issue of gender diversity, she was put down by stating gender diversity is not of concern. From policies to lack of facilities she stated a need for change. She mentioned that the school leadership team does try their best to accommodate all students, but the teachers do not implement this equally.

\section{Teacher E (TE)}

Teacher E supports and works for the gender diverse students and feels that there is nothing special about the gender diverse students, and they shouldn't be treated differently whether it be police or facilities. She also mentioned that responsibility lies with everyone yet felt we cannot force anyone to follow these.

The responses of the participants are further classified into themes as below in the findings section. 


\section{2 $\quad$ FINDINGS}

\subsubsection{THEME 1: THE CONCEPT OF GENDER DIVERSITY AND}

UNDERSTANDING.

\subsubsection{Understanding Gender Diversity}

The interviews started with exploration of concept of gender diversity and the participants perceptions related to gender diversity. Most of them believed that it is like being like any other person who have equal rights, the right to be happy and to do what they feel is right. Nearly all the participants were very supportive of the concept and have a fair idea of what it is yet more in-depth knowledge is. The participants support gender diversity in their society and community at large. They felt they are same as any normal person who has the right choose how they wish to be, what they want to wear and who they prefer to stay with. They feel that LGBTQIA individuals deserve equal rights as any heterosexual counterpart and should be treated equally and given the same rights in schools and society at large. The following are the extracts of the participants thoughts related to gender diverse individuals:

“...normal people. They just a person. Pretty much normal in society...why shouldn't we support them...” (SB)

“...showing who they are...” (SC)

“...support. Love is love...find your world...make them feel that they got a place ...okay to be yourself...” (TA)

“...people who be, who are unsure of their gender identity, LGBTQIA, anything that is not straight...." (TB)

“...people who are unsure to they male or female and choice who they want to be...” (TC) 


\subsubsection{Same-Sex Relationship and Marriage}

Same-sex relationships and marriages are equally encouraged and supported by both students and teachers. Again, as the participants are supportive of gender diversity, they felt that the individuals have the right to spend the rest of their lives with people with whom they feel is right for them. It is the individual's choice. It was surprising to note that their where few student participants who were unaware that same-sex marriage is legal in New Zealand. The following outlines the participant's thoughts on this concept:

“...we are all one...” (TE)

“...anyone can do so...” (TC)

“...if they not hurting anyone they should be together...as far as they are happy...” (SC)

"...to be allowed to be married..." (SB) The student was unaware of their right to be legally married to same in sex in New Zealand. Thus, there is a need to create awareness on the rights of the gender diverse students and school are the best place to do so.

“...see as normal...support each other...” (SF) The student wished that everyone could only accept them equally and support them to be with those they want to be.

\subsubsection{Struggles of Being Gender Diverse}

Some of the participants mentioned that they have experienced inner conflict as it was initially not easy for them to "come out” and to accept themselves. Family influences have also led to inner conflict within their selves which is not inflicted by the school but through family. In this case they commented that the school's effort in providing the support and counselling was needed for them to accept themselves. During this study, it was also indicated by some participants that they experienced inner turmoil while in the process of accepting themselves and 'coming out' as it was difficult for them to acknowledge their sexuality at school and among their friends. 
The participants mentioned that most of them were well support by their heterosexual counterparts and the educators who support them along. They also found comfort with other LGBTQIA students who are open and were well supported by their family and friends. Families as noted in the literature provided are integral to gender diverse individuals. As per research outcome some felt that the rejection by family was far more difficult for them when compared to the attitudes and behaviours of their friends and teachers as they felt that they could cope up with it. Some felt that their families did support them after a phase, but it was still very difficult to convince them. This was one of the most difficult phases of 'coming out' apart from losing friends. The students indicated the following struggles of themselves and their friends who have undergone various difficulties which has not been easy for them: “... however, it feels, like, if a person feels male though a female and they feel comfortable and I like when people they are comfortable and be who they are and how they want to be...”. $(S A)$

“...I haven't come across but other people who are called names by other people and picked on by other students just because they like the same gender, mainly like bullying...”. (SA) “... Approval of the family and friends. They get disowned, kicked out, bad experiences...” (SB) This participant indicated that the struggles mostly general comment based on others experience she has come across.

“...being bullied and not being able to speak about it...” (SC)

“...struggle of not being accepted. I lost some friends, when I came out to them.... like...I like them...so I lost some friends and regret losing them...” (SD)

As described the difficult phase in life and lost friends who she could confined to. She has yet not opened to her family and felt after losing her friends she might not be accepted by her family. 
“...It is very difficult to open...I opened to my family, they were mad because my family is a religious family, it was like god's creation, you are not perfect...”. (SE) As indicated by this participant's religion and religious beliefs are other common factors that causes difficulties for gender diverse students. Their family's religious beliefs and seeing this as a wrongdoing are the key reasons of students being segregated by their families.

“...my family is Christian, friends - people judge us very quickly. I can’t tell my family, or I will be kicked out...”. (SC)

While some students indicated being positively accepted “...My family and teacher fine about it. It was bit of surprise...” (SA)

Some of the teacher voices collected were:

“...other people accepting them...staff not knowing how to refer them as he or she... staff not knowing whether to approach to discuss the issues... struggles when parents are not on board or don't know... they can be one person in school and out be another...”. (TB)

A teacher felt that she supports the gender diverse students but feels that “...I don't understand what they are going with and with due respect... I haven't experienced something I cannot understand it...”. (TA)

“...Human's the problem we have to put label on everything...I like to treat my students with equity but most of my gender diverse students like to push their boundaries...” (TD) feels the major struggle of the LGBTQIA students are

“...feel alone, not know who to turn to, ask a question...”. (TA)

“...Being treated, looked at, treat differently, not have confidence to stand up for themselves or have to fight to be recognised. They are like just exhausted...” she further discusses a case of student... "she changes her gender identity to accommodate for those who are around...". (TD) 


\subsubsection{THEME 2. STRUGGLES, DISCRIMINATION AND EXPERIENCES OF GENDER DIVERSE STUDENTS}

\subsubsection{Threats, Insults and Humiliation}

The student participants reported that the some of the teachers had outwardly been sarcastic, insulting and using name. This was not only confined to the classroom but some of the teachers tend to talk about these students in the staffroom. As students indicated they had heard about all these issues as it came back to them via other students.

The participants also reported being threatened and humiliated by their peers. Despite being ridiculed and verbally harassed most of the gender diverse students did not report these incidences to any teacher concerned, or the school leadership team. Some of them preferred not to report incidences as they felt that they would not be listened to. The following is the transcribed data from the interviews which illustrates these points:

“...Not necessary me but I have heard students who say about other students and how they are and it not very nice...”. (SA) Here the student indicates students' passing remarks and the teachers talking about them.

“...as a student, I got teased a lot and I was bullied and mocked about it. It started with one person and turned into rumour ... the more I heard about it the more pressure I had on me...”. $(S F)$

“...bullying does happen in here...they are well accepted here but in saying that there are pretty remarks...” (TB) Teachers are aware of the situations as indicated by the teacher participant. However, students stated that they did not rely on their teachers as they believed there would not be much done for them.

A student indicated her biggest struggle is her parents knowing about her choice. “...my family is Christian, friends - people judge us very quickly. I can't tell my family or I will be kicked 
out...”. She also mentioned being call derogatory name for being out “...Being called gay, lesbian... $P^{* * * *}$ eater...” (SC)

“...being bullied and not being able to speak about it...” (SC)

“...They [school and staff] let you express yourself. It is more verbal then physical. They go and talk about you and that comes back to you...” (SD) The participants indicate that the school had placed some emphasis on self-expression, but it was not practiced well.

Likewise, a teacher participant indicted that “...they [staff] should be [accommodating gender diversity in class and related topics] but I don't think it is happening. The principal has a big vision but not all teachers support though our principal is a big advocate for this...” (TD)

\subsubsection{Teacher Perceptions and Attitudes}

Some of the teachers in this study indicated that the heterosexual students or the LGBTQIA students in their class had not reported any incidences of any homophobic verbal abuse. Some the teachers believed that complaints did not come to them because there were no issues. The teacher participants indicated that they lacked the information and education related to gender diversity. Also, they indicated that they were unaware of any form of homophobic verbal abuse in the school. While some teachers genuinely wish to work towards equality for gender diverse students, the teachers they also indicated that the gender diverse students do not wish to share their experiences with them. This could be as indicated earlier by students that this be turned against them as the students feel that will be targeted, excluded and ridiculed by some teachers.

“...one person that I know off seem to cope up well. The students have accepted well. One thing about our school, we have a Pasifika community and 'fafafine' students who are quite acceptable...” (TC)

“... not aware of...once again the students need to complaint if they need help...”. (TC continues...) 
A teacher mentioned that the policies should be equal for all. "I don't think so we all one..." "If we make policies for them (LGBTQIA students), then we willh have to make polices for white people, coloured people...” (TE) When asked about student's complaints the response was: - "students are reluctant ...." (TE) But she was firm on the need to differentiate any policies for gender diverse students.

\subsubsection{A Lack of Understanding}

During the interview session, some of the participants (both teachers and students) indicated that there was a lack of understanding related to homosexuality and gender diversity amongst the heterosexual students and teachers. It was indicated that there were some students and teachers who did not wish to change their attitudes toward gender diverse students. They believed that there was no difference between a heterosexual and a gender diverse student and felt that there should be no reason to treat them differently. Some teachers felt that there were no productive measures to protect the LGBTQIA students at the school. There was a need for the school to respond to issues, and to the harassment.

Some ideas shared were:

A teacher shared her experience - “... I know a teacher who was strongly religious and ultraconsecutive, firm and he would be... 'it is not a choice...but I say it is a choice' ...we have a very accepting body[school] here but you gonna find some who are very critical.... I also have some boys in my class who are quite feminine. I cannot ask then, it is disrespectful...” (TC) “...I have a gender diverse student who like to push her boundary. She thinks I am homophobic...”. (TD)

“...ignorance of both staff and students around sexuality and lack of education...”. She continued “... building relationships between teachers and students are some feel that it is something contagious or something. It automatically excludes especially if the teacher oversees our education, it automatically makes you feel uncomfortable. Teacher should put things 
aside...”. (TD) The teacher spoke of her experiences of how some teachers treat gender diverse students differently however, as indicated earlier this is not limited to teachers but some teachers feel that the gender diverse students tend push themselves and their boundaries and this makes it difficult for some teachers to reach out and help the students.

SF- “...I have been twice (being ignored) I got pretty annoyed; I got a complaint to DP's. I they had a talk to the staff member. It stops... yes the (teachers) do ignore...” (SF) Teachers isolating the students in class is another indication that these teachers do not understand the needs of these students and they cannot separate themselves from their beliefs in order to accommodate these students.

A Teacher's response “... the only thing I would say just 'hey stop it!'...” and she also mentioned that “...heterosexual students are very accepting...” (TD) When questioned as to how the teacher handles homophobic abuse in her class. This clearly indicates the teacher misunderstanding and the lack of professional development available to educate the teachers on such issues.

\subsubsection{Verbal Abuse}

Most of the student participants indicated that they were verbally abused with words such as gay, lesbian and ' $\mathrm{p}^{* * * *}$ eater'. None of the participants encountered any form of physical abuse against them. Some indicated that their friends were protective of them as they would stand up for them if any student passed comments to them. The heterosexual friends actively participated with them in rainbow events in school to show their support. Furthermore, the Social Services department being located at the school premises had helped to decrease the number of abuse cases in the school. The presence of the department allows for gender diverse students to take their grievances to the staff and then the issue is reported to the school authorities to deal with the students and inform other students as well. Based on the feedback 
from the teachers, they indicated that they had not received any complaints from students, and they perceive this as no occurrence of any form of abuse in the school premises.

As indicated below:

“...Being called gay, lesbian... P**** eater...”. (SC)

“...most of the students are quite accepting...” (TC) further in the interview mentioned again that “...heterosexual students are very accepting...”. (TC) indicated that students are protective of their friends and peers as much she has experienced.

“...we are friends with people who understands us but are judged quickly...”. (SC)

When asked about the verbal abuse “...it does happen in school, I will not disagree...” (TB)

\subsubsection{Isolation and Rejection}

Some of the participants indicated that after 'coming out' to their friends and classmates, many of them had experienced being isolated or rejected by their friends. Some of the participants indicated that they had lost friends as they did not share the same interests. Gender diverse students preferred to isolate themselves from their heterosexual friends in order to save themselves from humiliation. Thus, to avoid awkward situations most of the gender diverse students tend to befriend other gender diverse students as a community. The following statements are some of the views of the students and teachers on various occasions when they were treated indifferently:

“...struggle of not being accepted. I lost some friends when I came out to them...like...I like them so I lost some friends and regret losing them...”. (SD)

Further into the interview when asked being included equally “...Yeah a washroom but not so much. If you are a trans. They let you express yourself. It is more verbal than physical (in other words done). They (school and teachers) go and talk about you and that comes back to you...”. $(S D)$ 
was upset during 'kapa haka' the choice was denied to the students “...students forced to stand with biological gender where two biological female students who identified as male were forced to stand with females ...”. (TD)

“...they talk about boys or girls but the moment I talk about my girlfriend everyone like make you feel uncomfortable and gives you dirty looks...we cannot express ourselves openly...” (SD) and this is one of the reasons for her to isolate herself from other students.

\subsubsection{Self- Disengagement from Activities}

Some of the students also indicated that they purposely disengaged themselves from activities such as sports and cultural activities as well as classes. The reasons for this was that they felt excluded by teachers and in some circumstances having felt not part of the school hence come to the school for the purpose of attending as they are not treated equally.

In certain circumstances, such as in Physical Education classes the teams are mostly divided into males and females and the students are divided in their assigned gender. Most of the gender diverse students avoid this process of gender division due to discomfort and negative attitudes from their peers. Also, other activities such as school camps and other off-site activities did not accommodate gender diverse students' needs, and this led to the students dropping out of the activities.

“... It is really not talked in the school.... we have legal implications at the moment like if we went for camp, we have to look at their legal gender. It is a sad state...” (TC). This could be one of the reasons for exclusion as well as indicated by one of the teachers.

“...like they push it to the side. I feel accepted here, but I feel I get not treated the same or less for example if I am name called, I am told to ignore them. If me or my friends call the ' $b$ word' we get massive growling. Being called gay, they just brush it off. I feel being called as such as gay, lesbian or ' $p^{* * *} y$ eater should be treated as same as being called a ' $b$ ****...”. (SD) 
“...students forced to stand with biological gender where two biological female students who identified as male were forced to stand with females ...”. (TD)

\subsection{3}

THEME 3: SCHOOL ENVIRONMENT AND RESOURCES TO ACCOMMODATE THE NEEDS OF GENDER DIVERSE STUDENTS.

\subsubsection{School's Impact}

Some teachers believed that the school provided a good environment, such as having a unisex washroom, diversity group, rainbow events for gender diverse students and having full time school social workers on site to provide counselling and support as need arises with the students. The students were free to visit the social services hub whenever they felt the need for it. However, the students felt that the school could do more in terms of school environment and the resources for the gender diverse students and about gender diversity. The participants indicated that a school which is safe, had less homophobic abuse and harassment and this could only be achieved through more specification in school policies and creating more awareness for the students and teachers of the school. The following are some of the supporting transcripts from the interviews:

“... we have $X$ and $Y$ (social workers - names suppressed) to talk to and we celebrate pride day and not many people being judged...”. (SA) The student also indicated that when they are with their diversity group they are not judged for their choices and feel secure.

“...yeah, I think so. Diversity groups/workshops. We do have unisex washroom...”. (SB)

“...not the school as a whole but counsellors... I get questioned because I like same sex...”. (SD) The student indicates that she is easily picked on by teachers due to her diverse choice.

“...support team, social workers, nurses, support group, meet frequently to provide support and place to connect, become friends, make connections with staff... Yet, can do better (school)...” (TA) 
“...changing room - no single cubicle to dress separately...forced to expose ourselves...children are in puberty and doing the same (changing together) is not justified...”. (TD) The teacher indicated that the having one unisex bathroom was not enough. Due to time constraints, most of the gender diverse students were forced to change their clothing in front of their heterosexual counterparts.

This indicates that although the school had put in some measures to accommodate the needs of the students, there is a lot more effort required to provide a safe environment for the gender diverse students.

\subsubsection{Information related to LGBTQIA Lifestyles and Needs}

Most of the teachers indicated that they were working towards the betterment of their students and they indicated that the school had the best facilities to provide safe processes for them. They indicated that the school had a unisex bathroom for the students. However, many did agree that the school lacked the relevant and current information to educate other heterosexual students. The school did not have any resources in the library or at the schools for the LGBTQIA students to seek any further help. Nearly all participants agreed that the school lacked basic resources to educate the all the students. The LGBTQIA students could learn of their rights as a student and as an active member in the community. This is indicated by the following extracts from the transcript:

“...there there maybe but I have never looked...”. (SA)

“...it is quite general, nothing specific but only in support office. Students could benefit more from the library...”. "General but definitely could be improved. Not all at the moment...”. (TA) agrees that there is need for more resources in the school and the resources are only available in the social service hub. The participants agreed that the information which they have is basic and the issue of those students who were 'closeted' may not come down to social serves hub for the information thus, this may lead to negative effects on them. 
“...I haven’t look. The only kind of pamphlets are kept are kept in social services office. It is not bad idea but will see if there are some in the library...”. (TB)

“...nothing if they do, they are outdated...”. (TD)

\subsubsection{Appropriateness of the School Facilities}

The school provided the unisex bathrooms for the students which was located in the physical education changing room. However, the students felt that this was not sufficient for their needs nor was it safe to do so. Due to its location, what students mentioned it to be isolated and gender diverse students have a long way to walk to use the washrooms, and in most cases had to use the facility that was available nearest to them as described by the following: “...changing rooms - no single cubicles to dress separately...forced to expose ourselves...”. (TD) Here the teacher identifies that students are not in primary school, so cannot simply change in one room. The students are in the process of their puberty and their orientation differs. Thus, it was not appropriate for them to change their clothing in one room.

“... I believe the school is meeting the requirements example we have multiple girls and boy's toilets and a unisex washroom...”. (SA)

“...we do have a unisex washroom...”. (SB) This indicated that there was a lack of facilities for LGBTQIA students as there was only one washroom for them.

\subsubsection{Lack of Teacher Support towards Gender Diverse Students}

The lack of teacher support had been indicated by both students and teacher participants. During the interview session, some teachers indicated that it was not their role to reflect on the issue of gender diversity and touch on the areas concerning LGBTQIA rights as their subject did not requires them to do so and it is not their responsibility to inform the other students on gender related issues as it not part of their subject area. Some of the learners indicated that they hardly requested for support from their teachers even if they felt insecure in their class. The reason for this was that they perceived their teachers as not being supportive and some felt that 
they were isolated by their teachers while some of the students indicated as stated below were ignored in the class for their choice. The following are the views of the participants:

“...most students so some of the students refuse to accept but the school cannot force them...”. $(S A)$

“...definitely a lot of students know about us. School is doing well, definitely they bring in more students to the group.... We are judged quickly...”. (SC) The student indicated that when they wanted to mix with other students they were judged differently, because they might have feelings for their heterosexual counterparts.

“...No if my friends know about it more I recon they would have accepted, the would have understood us more...” (SD). Continues “...teachers and students to be given more information to make us more comfortable. You walk around the school and you hear girls talking about you... they talk about their boy or girl but the moment I talk about my girlfriend everyone like make you uncomfortable and give you dirty looks. So that we can talk about experiences openly and not be judge be ...”. (SD) again an indication that LGBTQIA students side-lined or being ignored.

"...I feel our school is doing really, really good and feel safe and supported. They did mention being bullied...”. (TA)

“...No, no, I don't think so. It is something is are happening. I do think it is responsibility for the school. Yeah, teachers should be. We talk about things. PD for staff...”. (TB) “...No, I don't think so .... Nothing is said in the staff meetings...”. (TC) This is an indication that the gender diverse students are largely ignored and hardly mentioned among teachers to better inform them on the needs of the gender diverse students.

“...students get shoulder tapped if you are somewhat fem..." indicating that it is still difficult for students to approach for support if you do not portray those diverse characteristics. (TD) 
and further states that - “...they should be but I don't it is not happening. The principal has a big vision but not all teachers not support, though our principal is a big advocate for this...”

“...Yeah, I think so. You can't get them to accept you. You don't have a choice. It's up to them..." (TE) When asked about responsibility of equal treatment of the gender diverse students by teachers and student.

\subsubsection{Complaints}

The participants indicated that the school pastoral care was providing support for having a social services department at the school, a unisex bathroom, freedom to choose their uniform, celebrating rainbow festivals and having a school to accommodate their needs. While it was indicated that there were no formal complaints procedures in place, the gender diverse students indicated they had a choice to see the social service department or see the Deputy Principal Pastoral Care, but there were no set guidelines to protect gender diverse students against harassment and abuse. Most of the participants indicated that there was nothing specific in terms of a clear policy for gender diverse students and some even indicated that they were not even aware of any bullying, harassment or abuse policies in school. The following are the responses by the interviewees:

“...come to $X$ and $Y$ (social office, names withheld) or go to the principal or DP...”. (SA)

“...No policy, we feel excluded, but we have powers to go to the DPs...”. (SF)

“...I am pretty sure there must been, but I have not seen them...”. (TB)

“...Policies are more verbal...expectations...if a teacher ignores and the student's complaint... the teacher will be interviews by the senior team and they go from there...in my case it did not.... I complaint about it (teacher mistreating a gender diver student) ... I abided by the policies and ticked all the boxes, but nothing happened to the reliever...it just puts us out...”. (TD) 
“...No complaints policy/guide especially for these students (gender diverse students), we make it sensitive if we want to ..." (TE) (when asked about the sensitive nature of treatment of the gender diverse student compared to a heterosexual student). There was a clear indication that there was no policy specifically for gender diverse students to cater for them and to protect them and their rights. Also, there are no formal or a streamlined procedure for the students to follow so that their complaints could reach the right authorities.

\subsubsection{Positive Changes}

Some of the participants also indicated that there was a positive change in the school environment, due to the positive changes being made by the school and the social services department having a presence at the school. Programmes such as Rainbow Day celebrations was a key feature of such changes and had led to an increased awareness of LGBTQIA students. The inclusion of a pastoral care portfolio in the school leadership was a positive move as well. A Deputy Principal is specially appointment to investigate the affairs of the students' needs and since the school fully recognising and accepting gender diverse students the Deputy Principal closely work with these students and the social services department to provide prompt services and counselling. The following changes were noted:

“...X and Y (social workers) to support and if they want to come out...the school is handling the gender diversity well; few students are tough...”. (SA) The school is fully committed in supporting students if they wish to 'come out' they provide counselling sessions and they also have one on one discussion with the family members if the student wishes to 'come out' to his family.

“...really good team in social works department. The nurse, it is not really talked by in school. Toilets in the gym. You can use the single toilet. We don't have the legal implications at the moment like if we went for camp, we have to look at their legal gender. It is a sad state...”. (TC) 
“...absolutely, we have diversity days. Separate area for kids to change...”. (TE)

Because of their recognition through providing better facilities such as a unisex bathroom, and support services the participants indicated that they felt worthy, proud and confident of themselves. They were more visible in the school and were acknowledged for their decisions such as their choice of uniforms (male or female) and who they wanted to wear.

“...Gender diverse are allowed to wear heels on skirts. Policies are quite free who wear makeup and dress up and even though are males...”. (SA)

“...as school, we are doing very well...”. (TE)

\subsubsection{The School's Effort}

The student participants mentioned that the school had put in some effort to help support the students, such as providing space such as the social services department which is accessible to students especially gender diverse students at any time of the day if they need to talk to someone, complaint or are feeling disturbed. Some teachers also made the school environment safe for the gender diverse students to decrease any harassment against them. Some teachers were creating environments in their classes so that students felt appreciated. A teacher indicated that their department regularly met to brainstorm and create activities which were suitable all students that is to actively involve gender diverse students and avoid being biased. Some of the teachers believed that the school was doing well in helping the LGBTQIA students by having pride day celebration. However, the students felt that more was needed to be done in terms of educating other students and teachers.

The following are the extracts that denotes the efforts of the school and teachers:

$\mathrm{SD}$ - “...they do like we have diversity group ... trans wear skirts...”. (SD)

TA - “...I feel our school is doing really, really good and feel safe and supportive. They (gender diverse students) did mentioned being bullied...”. (TA) 
The participant indicated that that despite support some students feel - “...access support (social department) means trouble...”. (TB) They further state that the school is doing well as “... we have unisex toilets, identified places in PE changing rooms that is gender diverse that is girls, boys and another, we have a uniform that can be worn, there is no issue around who wears what uniform...”.

“...we have an amazing team... a lot more could be done like health department to put it into a curriculum. We don't prioritise as much as we should such as mental health, the school has just identified LGBTQIA issues. School does much more than other schools...”. (TD)

\subsection{4}

THEME 4: THE CURRICULUM AND THE POLICIES AT SCHOOL

\section{LEVEL}

\subsubsection{Harassment and Bullying Policies}

Some students indicated that there were some school policies and rules such as antibullying policy for all students. They also believed that the schools did not have anything specifically for gender diverse students which could safeguard them. There were no complaints policy and procedures for gender diverse when students considering sensitivity of the situations, they may be in.

Student participants indicated that policies such as harassment and complaints were the same for all students and this negatively impacted their experiences at school. The one for all policies meant that they felt their voices could not be heard when they raised their issues. However, the participants did mention that more could be done especially about streamlining and prioritising the harassment policies and procedures for the LGBTQIA students in secondary school. The following were the responses of the participants when asked about the school policies: 
"I really don't know...Not really, share in our groups...”. (SC) the only placed this student indicated that he feels comfortable to talk about harassment or any form of abuse is among his peers of the diversity group.

“...they have major thing on bullying. They come and tell $X$ (social worker) and $X$ will talk to the other person and try and limit the bullying...but necessary for gender diverse student...”. (SA) While the school is progressing with new initiatives, it still lacks written policies thus many of these students seek the Social Service department of the school for support.

“...No, I don’t know about bullying policy...”. (SB)

“...Yeah we go to the counsellors and principals and talk to the people we are complaining about...”. (SC)

“...None really. They not really care if not in the circle (diversity group). They (school) talk about you, they care but nothing is written...”. (SD)

“...no... not that I can think of. the school has gone on to values. Dress in the way they want to. Unethical to uphold student's right...safety and confidentiality in general...have to go through counselling to be identified trans...need to be assessed to identify themselves...more generalised polices nothing gender specific...most of our students are supportive...”. (TD) “...that there are but not aware of... confidentiality by social workers...Not policies as such, we have a school health care ...”. (TC)

There are no policies however the teacher indicates that, “...situations are dealt as to who is dealing with...”. (TB)

“...it is quite general. There is nothing for gender diverse students. Nothing that I know off. Policies are pretty generic...”. (TA)

\subsubsection{Teacher Perceptions on School Policies}

Some teachers strongly believed that the school's policies were non-discriminatory and applicable to all learners. One teacher strongly believed that that gender diverse students were 
not to be treated as 'special' therefore, no provisions should be made for them. Some of the teachers also indicated that as far as the policies were concerned, they agreed that there was nothing specific for the gender diverse students to specifically safeguard their interests or any form of harassment. They also felt that there was a need for change in the policies to include these issues. This was same for the students as they felt that there was nothing specific for them either.

“...confidentiality when to us. Safety. There is a written kind of thing. Confidentiality. Who share with have a signed document with staff...”? (TA) “...not policies as such as, we have a school health care run by $X$ and he is very good...”. (TC)

“...Not that I am aware off...”. When asked as there is need? “...but if there is a concern with a teacher, they can talk to us. We will talk to the teacher. I don't think we need a policy for this. Should be unwritten guideline. Deal with the DP pastoral care...I don't think so, we are all one...” and adamant that is no need for special provision for LGBTQIA students “...No, I don’t think so...”. (TE)

“...I don't know I am not sure I have not seen. Decision about the uniform. I have not read them... (Policies) nothing for the LGBTQIA. I have not come across anything it is dealt as same and who deals with it...”. (TE)

\subsubsection{Addressing Complaints}

It was evident that there were no formal guidelines for complaints to be taken up such as bullying and harassment of the gender diverse students. If any issues arise, students would usually talk to a teacher they trusted or felt comfortable with. There was no formal way to lodge complaints.

“...Just general...we have diversity group that is run at the school. We just come along to the social worker or just go to a teacher...”. (SD)

“... there is no rigid way...”. (TE) 
“...not aware of. Once again the students to complaint if they need help...there is a referral process but probably not so gay students but for students who feel withdrawn...”. (TC)

“...I don't think that there is anything specific written, it is pretty broad...”. (TB)

“...inform a teacher/dean to refer to social workers. It is more case by case and who they are comfortable to talk to...”. (TA)

Most of the students stated that they would go down to the Social Services Department hub if they needed to complain about an issue and the social workers relayed the complaint to the Deputy Principal, Pastoral Care which was an extremely long procedure of investigation which usually resulted in very little being done about the problem.

\subsubsection{School Curriculum Content}

The curriculum content did not reflect LGBTQIA lifestyles. As indicated that the topics and issues related to gender diversity is briefly touched and the student participants indicated that such topics are subject based such Biology. The teacher participants further reported that they did not have a specific class such as family life and other issues related to sexuality. This was noted in the education of other heterosexual students on the issues related to the LGBTQIA students and their responsibilities towards their gender diverse peers. A teacher indicated that in a curriculum development workshop she attended, the issue of teaching gender related topics was suppressed as it did not apply to all students. The issues were not reflected in classroom teaching and these issues were only discussed among those who classified themselves as gender diverse. Family life classes were also extremely important to students of all genders and inclusion of the LGBTQIA community.

The following are the views of the participants related to the issue.

“...really depends on what you pick. The school doesn't have much on homophobia...are have diversity group but not in class...there is no family life class. Assembly we are told we have a 
diversity group...”. (SA) The student clearly indicated that there were no discussions in class on the issues related to gender diversity.

Further into discussion “...more in diversity groups not during the class...biology class taught more about reproductive system not family life. The class is not addressing much...” (SA). This also shows that the focus even in specific subjects the contents are still general and does not focus on the issues related to gender diversity.

“...I don't think so...I feel that is not good...”. (SC)

“...no, not at all. Teacher not at all as well...”. (SF)

“...Health studies briefly touches, general awareness campaign to inform others...”. (TA)

“...I don't think it does. A short part in health. But nothing in the curriculum. Teachers so, I don't think so...it depends on the teachers. Family life...I don't think we have anything like that...”. (TB)

“...speak to the P.E teacher. If you make an issue of something it becomes an issue and it just explode...”. (TC)

“...Not at all. Mis-link between P.E and social services centre/wellness centre. There was a workshop and I said we should be teaching all the students and was told that this doesn't apply...why is that...ones who choose to be gender diverse are the ones who knows about it. It should be for everyone and later as things might change...”. (TD)

The teacher participants were clear that the curriculum did not deliver such content and for some it was not their subject matter.

\subsubsection{The Uniform Policy}

All participants were extremely happy on the choice of uniform that they could wear and had the freedom to make such choices as to what they wish to be identified as giving them a sense of belonging. The students were able to choose to wear the school uniforms they felt comfortable in. For instance, lesbian students could either wear skirts or pants or a transgender 
male could dress in female clothing. This was widely accepted by all students and this made them feel more comfortable in school as it allowed them to openly express themselves.

The following extracts describes their feelings:

“...gender diverse are allowed to wear heels on skirts...put makeups...”. (SA)

SA further informs that - "...Polices are quite free.... can wear dress even though are males...”. (SA)

“...uniform that can be worn of their choice...school allows who wears what uniform...”. (TB)

\subsubsection{The Need for a Policy}

During this study it has surfaced that it is imperative for schools to have anti-bullying policies which contributed positively towards the school life of LGBTQIA learners as well as strengthening their well-being and safety. The student participants acknowledged that the schools had contributed to anti-bullying, but they believed that there was a lot more work required for actual implementation. It was noted that many participants including teachers were unaware that there are such policies in the school. The flowing are the extracts from the transcribed data:

“...they could probably do more but good at the moment...”. (SA)

When asked about the policies in school related to complaints procedure - this was explained as policies as “...verbal or written procedure and it goes to the board of trustees, but yet general...”. (TA)

A participant's explanation on the policies related to gender diversity “...No, not that I can think of the school has gone into values...”. Continues “...more generalised policies nothing genders specific...”. (TD)

“...there are no policies as such. There should be anti-bullying policies that every school should have...” when asked about gender diverse students - “...no actual policy that I know of but we do have anti-bullying policies...”. (TC) 


\subsubsection{Recommendation for Changes}

Finally, most of the participants felt that there was a need for the change in the current school policies and to include the LGBTQIA issues effectively which addressed them. All students and teachers needed to be made aware of the policies and procedures to support the safety and identities of gender diverse students.

The participants recommended that the school needed to put in more effort to educate all the other students and teachers in the school on the issues affected gender diverse students. Many participants indicated that they are unaware of the general policies and procedures in the school. But the school needed to educate the staff and students on such policies, and this could only be achieved through staff meetings, workshops, notices to the students and constant reminders in assemblies and classes.

The school curriculum could be adjusted to make room for further education and issues to be discussed as in a family life class or counselling class to create better awareness.

“...health studies briefly touch, general awareness campaign to inform others...”. (TA)

“...I don't believe it does. A short part in health...yeah teachers should be we have talked about to get PD for staff...”. (TB)

A teacher participant suggested that the education and curriculum hardly address on the issue also feel that “...PE could be a biggest discriminator such as change rooms, teams in two genders, so we sit and make our pedagogies to accommodate all...”. (TD) 


\subsection{CONCLUSION}

This chapter summarises that the gender diverse students experience challenges such as homophobic harassment and abuse as school and however, have coped with these issues and challenges as they are support by some of their peers and educators as well. The positive experiences provided by the school has given them the opportunity to accept themselves well to be more confident and prouder of who they are. The next chapter further analysis the data gathered. 


\section{CHAPTER 5 DISCUSSION}

\subsection{INTRODUCTION}

The main objective of this research was 1) To study and scrutinise the New Zealand education curriculum and policies in relation to gender diversity and the struggles faced by senior secondary students; 2) To explore the issues faced by gender diverse students in a NZ school and 3) To make recommendations as to how the education system and schools support gender diversity for their optimum growth. This chapter provides the discussion and analysis of the findings, provides some recommendations and conclusions.

As NZ diversifies as a society, schools can no longer overlook the issues pertaining to the LGBTQIA community or gender diverse students. There is a need for schools to provide necessary support to facilitate spaces that are safe and free of anti-homophobic policies. All of this must be supported by the relevant resources and people. These actions will help to increase positive images and mental well-being of the students in the long run.

\subsection{FINDINGS OF THE STUDY}

\section{Here is a revisit of the study's research questions:}

- To what extent does the New Zealand curriculum and secondary schools support gender diversity?

- What are the key issues for LGBTQIA young people in NZ schools?

The study indicated that the LGBTQIA students have experienced various forms of abuse and harassment in their school. They also mentioned that with time they learnt to cope with these situations and with the support from their school became more confident and self-accepting. They also indicated that there was a significant change in the perceptions of their heterosexual 
peers' attitudes and behaviours related to positive interventions from the school. The following section summarises their experiences in the school and the recommendations for change.

\subsubsection{Attitudes lead to exclusion}

This study found that the gender diverse students were exposed to some form of homophobic verbal abuse in the school. This was in accordance with previous researches from studies which revealed that homophobic abuse and verbal abuse was evident in schools (Kosciw et al., 2009, Coyle \& Kritzinger, 2002). Savin-Williams (1994), research study also indicates that sexual minority youths are ridiculed by other teens in academic settings the forms of homophobic abuse by the students included name calling and humiliation. Further, the use of derogatory names words to address gender diverse students were also indicated while Bulter and Astbury (2005) reports also supports the outcome of this research that the LGBTQIA students experience deep-seated homophobia in their school context and the report further states the teachers and students are responsible for name calling, exclusion and emotional and physical abuse. As indicated in this research Turiel et al. (1991) in their report closely justifies the findings points out that there seems to an assumptions, beliefs and values about reality are part of a heterosexual individual's knowledge of the social world. As reports indicate homophobia are challenges of LGBTQIA student's everyday life and exclusion are not limited to one setting as Munoz-Plaza, Quinn \& Rounds (2000) and Wernick et al. (2014) suggest gender diverse students face extreme discrimination within educational settings, including tertiary institutions.

Such forms of harassment of gender diverse students are not only unprofessional but also unconstitutional. Available literature indicates that gender diverse students are at high risk for various health issues which most of these issues are being brought by the bullying and abuse they experience due to their sexual orientation (Munoz-Plaza et al., 2002). For instance, Fisher et al. (2012, p.161), reports that "unsafe school environments where harassment and bullying 
go uncontested, can result in a variety of challenges for all students, especially LGBTQIAI students.” Therefore, bullying is noted to be one of the most dominant form of homophobic abuse in any educational settings.

Furthermore, social exclusion and emotional abuse has been one of the issues that was discussed by the participants and some teachers. This finding is supported by Bulter (2008) who identified that gender diverse students can experience rejection from some of their heterosexual peers in school. The findings of this MA research indicated that some of the heterosexual students do refrain from socialising and interacting with the gender diverse students.

Exclusion for these students meant that students who call gender diverse students names can lead to gender diverse students being alone and losing the safety of their peer group. These learners indicated that these behaviours expressed by their friends and students in school hurt and demoralised. One strategy that students used was to utilise the support provided by the school. The literature further supported the outcome of this research where heterosexual girls who wanted to be friends with gender diverse students are pressured by their peers to not to do so (McCormack, 2011).

Furthermore, the feeling of exclusion was also generated by teachers who were either aware or not aware of their actions and attitudes. As research indicates that schools that do not address issues related to gender diversity such as homophobic harassment contribute to the impression that discrimination against the gender diverse students are acceptable (Mikulski, 2005 \& Macgillivaray, 2004). As indicated in the report and supported by research done by Turiel, et al. (1991) bullying is one the most dominant form of homophobic abuse in educational settings. Finding articulates that their abusers are mostly their heterosexual peers as they feel that homosexuality is not natural and their views related to homosexuality as not normal, is 
interconnected with their judgements about the acceptability of homosexuality. These all leads to negative impact on gender diverse students.

\subsubsection{The School's Commitment}

Numerous evidences is available which indicates that young gender diverse students experience range of issues in educational institutions. As indicated in this report and supported by the report by Post Primary Teachers' Association (20070 indicates that these students struggle to fit into traditional models of schools where norm-based practices often exclude diverse sexualities or gender. As indicated in the literature, schools and other educational institutes are the first sites of victimisation of gender diverse students (D'Augelli et al., 2006). As students' progress through high school they undergo complex emotional, physical and psychological changes related to puberty. While some endure growing pains with ease and there are others faced with issues related to body image, uncertainty around sexuality and gender identity and fear of bullying affects their focus and engagement at school. As this report indicated that school's commitment paramount the PPTA (2017) report also suggests that areas where direct supervision by the staff proves challenges, equally from practical sense and with respect to health and safety of teachers, school's commitment to design changing rooms and toilets in way to provide implicit safety and security for all user. Further supporting Happel (2013) indicates that proving options for the students to shower and change in privacy as this will alleviate any potential safety concerns as this one of the concerns raised in this research.

More recently, as indicated by PPTA (2017) there are many advocates of gender neutral facilities and this has been gaining attention, while gender diverse students have been highlighting their concerns of bullying and perceived threat of physical abuse when using shared gender specific facilities. Status quo has often required students to ask for permission for a special accommodation to access 'safe' alternatives to shared gender assigned facilities 
(Happel, 2013). Given these facilities are labelled and located in highly visible areas of the school risking 'coming out' which could lead to unnecessary reprimanding by homophobic staff and peers in order to perform some of the basic life's function is problematic. In support, the PPTA (2017) in their report suggest that schools are urged to create conducive environment in with safety and dignity of gender diverse students can be maintained by maximising the opportunities of personal privacy through individual toilets and showers with lockable doors. It is clear from the findings that the need for more unisex bathrooms and other gender-friendly facilities. Goldberg (2017) further suggest that all existing restrooms should be reviewed, and a not insignificant number should be modified to be gender-inclusive or single-stall and these restrooms should be just as well maintained as all other restrooms. The point was made that Trans students may become victim to bullying or sexual violence in a space that everyone should have the right to use without hassle (Besley, 2016). This report clearly outlines the need for creating a safe, healthy and accommodating school environment for all leaners despite the differences.

Moreover, the respondents in this research indicated the lack of resources specifically dedicated for gender diverse students and towards issues of sexual identity. The school library and other academic resources lacked the resources specifically to cater for the LGBTQIA needs. While Sanlo (2004) in his research and closely relatable to this report indicates that the researched school have visible resources (social Works Department) there is a need for confidential options so that fearful and or questioning students have an opportunity to receive services without being 'publically know' to others. As per data students believe that not enough effort is dedicated towards the gender diverse students in the school. There is a need for more comprehensive resources for the specifically dedicated to gender diverse students.

Further discussing the school's commitment towards the students' academic well-being. Crothers (2007) adds that failure of academic success may also be precipitated by fear, anxiety 
and isolation that LGBTQIA individuals face at academic institutions. This can have a negative impact on academic outcomes due to poor attendance and levels of aspiration and raise mental health concerns such as increased anxiety or reduced self-esteem (Fisher et al., 2012). This leads to gender diverse student's difficulty in learning to cope and perform well in schools because of the hostile academic environment. Many students as indicated by literature PPTA (2017) attend schools with fear for their safety and emotional wellbeing. This MA research also indicates the lack of adequate resources for the gender diverse students. This is well supported by the 2016 GLEN report which suggests that multicultural literature excludes LGBTQIA people and history and leaving out LGBTQIA people, history and events in the library can lead LGBTQIA students to feel excluded from their school. The report stipulates that the school requires resources to better inform both gender diverse and heterosexual staff and students on the issues related to be a gender diverse student. The PPTA (2017) report is the guide set by the Ministry of Education to support effective sexuality education programmes towards a positive and holistic development of all students in New Zealand schools. The guidelines also suggest that affirmation of sexuality is offering of the whole school community (PPTA, 2017). Goldberg (2017) suggests that school uniforms could reinforce gender norms thus the schools should consider gender-neutral clothing and this is one of the aspects this research indicates has been positively implemented towards their commitment to create equality in the school.

\subsubsection{School Policies and Bias}

Research reports over the years has been strongly indicative for the need of inclusive policies for the gender diverse students to create a safer learning environment. The deliberation, designing and implementation of effective anti-bullying policy are key to these efforts but as reports by GLEN (2016) indicates that most of the schools are falling short of effective inclusive policy and this has been indicated in this research. GENS report (2016) further indicates that most of the policies do not explicitly protect gender diverse students. Schools’ policies should 
provide LGBTQIA students with recognition, support and equality. As the literature indicates institutions do not provide anti-homophobic harassment and bullying policies, antidiscrimination policies and inclusive programmes contribute to the idea that hetrosexism is the dominant discourse in the school (Chesir-Teran, 2003). Bhana's (2012) study indicates that due to the lack of proper policies addressing gender diversity heterosexuality is given priority over homosexuality.

As this report indicates the absence of effective policies in favour of the gender diverse students PPTA (2016) states that most of the school policies are designed from the perspectives of heteronormative expectations which fails to take into consideration the vibrancy of gender diversity and identities. The work in this area as indicated by this research needs to be approached with respect for individuality. Though the report indicates that confidentiality of information is maintained, the PPTA (2016) report indicates that this is absent in many schools. Walker (2015) reported that although most districts have anti-bullying policies on their books, the effectiveness of the policies are undermined by number of factors. The GLSEN (2016) reports further suggest that there is a strong need for provisions towards accountability and professional development for staff. Walker (2015) asserts that there is a gap between the intention of law and implementing the policies as many schools fail to design and effectively implement protection polies despite required by law. GLSEN (2016) reports also indicates that there are students who were unaware that specific protection existed as this report also found that the students were unaware of many laws that protect their interest

\subsubsection{Building relationships}

Supportive educators play a key role in supporting LGBTQIA students influencing both their school experiences and psychological wellbeing (Kosciw, 2011). The lack of direct support from teachers was a major issue in this study as this was a one factor that contributed to their negative experiences at school. As per GLSEN (2011) report that in most instances 
teachers never intervene when homophobic remarks are made in their presences, thus teacher training would and extremely component for the institutions and this is in line with the research findings as indicated that teacher support was not provided to the gender diverse students as it is to heterosexual students. As literature further indicates educators should not ignore such issues for young people and it is important that they explore these issues openly in the classroom. Boyd (1999) discussed that educators should teach not to discriminate others but to accept and respect difference. Boyd (1999) further states that educators believe the responsibility lies with the family to discuss issues pertaining LGBTQIA students. Moscow (2004) indicated that students are afraid to report their experiences of physical and sexual harassment to their teachers and principals when support was not apparent.

The GLSEN (2011) report indicates that being an LGBTQIA-supportive staff member simply means that that staff member is prepared to provide support and guidance to LGBTQIA students. Goldberg (2018) further reports that relationships with educators may be an important source of support and potentially buffered to homophobic treatment that students may face in schools and society. Goldberg et al. (2018c) in a research report on relationships with educators and gender diverse students indicated participants appreciated when their advisors or educators took responsibility for their actions and correcting themselves and thus this report also indicates the need for the teachers to accept ownership of their actions and treat students equally regardless of their gender identities. McKinney (2005) indicated that the students are aware of the power differentials and are mainly silent as means of any form of retribution that could hinder their academically and further indicates that there is need for more visibility of gender diverse students as this research report suggests. There is a need for improved relationships between the teachers and heterosexual peers and the gender diverse students (Cornelius-White, 2007; McCombs, 2004) as it is an integral part of feeling connected to the school and their school experiences. The research responses suggest student-teacher relationships are important 
as they hugely impact their success. Furthermore, Sanlo (2004) suggests if nothing else, a gender diverse student needs to feel safe and supported in their academic environment and such can be created by an impactful teacher further stating that "students who worry about an unsupportive environment and harassment are unable to focus on either academic or cocurricular learning” (p. 97). Report suggest some students being ignored in the class thus the students felt that they are deprived of their academic endeavours and if a relationship not being able to be developed teachers and peers work towards creating a safe place for all learners (Sanlo, 2004).

\subsubsection{Inclusive Curriculum Content}

Implementing curriculum that is inclusive of lesbian, gay, bisexual, transgender, queer, and questioning (LGBTQIA) people has the potential to create an equitable learning environment (Sapp, Burdge, Licona, Moody and Russell, 2005). For many students who identify as gender diverse, school is a hostile environment that can negatively affect academic performance and personal well-being. However, as per GLSEN report (2009) one strategy’s that educators can employ to promote safe and affirming school environments is including positive representations of LGBTQIA people, history, and events in the curriculum. The MA research noted that the curriculum does not support the gender diverse students and also it was evident that the New Zealand curriculum does not fully allow for a full discussion as it briefly discusses the issues of gender diversity and there is no obligation if the schools wish to teach these issues or not. The teacher participants indicated that inclusion of such issues is not part of their curriculum/syllabus thus do not see a need to discuss such issues.

The inclusion of LGBTQIA people, history, and events in the classroom curriculum according to Walker (2015) that it educates all students about LGBTQIA issues and may help to reduce prejudice and intolerance of gender diverse students. The GLSEN (2009) report further points out that researches consistently show that there a strong association with inclusive 
curriculum and peer support for gender diverse students. Moreover, this MA research also indicated and supported by Snapp et al., (2015) LGBTQIA inclusive curriculum are mostly taught in science or humanities class standalone lessons and the LGBTQIA inclusive rarely met the standards of social justice education, through opportunities for critical conversations about systemic oppression regularly emerged. Snapp et al., (2015) further students that gender diverse also indicated that the ways such curriculum reflected their issues and identities which has created a supportive school environment as indicated in this master's research as well. However, GLSEN (2017) report indicates that despite the benefits of inclusive curriculum, most the gender diverse students do not have access to an inclusive curriculum. GLSEN (2011) research consistently finds that students in schools with an inclusive curriculum are more comfortable talking with teachers about LGBTQIA issues and speak with their teachers about these issues more often. Kosciw (2011) and closely supported by Snapp et al., (2015) that by having a safer environment and positive representation of gender diverse people, history and events in classrooms may promote positive environment for gender diverse students.

The research further states that gender diverse students required more visibility in schools as the mostly absent from schools (D’Augelli, 1989). This could be due to an important aspect that curriculum lacks visibility as the gender diverse students feel that they are no part of it as Clift (1988) and Pollock and Eyre (2012) states about issues of sexual identity in higher education that there is a lack of "scholarly attention to sexual orientation" (p. 141). The research indicates that the topics of sexual orientation and sexual identity in general should find its way into more into curriculum. Bhana (2012) the data that transpired revealed a lack of curriculum content regarding alternative lifestyles. Further supporting, 'GLSEN's National School Climate Survey consistently finds that students with inclusive LGBTQIA curriculum in their schools have a greater sense of belonging to their school community, hear fewer homophobic and transphobic remarks and are less likely to be victimized or feel unsafe at school than those 
without an inclusive curriculum' (GLSEN, 2016, 22) and further suggests that sexuality identity should be included in all aspects of education level. Tinto (2006) has illustrated that there is need to create a feeling of gender diverse students being integrated into their academic experiences to be more successful academically. As Tinto (2006) and Sanlo et al. (2002) feel that if the gender diverse student feel more connected to their studies through curriculum are likely to succeed academically thus, if the gender diverse students feel less connected, they are likely to be less successful.

\subsubsection{Student Experiences}

The experiences of students as indicated by this research has been some of the adverse effects on the students such as report of experiencing psychological challenges which has led to depression, fear, low self-esteem, loneliness and being suicidal and as Turiel (1998) further reports that such emotional and behavioural problems as the result of negative experiences and treatment they gender diverse students encounter in schools. Students undergo mental stress when coming out and some did when their family was not ready to accept them for their choices and some due to rejection by their friends. As indicated in research by Munoz-Plaza, et al. (2002) learners experienced inner turmoil during the process of 'coming out' as it was difficult for them to accept their sexuality. Research conducted by Russell et al. (2011) found that learner participants do experience emotional distress in forms of depression, sadness and feeling suicidal.

While some learner participants indicated they were lucky to be supported but some of their friends were not and have gone through tough situations to be accepted by their friends and family. Aligning with other research literature this study indicates that though there were some who have not undergone negative experiences but there were some who do (Munoz-Plaza et al., 2002; Butler, 2008; Kosciw et al., 2013). Researchers have strongly indicated that gender diverse students report more emotional and behavioural difficulties when compare to their 
heterosexual counterparts (Saviv-Willams, 2001; Lozier and Beckman, 2012). Reports also indicate that the greater the extent of openness, comfortability and risks, the greater the extent that gender students are open about their sexuality (Arndt and Debruin, 2006).

The reports mostly indicated that the teachers did not identify adverse mental or physical experiences of the students however the social workers have received situations where students have been going through mental stress. While Weiler (2004) is not surprised that many gender diverse students do not open about their identities due the hostility of the school environment. Furthermore, Rivers and D-Augelli (2001) pointed that the gender diverse students are of high risk of emotional and physical refection by their families as a result of od their disclosure. Therefore, most of the students tend to remain silent as indicated in the research has well (Bortolin et al., 2013). It can also be due to fear of being treated badly (D'Augelli et al., 2006).

\subsubsection{Positive School Environment}

A positive school environment is when schools and teachers establish a trusting, supportive, and inclusive learning environment for their students (Health.tki.org.nz, 1999). As Goldberg (2018) suggest that a school environment could play a powerful role in reinforcing or refusing, the treatment of the gender diverse students at the students may face in schools and society at large. A positive environment could be beneficial to the students as noted in this report as well as This is in accordance to study by McCormack study (2009) the study at the school really benefited from the academic support because it helps them to address their academic needs to achieve their full potential.

Analysis of the existing literature indicates that the positive involvement of the LGBTQIA students will greatly reduce and prevent victimisation and bullying of gender diverse students in schools (Kosciw et al., 2009). Furthermore, there is a need to for active participation of gender diverse students in school affairs. Smith and Leaper (2006) indicate that 
the active participation and inclusivity in discussion related to the issue pertaining gender diversity could greatly reduce distress among students.

According to empirical evidence, both schools and individuals need to strive to improve the school environment for gender diverse students through interventions which encourages teachers to beyond the school based meetings and professional development and pushing the authorities to reorganise school policies and curriculum that promote gender diversity and to create an inclusive environment (Kosciw et al., 2009). Research indicate that the work and progress in the school has been positive for them that provides the same rights and importance as their peers and making the school more inclusive (Kosciw et al., 2009).

In the research by McCormack (2009) it further indicated support of this research findings that students can be themselves in an environment where they are respected and understood and acknowledged whereby the school made more positive experience for gender diverse included in this study. Despite the existence of homophobic harassment there has been a decrease in the frequency of harassment and much safer environment for students report analysis suggest that teachers and students at school have become more tolerant and accepted of their choice and have been more accommodating over the years. StopBullying.gov (2018) states that 'while safety starts in the classroom, students should feel safe everywhere on campus" and further indicates that in order to have a safe environment there is a need to establish as culture of respect and inclusion of students; students interact safely; support from all school staff and sets a tone of respect in class. Safe working and academic environments are intentionally created and could lead to acceptability of gender diverse students and create a sense of security within the school environment.

\subsubsection{Acceptance, Inclusiveness and Positivity}

Acceptance and inclusiveness are concerned with giving equal opportunity to all children and to have a right to education whereby there is a need for significant changes one's 
ideologies and actions in education that ranges from school and educational policies to classroom practices. Kosciw et al. (1999) reports that inclusion is concerned with education for all and for those who are academically excluded as this report study indicates that a conducive environment has been create for functionality and freedom of choices for gender diverse students.

The positivity in the school environment has been noted through school's initiative and peer support as the peers are defensive against any form oppression towards the gender diverse peers. Closely supported by Craig et al. (2008) this study also revealed that the LGBTQIA learners found support from other gender diverse youth through friendship groups. There is a sense of realisation among peers related to gender diverse student's sexual preferences and choices and tend to see them beyond their sexuality. There is an increased sense of empowerment and being together helped them feel less isolated as indicated in a research by Craig et al. (2008). According to Grossman et al. (2009) coming together is regarded as a positive school experience for gender diverse learners because it gives them the opportunity to meet people who accept and support them. Further, Kosciw et al. (2013) stated that the involvement of LGBTQIA learners actively in schools will lower the incidences of victimization and can lead to improved academic performance, positive sense of self identity and improved relationships (Bhana, 2011).

Furthermore, Kosciw et al. (2013) found that the implementation of safety policies positively contributes to the gender diverse learner's psychological wellbeing as it strengthens the sense of belonging, increased the feeling of being safe and self-worth. The learners stated the best policy at the school was to allow them to dress as they wish to. In relation to research conducted by Msibi (2012) and Robinson (2010) this study revealed that a positive self-concept, a sense self-worth and hope contributed to the learner participants' positive experiences at school. The school through policy has greatly support them and they feel that it is given the 
sense of acceptance and feel an integral member of the school's system. They feel more confident and feel safe at school.

Teacher support in this report suggest has increased overtime despite some who may not approve of their choice and orientation they can be academically support by most of them. It was evident that when educators were accommodating, it made them feel accepted. As research by Msibi (2012) stated that gender diverse learners in schools are no longer powerless, hopeless and passive, as they are now more proud, self-worthy and confident. Msibi (2012) also suggest that the teachers felt that teachers have the responsibility to support each child in the school despite their choice or alternative lifestyle. Furthermore, it concludes teachers' suggestions that teachers felt that teachers need to change their mind-sets and accept the nature of student's choices; they can be mentors and support the students. As noted, that increased visibility, sense of pride, and being more vocal are all positive signs of increased confidence and self-worth. As McCormack (2011) in support to this study indicated that LGBTQIA students are experiencing increased visibility due to positive attitude towards them by their peers and teachers.

\subsection{RECOMMENDATIONS FOR STUDENT SUPPORT IN NEW ZEALAND}

\section{SCHOOLS}

This research summarises the following recommendations in order to create a positive learning environment for the gender diverse or the LGBTQIA students in New Zealand secondary schools:

1. The Ministry of Education, New Zealand should consider polices and educating the all learners and teachers in New Zealand schools related to the behaviour and attitudes related to homophobia. There is a possibility or an opinion that by educating or creating awareness among learners and educators can be significantly achieved through workshops for the teachers and 
curriculum itself. The gender diverse students currently lack important legal protection which would enable them to participate fully in schools. Lack of protection has been a barrier for the ability to participate and succeed academically. In order to encounter negative experiences climate and for student well-being there is a need for explicit non-discriminatory policies.

2. There is a need for curriculum reform and understanding that LGBTQIA and gender diversity are prevalent in our schools. There is a need for designated time allocation to educate the students in secondary related to sexuality and family life. The curriculum should address gender identities and experiences in depth. The schools can include this through actively developing the educators into skills required to address these issues.

3. There is a need for policy reforms in the schools whereby the Education Department should make provisions that the LGBTQIA students are specifically aimed and protected against any form of harassment and abuse.

4. Students and teachers should be provided with training to enhance understanding and create acceptance for gender diverse students. Training student leaders could lead to transformations as well and create respectful space for all students. Such training could be role plays or educational content which can help to develop comfort for gender diverse students.

5. School staff should undergo mandatory training which includes the issues related to gender diverse students, terminologies and best practices so that the staff can create a more inclusive institution and curriculum.

\subsection{RECOMMENDATIONS FOR FUTURE RESEARCH}

This research has been intended to provide the insight of the issue that the gender diverse students face in secondary schools in New Zealand. This may serve as the basis for future research in the field of education and psychology to better understand the issues related to LGBTQIA students. 
The future possibilities could be:

1. Similar research could be carried out at more impressionable age groups that is aged 12 to 15-year olds. As per literature this is one of the most crucial age group and this the age group when students realise their sexuality and the better time to educate the heterosexual learners and change their mind set as they develop.

2. This research could be carried out amongst different socio-economic environment. The research could be carried out in different school deciles and make comparisons of different decile schools and their policies which can expand our understanding and experiences of the LGBTQIA leaners in New Zealand schools. This could also enhance our practices and experiences.

3. To better understand the level of acceptance of teaching the gender diverse issues in schools by the teachers. A larger sample of teachers and leaners from wider districts should be included.

\subsection{STRENGTHS OF THE STUDY}

As per literature review and available literature this topic has been well researched in some Western countries however, there has been a limited research that focuses on the secondary school students as most of the literature available focus on the LGBTQIA youths. Thus, this justifies the need for this research in New Zealand secondary schools especially among the senior students.

Furthermore, the use of the research approach that is the qualitative methodology allowed be to use different sources mainly narrative, for data collection and in-depth analysis. The use of the open-ended questions provided me with the students and teachers views and perceptions. This allowed me to closely analyse their reactions as they discuss and to take in consideration of both verbal and non-verbal feelings. This was an opportunity to discuss the 
issues and experiences at school. Some of the participants felt that this was one of the ways that could express their feelings with the hope that positive change could be brought about.

This research has given me a better insight of the lives of the LGBTQIA students in a developed country as where I have taught and was raised is totally different. It allowed me to compare the situations and to think back what and how the students back home would be feeling and going through as the system is still very consecutive. This has increased my respect for the schools, teachers and the LGBTQIA students who fight through to be recognised and appreciated by others. 


\section{CONCLUSION}

Despite having limited literature prevalent from the New Zealand secondary schools, several conclusions can be drawn based on the data provided by the participants.

The research concludes that education being fundamental right of every child and they and their interest needs to be well protected. As the New Zealand Curriculum outlines that the learners must be supported holistically so that the diversity needs stated by the participants could be addressed and worked upon. The result does indicate that though a small sample of student's participants were interviewed the students do have difficulties both psychologically and physically. Research notes that the students are subject to mental health challenges while being at school due to harassment and abuse at school. The teachers in this study reflected that the LGBTQIA issues in their classroom was minimum to none. The most teacher participants did not state that they do discuss the gender issues in their classrooms.

This is consistent with the literature provided that most teacher believe and treat their students as heterosexual and feel that it is not their subject matter. The findings of the study reveal that the school and some teachers do their best in order to accommodate, recognise, support and protect the gender diverse students in their school. Unfortunately, some teachers are unaware of the difficulties gender diverse students face and were insistent that they should not be treated as any special from other students. Therefore, the challenges faced by the students in terms of abuse and harassment were hardly addressed by their teachers in their class and were not supported psychologically in class despite the fact the school has on site social work department with counsellors the classroom is yet the place these students spend most their time in. it is where they need to be support more.

Finally, I draw my conclusion that there is an urgent need for intervention to educate and to build teacher capacities schools in New Zealand. The more specific attention needs to be met such as sexual orientation, harassment and abuse and the negative experiences the 
gender diverse students in their class and schools undergo. The study indicates that change in teacher attitudes, more resources, better information techniques and intervention will enable teachers as well as the students in schools to address the difficulties and challenges faced by gender diverse students. 


\section{REFERENCE LIST}

Adams, M., Bell, L., Goodman, D. and Joshi, K. (2016). Teaching for diversity and social justice. New York: Routledge.

Akerlof, G. and Kranton, R. (2002). Identity and Schooling: Some Lessons for the Economics of Education. Journal of Economic Literature, 40(4), pp.1167-1201.

Alice, L. and Star, L. (2004). Queer in Aotearoa New Zealand. Palmerston North, N.Z.: Dunmore Press.

Allan, A. (2008). Ethics in Psychology and Law: An International Perspective. Ethics \& Behaviour, 25(6), pp.443-457.

Alton-Lee, A. (2003). Quality Teaching for Diverse Students in Schooling: Best Evidence Synthesis. Wellington, New Zealand: Ministry of Education. [Online] http://intra.bay.net.nz/Learning_objects/datas/quality.pdf, [Accessed 2 Mar. 2018].

American Psychological Association. (2011). Definition of terms: Sex, gender, gender identity, and sexual orientation, Available at: http://www.apa.org/pi/LGBTQIA/resources/sexuality-definitions.pdf/ [Accessed 7 Feb. 2018].

Anon,

(2019).

[online]

Available

at: https://www.researchgate.net/publication/304356584_Member_Checking_A_Tool_to_E nhance_Trustworthiness_or_Merely_a_Nod_to_Validation. [Accessed 1 Apr. 2019].

APA (2012) Guidelines for psychological practice with lesbian, gay, and bisexual clients. American Psychologist, 67(1), pp.10-42. 
Arndt, M., \& De Bruin, G. (2006). Attitudes toward lesbians and gay men: Relations with gender, race, and religion among university students. PINS, 3.

Aronson, D. (1995). The inside story: Teaching Tolerance. 4th ed. pp.23-29.

Barker, R. (1999). The social work dictionary.

Bass, E. and Kaufman, K. (2016). Free your mind. New York: Harper Perennial.

Bennett, L. (1997). Break the silence. Teaching Tolerance. 6th ed. pp.24-29.

Beren, M. (2013). Gay and lesbian families in the early childhood classroom Evaluation of an online professional development course. LEARNing Landscapes, 7(1), p.20.

Bhana, D. (2012). Understanding and addressing homophobia in schools: a view from teachers. South African Journal of Education, 32(3), pp.307-318.

Biggam, J. (2008). Succeeding with your Master's dissertation. Birkshire, England: Open University Press.

Boyatzis, R. (2009). Transforming qualitative information. Thousand Oaks (Ca.): Sage Publications.

Braun, V. And Clarke, V. (2006). Using Thematic Analysis in Psychology. Qualitative Research in Psychology. The University of Auckland and The University of The West of England.

Braun, V. and Clarke, V. (2006). Using thematic analysis in psychology. Qualitative Research in Psychology, 3(2), pp.77-101.

Brown, R., Clarke, B., Gortmaker, V., \& Robinson-Keilig, R. (2004). Assessing the Campus Climate for Gay, Lesbian, Bisexual, and Transgender (GLBT) Students Using a Multiple Perspectives Approach. Journal Of College Student Development, 45(1), 8-26. doi: 10.1353/csd.2004.0003 
Bryman, A. (2004). Social research methods ( $2^{\text {nd }}$ ed.) University Press, Cape Town

Bryman, A. B. (2008). Social research methods ( $3^{\text {rd }}$ ed.). London: Oxford University Press.

Bullock, J. (2002). Bullying among Children. Childhood Education, 78(3), pp.130-133.

Burford, J., Lucassen, M.F.G., Penniket, P. \& Hamilton, T. (2013). Educating for diversity: An informative evaluation of the Rainbow Youth sexuality and gender diversity workshops. Auckland: Rainbow Youth Incorporated.

Butler, A. (2006). Navigating Institutional Homophobia. Journal of Gay \& Lesbian Social Services, 19(1), pp.71-88.

Butler, A., Alpaslan, A., Strümpher, J. and Astbury, G. (2003). Gay and Lesbian Youth Experiences of Homophobia in South African Secondary Education. Journal of Gay \& Lesbian Issues in Education, 1(2), pp.3-28.

Caughey, J. (2006). Negotiating cultures and identities. Lincoln: University of Nebraska Press.

Chesir-Teran, D. (2003). Conceptualizing and Assessing Heterosexism in High Schools: A Setting-Level Approach. American Journal of Community Psychology, 31(3-4), pp.267279.

Cohen-Kettenis, P., \& Pfäfflin, F. (2010). The DSM Diagnostic Criteria for Gender Identity Disorder in Adolescents and Adults. Archives Of Sexual Behavior, 39(2), 499-513. doi: 10.1007/s10508-009-9562-y

Collier, K., van Beusekom, G., Bos, H., \& Sandfort, T. (2013). Sexual Orientation and Gender Identity/Expression Related Peer Victimization in Adolescence: A Systematic Review of Associated Psychosocial and Health Outcomes. Journal Of Sex Research, 50(3-4), 299-317. doi: 10.1080/00224499.2012.750639 
Cornelius-White, J. (2007). Learner-Centered Teacher-Student Relationships Are Effective: A Meta-Analysis. Review of Educational Research, 77(1), 113-143. doi: $10.3102 / 003465430298563$

Corsini, R. (2002). The dictionary of psychology. UK: Brunner Routledge Taylor \& Francis Group.

Coyle, A. and Kritzinger, C. (2002). Lesbian \& gay psychology. New Perspectives.

Craig, S., Tucker, E. and Wagner, E. (2008). Empowering Lesbian, Gay, Bisexual, and Transgender Youth: Lessons Learned from a Safe Schools Summit. Journal of Gay \& Lesbian Social Services, 20(3), pp.237-252.

Craig, S., Tucker, E., \& Wagner, E. (2008). Empowering Lesbian, Gay, Bisexual, and Transgender Youth: Lessons Learned From a Safe Schools Summit. Journal of Gay \& Lesbian Social Services, 20(3), 237-252. doi: 10.1080/10538720802235310

Craig, S., Tucker, E., \& Wagner, E. (2008). Empowering Lesbian, Gay, Bisexual, and Transgender Youth: Lessons Learned From a Safe Schools Summit. Journal of Gay \& Lesbian Social Services, 20(3), 237-252. doi: 10.1080/10538720802235310

Creswell, J. and Creswell, J. (2009). Research design. 3rd ed. United Kingdom: SAGE Publications.

Creswell. J.W. (2003) Research Design: Qualitative, Quantitative and Mixed Methods Approaches. London: Sage. $2^{\text {nd }}$ ed.

Culpan, I. (2004). Physical Education Curriculum Development: A humanistic positioning. In A-M. O’Neill, J. Clarke, \& R. Openshaw (Eds.), Reshaping culture, knowledge and learning? Policy and content in the New Zealand Curriculum Framework. Palmerston North, New Zealand: Dunmore Press 
D. Snapp, Shannon \& Burdge, Hilary \& Licona, Adela \& Moody, Raymond \& Russell, Stephen. (2015). Students’ Perspectives on LGBTQIA-Inclusive Curriculum. Equity \& Excellence in Education. 48. 10.1080/10665684.2015.1025614.

D'Augelli, A., Hershberger, S. and Pilkington, N. (2001). Suicidality Patterns and Sexual Orientation-Related Factors among Lesbian, Gay, and Bisexual Youths. Suicide and LifeThreatening Behaviour, 31(3), pp.250-264.

D'Augelli, A., Hershberger, S., \& Pilkington, N. (1997). Suicidality Patterns and Sexual Orientation-Related Factors among Lesbian, Gay, and Bisexual Youths. Suicide and LifeThreatening Behaviour, 31(3), 250-264. doi: 10.1521/suli.31.3.250.24246

De Vos A. S; Strydom, H. and A. S. de Vos, H. (2005). Research at Grass Roots. Hatfield: Van Schaik.

Denzin, N. (2000). The SAGE handbook of qualitative research. Thousand Oaks: Sage Publications.

Denzin, N. K., \& Lincoln, Y.S. (Eds.). (2005). The Sage handbook of qualitative research ( ${ }^{\text {rd }}$ ed.). London, New Delhi: SAGE publications, Inc.

Department of Education and skills (2008). Relationships and Sexuality Education.

Dissertation.laerd.com. (2012). Purposive sampling | Lærd Dissertation. [online] Available at: http://dissertation.laerd.com/purposive-sampling.php [Accessed 14 Jan. 2019].

Dissertation.laerd.com. (2018). Purposive sampling | Lærd Dissertation. [online] Available at: http://dissertation.laerd.com/purposive-sampling.php [Accessed 5 Apr. 2018].

Education Review Office (2007). The teaching of sexuality education in years 7 to 13. Wellington [N.Z.]: Education Review Office. 
Education Review Office. (2017). Overview. [online] Available at: https://www.ero.govt.nz/publications/promoting-wellbeing-through-sexualityeducation/overview/ [Accessed 1 Feb. 2019].

Education, N. (2019). Home. [online] Bullying Free NZ. Available at: https://www.bullyingfree.nz/ [Accessed 30 Mar. 2019].

Epstein, D. (1994). Challenging lesbian and gay inequalities in education. Buckingham: Open University Press.

Ero.govt.nz. (2017). [online] Available at: https://www.ero.govt.nz/assets/Uploads/ERO18262-Sexuality-Education-brochure-Primary-whanau-v2.pdf [Accessed 7 Feb. 2019].

Ero.govt.nz. (2018). [online] Available at: https://www.ero.govt.nz/assets/Uploads/ERO18262-Sexuality-Education-brochure-Secondary-whanau-v2.pdf [Accessed 6 Feb. 2019].

Espelage, D., Birkett, M., Aragon, S., \& Koenig, B. (2008). Homophobic teasing, psychological outcomes, \& sexual orientation among high school students: What influence do parents and schools have? School Psychology Review, 37(2), 202-216.

European Union Agency for Fundamental Rights. (2013). Fundamental rights: challenges and achievements in 2013 - Annual report 2013. [Online] Available at: http://fra.europa.eu/en/publication/2014/fundamental-rights-challenges-andachievements-2013-annual-report-2013 [Accessed 2 Mar. 2018].

Eyre, L. (1993). Compulsory Heterosexuality in a University Classroom. Canadian Journal of Education / Revue Canadienne De L'éducation, 18(3), 273. doi: 10.2307/1495387

Faculty of Medical and Health Sciences (2017). "Youth'12: Fact Sheet about Transgender Young People”. [E-book] Auckland: The University of Auckland. Available at: 
https://www.fmhs.auckland.ac.nz/assets/fmhs/faculty/ahrg/docs/Youth12-transgenderyoung-people-fact-sheet.pdf [Accessed 7 Mar. 2018].

Feldman, R. (2007). Understanding psychology. New York, NY: McGraw-Hill Education.

Fonagy, P. (2001). Attachment Theory and Psychoanalysis. Milton: Routledge.

Fonagy, P., Gergely,, G., Jurist, E., \& Target, M. (2004). Affect Regulation, Mentalization and the Development of the Self. Milton: Routledge.

Fone, B. (2000). Homophobia. New York, NY: Metropolitan.

Francis, D. and Msibi, T. (2011). Teaching About Heterosexism: Challenging Homophobia in South Africa. Journal of LGBTQIA Youth, 8(2), pp.157-173.

Garner, R. (2015). Sex education lessons 'ignore gay and lesbian relationships'. [Online] The Independent. Available at: http://www.independent.co.uk/news/education/educationnews/sex-education-lessons-ignore-gay-and-lesbian-relationships-research-saysa6745351.html [Accessed 7 Jan. 2018].

Garofalo, R., Wolf, R., Kessel, S., Palfrey, J., \& DuRant, R. (1997). The Association Between Health Risk Behaviors and Sexual Orientation Among a School-based Sample of Adolescents. PEDIATRICS, 101(5), 895-902. doi: 10.1542/peds.101.5.895

Gastic, B. and Johnson, D. (2009). Teacher-Mentors and the Educational Resilience of Sexual Minority Youth. Journal of Gay \& Lesbian Social Services, 21(2-3), pp.219-231.

Gay, Lesbian Equity Network (2016). Being LGBTQIA in schools. A Resource for PostPrimary Schools to Prevent Homophobic and Transphobic Bullying and Support LGBTQIA Students, Wellington. 
GLEN's (1999). National School Climate survey. [online] Available at: http://www.glsen.org/pages/sections/news/natlnews/1999/sep/survey [Accessed 11 Nov. 2018].

Goldberg, A., \& Kuvalanka, K. (2018). Navigating identity development and community belonging when "there are only two boxes to check": An exploratory study of nonbinary trans college students. Journal Of LGBT Youth, 15(2), 106-131. doi: $10.1080 / 19361653.2018 .1429979$

Grant, C., Elsbree, A.R., Fondrie, S. (2004). A Decade of Research on the Changing Terrain of Multicultural Education Research, (2nd Ed.) CA: Josey Bass.

Griffin, P. and Ouellett, M. (2003). From Silence to Safety and Beyond: Historical Trends in Addressing Lesbian, Gay, Bisexual, Transgender Issues in K-12 Schools. Equity \& Excellence in Education, 36(2), pp.106-114.

Grossman, A., Haney, A., Edwards, P., Alessi, E., Ardon, M. and Howell, T. (2009). Lesbian, Gay, Bisexual and Transgender Youth Talk about Experiencing and Coping with School Violence: A Qualitative Study. Journal of LGBTQIA Youth, 6(1), pp.24-46.

Gruber, J. and Fineran, S. (2008). Comparing the Impact of Bullying and Sexual Harassment Victimization on the Mental and Physical Health of Adolescents. Sex Roles, 59(1-2), pp.113.

Gunn, A. (2003). Heteronormativity and early childhood education: Social justice and some puzzling queries. [online] Researchcommons.waikato.ac.nz. Available at: https://researchcommons.waikato.ac.nz/handle/10289/2671 [Accessed 1 Apr. 2018].

Gwyn, C. (2006). Crown Law Opinion. [ebook] Wellington. Available at: https:/www.beehive.govt.nz/sites/all/files/SG\%20Opinion\%202\%20Aug\%202006.pdf [Accessed 7 Feb. 2018]. 
Health.tki.org.nz. (2019). Positive school environment / Philosophy to practice / Action for well-being / Key collections / Home - Health \& PE. [online] Available at: http://health.tki.org.nz/Key-collections/Action-for-well-being/Philosophy-topractice/Positive-school-environment [Accessed 7 Apr. 2019].

Higgins et al (2016). LGBTQIA Ireland Study: An Exploration of Lesbian, Gay, Bisexual, Transgender and Intersex Lives in the Republic of Ireland, GLEN and BeLonG to Youth Service, Dublin.

Hillier, L. (2012). Sexuality education school policy for GLBTIQ students. Sex Education, 12(4), 437-454.

Hoffman, J. (2011). Each Generation of Women Had to Start Anew: A Historical Analysis of Title IX Policy and Women Leaders in the Co-curriculum. Sterling: Stylus Publishing, LLC.

Holmes, S. and Cahill, S. (2004). School Experiences of Gay, Lesbian, Bisexual and Transgender Youth. Journal of Gay \& Lesbian Issues in Education, 1(3), pp.53-66.

Hooper, V. (2004). Gay, Lesbian and Bisexual Youth: Facing Challenges, Building Resilience in New York University Child Study centre letter. Child Study centre letter, 9(2).

Horowitz, A. and Loehnig, G. (2005). Safe Schools Manual. Minnesota: Saint Paul Public Schools

https://www.apa.org. (2012). Answers to Your Questions for a Better Understanding of Sexual Orientation and Homosexuality. [online] Available at: https://www.apa.org/topics/LGBTQIA/orientation [Accessed 6 Jul. 2018]. 
Human Rights Watch. (2019). Scared at School | Sexual Violence Against Girls in South African Schools. [online] Available at: https://www.hrw.org/report/2001/03/01/scaredschool/sexual-violence-against-girls-south-african-schools [Accessed 1 Apr. 2018].

Hyde, M. and Forsyth, E. (1994). Know about gays and lesbians. Brookfield: Millbrook Press. Iep.utm.edu. (2018). Pragmatism | Internet Encyclopaedia of Philosophy. [online] Available at: https://www.iep.utm.edu/pragmati/ [Accessed 1 Feb. 2019].

It's Elementary: Talking about gay issues in school. (1997). [film] Directed by D. Chasnoff and H. Choen. San Franscisco: Women's Educational Media.

Jackson, S. and Weatherall, A. (2010). Gender, health and sexuality in classrooms. Women's Studies Journal, 20(2), pp.166-185.

Johnson, R. (2003). Homosexuality: Nature or Nurture | AllPsych. [Online] Allpsych.com. Available at: https://allpsych.com/journal/homosexuality/ [Accessed 1 Mar. 2018].

Jones, T (2015) Policy and Gay, Lesbian, Bisexual, Transgender and Intersex Students. Cham, Springer International Publishing, Heidelberg, New York, Dordrecht and London.

Jones, T. (2013). How sex education research methodologies frame GLBTIQ students. Sex Education, 13(6), pp.687-701.

Jones, T. (2015). Comparing rural and urban educational contexts for GLBTIQ students. Australian and International Journal of Rural Education, Vol. 25 (2), pp. 44-55.

Kosciw, J., Greytak, E. and Diaz, E. (2009). Who, What, Where, When, and Why: Demographic and Ecological Factors Contributing to Hostile School Climate for Lesbian, Gay, Bisexual, and Transgender Youth. Journal of Youth and Adolescence, 38(7), pp.976-988. 
Kosciw, J., Palmer, N., Kull, R. and Greytak, E. (2013). The Effect of Negative School Climate on Academic Outcomes for LGBTQIA Youth and the Role of In-School Supports. Journal of School Violence, 12(1), pp.45-63.

Kosicw, J. (2003). The 2003 National School Climate Survey: The School-Related Experiences of Our Nation's Lesbian, Gay, Bisexual and Transgender Youth, New York: GLSEN.

Kosicw, J. (2004). The 2003 National school climate survey: The school related experiences of our nation's lesbian, gay, bisexual and transgender youth. The New Educator, 2(2), pp.149-157.

Kothari, C. (2004). Research methodology. New Dehli: New Age Publishers.

Kus, R., \& Saunders, J. (1985). Stages of Coming Out: An Ethnographic Approach. Western Journal Of Nursing Research, 7(2), 177-198. doi: 10.1177/0092055x8500700203

Laurie, A. and Evans, L. (2005). Outlines. Wellington, N.Z.: Lesbian \& Gay Archives of New Zealand.

Laurie, A. and Evans, L. (2009). Twenty years on. Wellington, N.Z.: Lesbian \& Gay Archives of New Zealand.

Leedy, P and Ormrod, J E (2005) “Practical Research” $8^{\text {th }}$ edition, Person, New Jersey, pp $133-245$

Lester, S. (1999). An introduction to phenomenological research. [online] Researchgate. Available at: https://www.researchgate.net/publication/255647619_An_introduction_to_phenomenolo gical_research [Accessed 11 Jan. 2019].

Lipkin, A. (2002). The Challenges of Gay Topics in Teacher Education: Politics, Content, and Pedagogy. Rowman and Littlefield Publishers Inc, New York. 
Littig, E. K. (Producer), \& Long, L. (Director). (1995). Hate, homophobia, and schools [Film]. (Available from Wisconsin Public Instruction, Studio B, Green Bay, WI).

Loftus, J. (2001). America's Liberalization in Attitudes toward Homosexuality, 1973 to 1998. American Sociological Review, 66(5), p.762.

Lozier, A., \& Beckman, O. (2012). Safe school environments for lgbtq youth: are nebraska schools providing a safe environment? International Journal of Psychology: A Biopsychosocial Approach, 11.

Macgillivray, I. (2004). Gay rights and school policy: a case study in community factors that facilitate or impede educational change. International Journal of Qualitative Studies in Education, 17(3), pp.347-370.

Making schools safe for gay and lesbian youth. (1993). Report of the Massachusetts Governor's Commission on Gay and Lesbian Youth.

Mallon, G. (1996). It's like opening Pandora's box: Addressing the needs of gay and lesbian adolescents within educational systems. Reston: Council for Exceptional children, pp.1-6.

Marcus, E. (1999). Is it a choice? (2 ed.) San Francisco: HarperCollins.

Maree, K. (2010). First steps in research. Van Schaik Publishers.

Marshall, C. and Rossman, G. (2011). Designing qualitative research. Thousand Oaks (Cal.) [etc.]: SAGE.

Mayock, P et al., (2009) 'Supporting LGBTQIA Lives: A Study of the Mental Health and Wellbeing of Lesbian, Gay, Bisexual and Transgender People', GLEN, BeLonGTo, Health Service Executive’s National Office for Suicide Prevention (NOSP), Dublin. 
Mayock, P., Brian, N., Carr, N. and Kitching, K. (2009). Supporting LGBTQIA Lives: A Study of Mental Health and Well-Being of Lesbian, Gay, Bisexual and Transgender People. GLEN and BeLonG to Youth Services. GLEN and BeLonG to Youth Services.

Mays, V., \& Cochran, S. (2001). Mental Health Correlates of Perceived Discrimination Among Lesbian, Gay, and Bisexual Adults in the United States. American Journal of Public Health, 91(11), 1869-1876. doi: 10.2105/ajph.91.11.1869

McCombs, B. L. (2004). The case for learner-centered practices: Introduction and rationale for session. Paper presented at the annual meeting of the American Educational Research Association, San Diego, California.

McCombs, B., \& Whisler, J. (1997). The learner-centered classroom and school. San Francisco: Jossey-Bass.

McCormack, M. (2011). Hierarchy without Hegemony: Locating Boys in an Inclusive School Setting. Sociological Perspectives, 54(1), pp.83-101.

McCormack, M. (2019). The Positive Experiences of Openly Gay, Lesbian, Bisexual and Transgendered Students in a Christian Sixth Form College. [online] Socresonline.org.uk. Available at: http://www.socresonline.org.uk/17/3/5.html [Accessed 4 Sep. 2018].

McCune, J. (2008). “Out” in the Club: The Down Low, Hip-Hop, and the Architexture of Black Masculinity. Text And Performance Quarterly, 28(3), 298-314. doi: $10.1080 / 10462930802107415$

McDermid, D. (2008). The Varieties of Pragmatism. London: Bloomsbury Publishing. McDermid, D. (2017). Pragmatism | Internet Encyclopaedia of Philosophy. [Online] Iep.utm.edu. Available at: https://www.iep.utm.edu/pragmati/ [Accessed 7 Feb. 2018]. 
McInnes, D. and Davies, C. (2008). Articulating sissy-boy queerness within and against discourses of tolerance and pride. Queer Youth Cultures, pp.105-121.

Mentalhealth.org.nz.

(2019).

[online]

Available

at:

https://www.mentalhealth.org.nz/assets/Suicide/2017-2018-Annual-Provisional-SuicideStatistics-Final.pdf [Accessed 3 Feb. 2019].

Mentalhealth.org.nz.

(2019).

[online]

Available

at: https://www.mentalhealth.org.nz/assets/Suicide/2017-2018-Annual-Provisional-SuicideStatistics-Final.pdf [Accessed 30 Mar. 2019].

Merriam, S. (2002). Qualitative research in practice. San Francisco: Jossey-Bass.

Mhlanga, R. (2016). Challenges of Gender Equity. Doctor of Philosophy. Zimbabwe Open University.

Mikulsky, J. (2005). Investigating the relationship between "school climate”, school-related outcomes and academic self-concept for Australian, secondary school-aged same-sex attracted youth. [online] Available at: http://edu.au/data/publications / 2005/mik05545.pdf [Accessed 5 Dec. 2018].

Mikulsky, J. (2005). M/C Journal: "Silencing (Homo)Sexualities in School ... A Very Bad Idea". [online] Journal.media-culture.org.au. Available at: http://www.journal.mediaculture.org.au/0502/06-mikulsky.php [Accessed 1 Dec. 2018].

Mikulsky, J. (2005). Silencing (homo) sexualities in school...A very bad idea. M/C Journal, vol. 8, pp 1.

Ministry of Education (2007). The New Zealand Curriculum. Wellington, New Zealand: Learning Media. 
Ministry of Education (2015). "Sexuality Education Guidelines”. [Online] Available at: http://health.tki.org.nz/Teaching-in- HPE/Policy-guidelines/Sexuality-education-a-guidefor-principals-boards-of-trustees-and-teachers [Accessed 7 Feb. 2018].

Ministry of Education, (2015) Sexuality Education: A Guide for Principals, Boards of Trustees, And Teachers. Wellington, New Zealand: Ministry of Education.

Ministry of Education. (2011). Positive behaviour for learning: Action plan. Wellington.

Ministry of Justice (2011). Human Rights Act 1993 No 82, Public Act Contents - New Zealand Legislation. [online] Legislation.govt.nz. Available at: http://www.legislation.govt.nz/act/public/1993/0082/latest/DLM304212.html [Accessed 1 Apr. 2019].

Ministry of Youth Development (2015). Supporting LGBTQIAI Young People in New Zealand. Wellington.

Mishna, F., Newman, P., Daley, A. and Solomon, S. (2009). Bullying of Lesbian and Gay Youth: A Qualitative Investigation. British Journal of Social Work, 39(8), pp.1598-1614.

Morris, M. (2000). Dante's left foot kicks queer theory into gear, Peter Lang Publishing, New York, pp.15-32.

Morrison, L. and L'Heureux, J. (2001). Suicide and gay/lesbian/bisexual youth: implications for clinicians. Journal of Adolescence, 24(1), pp.39-49.

MORRISON, L., \& L'HEUREUX, J. (2001). Suicide and gay/lesbian/bisexual youth: implications for clinicians. Journal of Adolescence, 24(1), 39-49. doi: 10.1006/jado.2000.0361

Msibi, T. (2012). 'I'm used to it now': experiences of homophobia among queer youth in South African township schools. Gender and Education, 24(5), pp.515-533. 
Muižnieks (2014). The Council of Europe Commission for Human Rights. [Online] Wcd.coe.int. Available at: https://wcd.coe.int/com.instranet.InstraServlet?command=com.instranet.CmdBlobGet\&I nstranetImage $=2810149 \&$ SecMode $=1 \&$ DocId $=2256624 \&$ Usage $=2$ [Accessed 3 Mar. 2018].

Munoz-Plaza, C., Quinn, S. and Rounds, K. (2002). Lesbian, Gay, Bisexual and Transgender Students: Perceived Social Support in the High School Environment. The High School Journal, 85(4), pp.52-63.

Murdock, T. and Bolch, M. (2005). Risk and protective factors for poor school adjustment in lesbian, gay, and bisexual (LGB) high school youth: Variable and person-centred analyses. Psychology in the Schools, 42(2), pp.159-172.

Nansel, T., Overpeck, M., Pilla, R., Ruan, W., Simons-Morton, B. and Scheidt, P. (2001). Bullying Behaviours Among US Youth. JAMA, 285(16), p.2094.

New Zealand AIDS Foundation (2017). AIDS in New Zealand. [Online] Available at: https://www.nzaf.org.nz/ [Accessed 7 Feb. 2018].

New Zealand Parliamentary Debates. (2013). Marriage (Definition of Marriage) Amendment Bill - Third Reading. Wellington, New Zealand: (Hansard) Government Printer.

Nzaf.org.nz. (2018). [online] Available at: https://www.nzaf.org.nz/assets/ee-uploads/annualreports-uploads/NZAF_Annual_Report_2018_WEB.pdf [Accessed 1 Jan. 2019].

O'Neill, A., Clark, J. and Openshaw, R. (2004). Reshaping culture, knowledge and learning? Palmerston North, N.Z.: Dunmore Press.

Ollis, D., Mitchell, A., Watson, J., Hillier, L., \& Walsh, J. (2001). Safety in our schools: Strategies for responding to homophobia, La Trobe University, Melbourne 
Olweus, D. (1991). Bully/victim problems in school: Knowledge base and an effective intervention program. The Irish Journal of Psychology, 18(2), pp.170-190.

Orne, J. (2011). 'You will always have to “out” yourself': Reconsidering coming out through strategic outness. Sexualities, 14(6), 681-703. doi: 10.1177/1363460711420462

Page, J.A. \& Liston, D.D. (2002). Homophobia in Schools: Student Teachers Perceptions and Preparation to Respond, Rowman \& Littlefield Publishers Inc, New York

Pascoe, C. (2007). Dude, you're a fag: masculinity and sexuality in high school. Choice Reviews Online, 45(08), 45-4702-45-4702. doi: 10.5860/choice.45-4702

Patel, S. (2015). The research paradigm - methodology, epistemology and ontology - explained in simple language. [online] Available at: http://salmapatel.co.uk/academia/the-researchparadigm-methodology-epistemology-and-ontology-explained-in-simple-language [Accessed 7 Feb. 2018].

Patterson, k. (2018).

Payne, G., \& Payne, J. (2004). Key concepts in social research, Thousand Oaks, California SAGE Publications, Inc.

Pollock, L., \& Eyre, S. (2012). Growth into manhood: identity development among femaleto-male transgender youth. Culture, Health \& Sexuality, 14(2), 209-222. doi: $10.1080 / 13691058.2011 .636072$

Positive school environment / Philosophy to practice / Action for well-being / Key collections / Home - Health \& PE. (2019). Retrieved from http://health.tki.org.nz/Keycollections/Action-for-well-being/Philosophy-to-practice/Positive-school-environment

Post Primary Teachers’ Association (2012). Affirming Diversity of Sexualities and Gender Identities in the School Community: Guidelines. Wellington, p.2. 
Quinlivan, K. (2002). Whose problem is this? Queering the framing of lesbian and gay secondary school students within "at risk” discourses. Journal of Gay and Lesbian Social Services, New York: The Haworth Press, pp.17-31.

Raymond, E. B. (1996). Making a difference: A call for education and action. Reston: Council for Exceptional Children.

Ream, G. and Savin-Williams, R. (2005). Reconciling Christianity and Positive NonHeterosexual Identity in Adolescence, with Implications for Psychological WellBeing. Journal of Gay \& Lesbian Issues in Education, 2(3), pp.19-36.

Rivers, I. (2000). Social Exclusion, Absenteeism and Sexual Minority Youth. Support for Learning, 15(1), pp.13-18.

Robinson, K. (2002). Making the Invisible Visible: Gay and Lesbian Issues in Early Childhood Education. Contemporary Issues in Early Childhood, 3(3), pp.415-434.

Robinson, K. (2005). Doing Anti-Homophobia and Anti-Heterosexism in Early Childhood Education: Moving beyond the Immobilising Impacts of 'Risks', 'fears' and 'silences'. Can We Afford Not To? Contemporary Issues in Early Childhood, 6(2), pp.175-188.

Robinson, K. (2005). Reinforcing hegemonic masculinities through sexual harassment: issues of identity, power and popularity in secondary schools. Gender and Education, 17(1), pp.19-37.

Robinson, K. and Ferfolja, T. (2001). 'What are We Doing This For?' Dealing with Lesbian and Gay Issues in Teacher Education. British Journal of Sociology of Education, 22(1), pp.121-133.

Robinson, K. and Ferfolja, T. (2008). Playing it up, playing it down, playing it safe: Queering teacher education. Teaching and Teacher Education, 24(4), pp.846-858. 
Rofes, E. (1989). Opening up the Classroom Closet. Education Digest Nov 90, Vol. 56, Issue 3 [Electronic version] Available at: http://web22.epnet.com/ [Accessed 7 Feb. 2018]

Ross, B. and Burrows, L. (2003). It takes two feet. Palmerston North, N.Z.: Dunmore Press.

Rossen, F., Lucassen, M., Denny, S., \& Robinson, E. (2009). Youth '07 the health and wellbeing of secondary school students in New Zealand: Results for young people attracted to the same sex or both sexes. Auckland: The University of Auckland.

Rubbert, J., Scarlet, K., Jimson-Healey, R. and Jeffares, A. (2016). Supporting Transgender Student Inclusion in a Changing Legal Environment.

Rubin, S. (1995). Children who grow up with gay or lesbian parents: How are today's schools meeting this "invisible" group's needs? Unpublished Master's thesis. University of Wisconsin, Madison.

Ry.org.nz. (2013). Rainbow YOUTH. [online] Available at: https://www.ry.org.nz/ [Accessed 11 Feb. 2018].

Sanlo, R. (2002). Our Place on Campus. Charlotte: Information Age Publishing.

Sanlo, R. (2004). Lesbian, Gay, and Bisexual College Students: Risk, Resiliency, and Retention. Journal of College Student Retention: Research, Theory \& Practice, 6(1), 97110. doi: 10.2190/fh61-ve7v-hhcx-0pur

SAVIN-WILLIAMS, R. (2001). A critique of research on sexual-minority youths. Journal of Adolescence, 24(1), 5-13. doi: 10.1006/jado.2000.0369

Seelman, K., Walls, N., Hazel, C. and Wisneski, H. (2012). Student School Engagement Among Sexual Minority Students: Understanding the Contributors to Predicting Academic Outcomes. Journal of Social Service Research, 38(1), pp.3-17. 
Shine, A., and Contributor, G (2018). Lesbian, Gay, and Bisexual - New Ways Ministry. [Online] New Ways Ministry. Available at: https://www.newwaysministry.org/issues/sexual-orientation/ [Accessed 7 Feb. 2018].

Slater (2000). Britain: Sex education under fire. The Courier, [online] July/August. Available at: http://www.unesco.org/courier/2000_07/uk/apprend.htm [Accessed 4 Sep. 2018].

Socialreport.msd.govt.nz. (2016). People: The Social Report 2016 - Te pürongo oranga tangata. [online] Available at: http://socialreport.msd.govt.nz/people.html\#gay-lesbianbisexual-and-transgender-people [Accessed 1 Feb. 2019].

Statistics New Zealand (2010). Characteristics of same - sex couples in New Zealand. Statistics New Zealand, Wellington:

Stormbreak (2003). Highlights of the Gay Life and style New Millennium survey. [online] Stormbreak. Available at: http://www.stormbreak.co.uk/ranbow.html [Accessed 9 Sep. 2018].

Straus, C. and Corbin, J. (1998). Basics of Qualitative Research: Techniques \& Procedures for Developing Grounded Theory. Thousand Oaks: Sage Publications Inc.

Stuff. (2018). Acceptance of LGBTQIA people still a way to go. [online] Available at: https://www.stuff.co.nz/manawatu-standard/news/65710497/null [Accessed 1 Feb. 2019].

Sumara, D. (2008). Small Differences Matter: Interrupting Certainty About Identity in Teacher Education. Journal of Gay \& Lesbian Issues in Education, 4(4), pp.39-58.

Surtees, N. (2008). Teachers following Children? Australasian Journal of Early Childhood, 33(3), pp.10-17.

Tashakkori, A. and Teddlie, C. (1998) Mixed Methodology: Combing Qualitative and Quantitative Approaches. London: Sage. 
Tasker, G. (2004). Health Education: Contributing to a just society through curriculum change. In A. O’Neill, J. Clarke, \& R. Openshaw (Eds.), Reshaping culture, knowledge and learning: Policy and content in the New Zealand Curriculum Framework (pp. 203-224). Palmerston North, New Zealand: Dunmore Press.

The New Zealand Health Curriculum. (2017). [online] Available at: https://nzcurriculum.tki.org.nz/The-New-Zealand-Curriculum [Accessed 7 Feb. 2018].

Thurlow, C. (2001). Naming the "outsider within": homophobic pejoratives and the verbal abuse of lesbian, gay and bisexual high-school pupils. Journal of Adolescence, 24(1), pp.25-38.

Tinto, V. (1975). Dropout from Higher Education: A Theoretical Synthesis of Recent Research. Review of Educational Research, 45(1), 89. doi: 10.2307/1170024

Tinto, V. (1982). Limits of Theory and Practice in Student Attrition. The Journal of Higher Education, 53(6), 687. doi: 10.2307/1981525

Tinto, V. (1988). Stages of Student Departure: Reflections on the Longitudinal Character of Student Leaving. The Journal of Higher Education, 59(4), 438-455. doi: 10.1080/00221546.1988.11780199

Toomey, R., McGuire, J., \& Russell, S. (2012). Heteronormativity, school climates, and perceived safety for gender nonconforming peers. Journal of Adolescence, 35(1), 187196. doi: 10.1016/j.adolescence.2011.03.001

Toomey, R., Ryan, C., Diaz, R., Card, N., \& Russell, S. (2010). Gender-nonconforming lesbian, gay, bisexual, and transgender youth: School victimization and young adult psychosocial adjustment. Developmental Psychology, 46(6), 1580-1589. doi: 10.1037/a0020705 
Turiel, E. (1998). The development of morality, in: W. Damon \& N. Eisenberg (Eds)

Handbook of child psychology. Social, moral, and personality development (5th ed.). New York, Wiley).

UNESCO. (2011). Rio Statement on Homophobic Bullying and Education for All. Rio de Janiero, Brazil

United Nations Educational, Scientific and Cultural Organization (2016). Out in The Open Education Sector Responses to Violence Based on Sexual Orientation and Gender Identity/Expression. Paris, France.

Valenti, M., \& Campbell, R. (2009). Working with youth on LGBT issues: why Gay-Straight Alliance advisors become involved. Journal Of Community Psychology, 37(2), 228-248. doi: 10.1002/jcop.20290

Valocchi, S. (2005). Not yet queer enough: The lessons of queer theory for the sociology of gender and sexuality. Gender and Society, 19(6), 750-770.

Waldo, C. (1998). Out on Campus: Sexual Orientation and Academic Climate in a University Context. American Journal Of Community Psychology, 26(5), 745-774. doi: 10.1023/a:1022110031745

Ward, J., \& Schneider, B. (2009) The reaches of heteronormativity: An introduction. Gender \& Society, 23(4), pp 433-439, Wellington.

Wayne, n. (2008). An Analysis of Student Teacher Preparation in Relation to Homophobia. The Faculty of Humboldt State University, p.23.

Weiler, E. (2004). Legally and morally, what our gay students must be given. The Education Digest, 69. 
Wells, H., \& Polders, L. (2005). Lack of empowerment among gay, lesbian, bisexual transgender people in Kwazulu Natal, South Africa.

Wilkinson, L. and Pearson, J. (2009). School Culture and the Well-Being of Same-Sex-Attracted Youth. Gender \& Society, 23(4), pp.542-568.

Williams, T., Connolly, J., Pepler, D. and Craig, W. (2004). Peer Victimization, Social Support, and Psychosocial Adjustment of Sexual Minority Adolescents. Journal of Youth and Adolescence, 34(5), pp.471-482.

Willig. (2008). Introducing Qualitative Research in Psychology. Milton Keynes: Open University Press.

Wright, L. and Cullen, J. (2001). Reducing College Students' Homophobia, Erotophobia, and Conservatism Levels Through a Human Sexuality Course. Journal of Sex Education and Therapy, 26(4), pp.328-333.

Wyss, S. (2004). 'This was my hell': the violence experienced by gender non-conforming youth in US high schools. International Journal of Qualitative Studies in Education, 17(5), pp.709-730. 

APPENDIX 
Phone 0-4-463 6028 Email judith.loveridge@vuw.ac.nz

TO Krishn Chandra

FROM Dr Judith Loveridge, Convenor, Human Ethics Committee

DATE 15 August 2018

\section{PAGES 1}

\section{SUBJECT Ethics Approval: 26058}

Gender identity: exploring struggles \& school support among New Zealand senior secondary students

Thank you for your application for ethical approval, which has now been considered by the Human Ethics Committee.

Your application has been approved from the above date and this approval is valid for three years. If your data collection is not completed by this date you should apply to the Human Ethics Committee for an extension to this approval.

Best wishes with the research.

Kind regards

Judith Loveridge

Convenor, Victoria University Human Ethics Committee 
Gender Identity: Exploring Struggles and School Support Among New Zealand Senior Secondary Students.

\section{INFORMATION SHEET FOR PARTICIPANTS [for Interviews]}

You are invited to take part in this research. Please read this information before deciding whether or not to take part. If you decide to participate, thank you. If you decide not to participate, thank you for considering this request.

\section{Who am I?}

My name is Krishn Chandra and I am a Masters student in the Master of Arts in Education programme at Victoria University of Wellington. This research project is work towards my thesis.

\section{What is the aim of the project?}

The research aims to cover:

- To study and scrutinize the New Zealand education curriculum and policies in relation to gender diversity and the struggles faced by senior secondary students.

- $\quad$ The issues faced by gender diverse students in NZ schools.

- To make recommendations as to how the education system and schools support gender diversity for their optimum growth.

This research has been approved by the Victoria University of Wellington Human Ethics Committee 26058.

\section{How can you help?}

You have been invited to voluntarily participate because as you meet the specific purpose of the study as the study focuses on senior secondary students. I will be recruiting six to eight students from Years 12-13 and five teachers from one Auckland secondary school. If you agree 
to take part, I will interview you outside of the school timetable on the school grounds. I can also offer the option of you emailing me your answers to the interview schedule.

I will ask you questions on your views about gender diversity and the role of the school with regards to supporting gender diverse students. The interview will take up to one hour. I will audio record the interview with your permission and write it up afterwards for you to check. You can choose to not answer any question or stop the interview at any time, without giving a reason. You can withdraw from the study by contacting me at any time before $30^{\text {th }}$ of August 2018. If you withdraw, the information you provided will be destroyed or returned to you.

\section{What will happen to the information you give?}

This research is confidential ${ }^{1 *}$. This means that the researcher named below will be aware of your identity, but the research data will be combined, and your identity will not be revealed in any reports, presentations, or public documentation. However, you should be aware that in small projects your identity might be obvious to others in your community.

You will not be named in the final report, but your organisation may be named (provided you have the authority to agree to this on behalf of the organisation).

Only my supervisors and myself, the transcriber (who will be required to sign a confidentiality agreement). I will read the notes or transcript of the interview. The interview transcripts, summaries and any recordings will be kept securely and destroyed on $31^{\text {st }}$ August, 2020. You can also access the content of the thesis to verify if confidentiality has been maintained and you feel that information you have provided accurate and not manipulated to suit others viewpoints.

\section{What will the project produce?}

The information from my research will be used in my Master's thesis.

\section{If you accept this invitation, what are your rights as a research participant?}

You do not have to accept this invitation if you don't want to. If you do decide to participate, you have the right to:

\footnotetext{
1* Confidentiality will be preserved except where you disclose something that causes me to be concerned about a risk of harm to yourself and/or others.
} 
- $\quad$ choose not to answer any question;

- $\quad$ ask for the recorder to be turned off at any time during the interview;

- $\quad$ withdraw from the study before $30^{\text {th }}$ August, 2018;

- $\quad$ ask any questions about the study at any time;

- $\quad$ receive a copy of your interview recording;

- $\quad$ receive a copy of your interview transcript;

- $\quad$ read over and comment on a written summary of your interview;

- $\quad$ be able to read any reports of this research by emailing the researcher to request a copy.

\section{If you have any questions or problems, who can you contact?}

If you have any questions, either now or in the future, please feel free to contact [either/me]:

\section{Student:}

Name: Krishn Chandra

University email

chandrkris@myvuw.ac.nz

\section{Supervisor:}

Name: Dr. Cherie Chu

address: Role: Senior Lecturer

School: School of Education

Phone: 04-463 5316

Cherie.chu@vuw.ac.nz

\section{Human Ethics Committee information}

If you have any concerns about the ethical conduct of the research you may contact the Victoria University HEC Convenor: Dr Judith Loveridge. Email hec@vuw.ac.nz or telephone +64-44636028.

For any further counselling the following societies do provide necessary advises both face to face and by telephone.

NZ Outline

31-35 Hargreaves St, 
Freemans Bay,

Auckland 1011

Phone

Free confidential info line:

0800 OUTLINE (688 5463)

092813409

Email

info@outline.org.nz

Rainbow Auckland

PO Box 147663

Auckland 1144

email: info@rainbowauckland.org.nz 


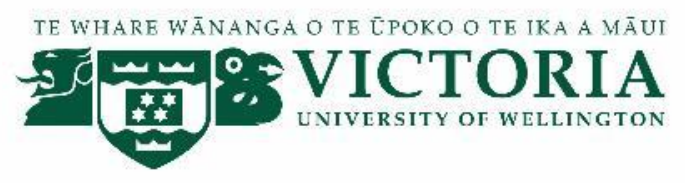

\section{GENDER IDENTITY AND STRUGGLES AMONG NEW ZEALAND SENIOR SECONDARY STUDENTS \\ A STUDY OF HOMOPHOBIA AND SCHOOL SUPPORT}

\section{CONSENT TO INTERVIEW}

This consent form will be held for 2 years.

\section{Researcher: Krishn Chandra, school of Education, Victoria University of Wellington.}

- $\quad$ I have read the Information Sheet and the project has been explained to me. My questions have been answered to my satisfaction. I understand that I can ask further questions at any time.

- $\quad$ I agree to take part in an audio recorded interview.

I understand that:

- I may withdraw from this study at any point before $30^{\text {th }}$ August, 2018, and any information that I have provided will be returned to me or destroyed.

- $\quad$ The identifiable information I have provided will be destroyed on $31^{\text {st }}$ August, 2018.

- $\quad$ Any information I provide will be kept confidential to the researcher and the supervisor and the transcriber.

- $\quad$ I understand that the results will be used for a Master's thesis.

- $\quad$ My name will not be used in reports, nor will any information that would identify me.

- $\quad$ I would like a copy of the recording of my interview: Yes $\square \quad$ No

- $\quad$ I would like a copy of the transcript of my interview: Yes $\square$ No $\square$

- I would like a summary of my interview: Yes $\square \quad$ No $\square$

- $\quad$ I would like to receive a copy of the final report and have added my email Yes $\square \quad$ No $\square$ address below.

Signature of participant:

Name of participant:

Date:

Contact details: 


\section{Transcriber Confidentiality Agreement}

\section{Research project:}

Gender Identity and Struggles among New Zealand Senior Secondary Students -

A Study of Homophobia and School Support

\section{Researcher: Krishn Chandra}

I have read the information sheet that has been sent to participants of this research project.

I agree to treat the names of the participants and their responses as confidential.

A Il e lectron ic inform ation w ill be kept in a passw ordprotected file and all written material will be kept in a locked file

Name:

Signature:

Date: 
GENDER IDENTITY AND STRUGGLES AMONG NEW ZEALAND SENIOR SECONDARY STUDENTS

A STUDY OF HOMOPHOBIA AND SCHOOL SUPPORT

\section{CONFIDENTIALITY AGREEMENT}

(Full Name - printed) agree to keep confidential

all information concerning the project

(Title of Project).

I will not retain or copy any information involving the project.

iignature:

Date: 
Gender Identity: Struggles \& School Support Among New Zealand Senior Secondary Students

\section{INFORMATION SHEET FOR PRINCIPALS}

Your school is invited to take part in this research. Please read this information before deciding whether or not to take part. If you decide to allow your school to participate, thank you. If you decide not to participate, thank you for considering this request.

\section{Who am I?}

My name is Krishn Chandra and I am a Masters student in the Master of Arts in Education programme at Victoria University of Wellington. This research project is work towards my thesis.

\section{What is the aim of the project?}

The research aims to cover:

- To study and scrutinize the New Zealand education curriculum and policies in relation to gender diversity and the struggles faced by senior secondary students.

- $\quad$ The issues faced by gender diverse students in NZ schools.

- To make recommendations as to how the education system and schools support gender diversity for their optimum growth.

This research has been approved by the Victoria University of Wellington Human Ethics Committee 26058.

\section{How can you help?}

Your school have been invited to voluntarily participate as the study focuses on senior secondary students. I will be recruiting six to eight students from Years 12-13 and five teachers 
from an Auckland secondary school. I will also invite 5 teachers from your school to volunteer as participants, with their consent.

If you allow the school to participate I will interview the participants outside of the school timetable on the school grounds. I can also offer the option of the participants from your school emailing me their answers to the interview schedule.

The questions will be based on their views about gender diversity and the role of the school. The interview will take up to one hour. I will audio record the interview with the participant's permission and write it up afterwards for them to check. The participants can choose to not answer any question or stop the interview at any time, without giving a reason. You can withdraw from the study by contacting me at any time before $30^{\text {th }}$ of August, 2018. If your school or participants withdraw, the information provided will be destroyed or returned to the participants.

\section{What will happen to the information provided?}

This research is confidential ${ }^{2 *}$. This means that the researcher named below will be aware of your identity but the research data will be combined and the participants' identity will not be revealed in any reports, presentations, or public documentation.

Neither the participants will be named in the final report nor your organisation to maintain any form information which may cause any unforeseen circumstances for the institution. Also, any information provided by the participants cannot be revealed to the institution but complied report could be provided to the school.

Only my supervisors and myself, the transcriber (who will be required to sign a confidentiality agreement) will read the notes or transcript of the interview. The interview transcripts, summaries and any recordings will be kept securely and destroyed on 31 $1^{\text {st }}$ August, 2020.

\section{What will the project produce?}

The information from my research will be used in my Master's thesis.

If you and the participants accept this invitation, what are the rights of the students and teachers as a research participant?

Your school do not have to accept this invitation if you don't want to. If you do decide to participate, please note that the participants have the right to: 
- $\quad$ choose not to answer any question;

- $\quad$ ask for the recorder to be turned off at any time during the interview;

- $\quad$ withdraw from the study before $30^{\text {th }}$ August, 2018;

- $\quad$ ask any questions about the study at any time;

- $\quad$ receive a copy of your interview recording;

- $\quad$ receive a copy of your interview transcript;

- $\quad$ read over and comment on a written summary of their interview;

- $\quad$ be able to read any reports of this research by emailing the researcher to request a copy.

\section{If you have any questions or problems, who can you contact?}

If you have any questions, either now or in the future, please feel free to contact [either/me]:

\section{Student:}

Name: Krishn Chandra

University email

chandrkris@myvuw.ac.nz

\section{Supervisor:}

Name: Dr. Cherie Chu

address: Role: Lecturer

School: School of Education

Phone: 04-463 5316

\section{Cherie.chu@vuw.ac.nz}

\section{Human Ethics Committee information}

If you have any concerns about the ethical conduct of the research you may contact the Victoria University HEC Convenor: Dr Judith Loveridge. Email hec@vuw.ac.nz or telephone +64-44636028. 
GENDER IDENTITY AND STRUGGLES AMONG NEW ZEALAND SENIOR SECONDARY STUDENTS

A STUDY OF HOMOPHOBIA AND SCHOOL SUPPORT

\section{SCHOOL CONSENT FORM}

I

(Full Name - printed) agree/ do not

agree to allow my school........................... (Name of school) in the above-mentioned research.

I do understand that all information provided will be kept confidential.

I do understand that all care will be taken to prevent any emotional distress to the participants.

Signature:

Date: 
Letter through emails.

Dear Teacher/Student,

My name is Krishn Chandra and I am a Masters student in Master of Arts in Education programme at Victoria University of Wellington. This research project is work towards my thesis. I would like to recruit six to eight students and five teachers from your school. Your school has provided your e-mail so I can invite you to be part of the research if you wish. The purpose of this study to investigate the issues faced by gender diverse students in NZ schools. Participation in this study involves:

- A time commitment of 1 hour.

- An interview in full confidentiality at your school.

- A \$20 gift card for participation

For more information about this study, please contact the principal investigator, Krishn Chandra, returning your queries or interest to this email.

Thank you,

Krishn Chandra

Principal Investigator 


\section{Study Title: GENDER IDENTITY: EXPLORING STRUGGLES \& SCHOOL SUPPORT AMONG NEW ZEALAND SENIOR SECONDARY STUDENTS. INTERVIEW SAMPLE QUESTIONS}

Age: Ethnicity: Gender:

Sexual orientation:

1. How would you explain gender diversity?

2. Do you support gender diverse students at your school? Why or Why not?

3. What are your perceptions towards the struggle of a gender diverse student?

4. Do you feel that your school meets the requirements of a safe physical environment for all students specially those who are struggling with their gender identity?

5. Are there any policies that tend to provide the support to all students at school especially those who have identity concerns?

6. Does the school have harassment, bullying and discrimination policies which includes gender identities and sexualities?

7. Is there any clear procedures to support for those who are experiencing about sexual orientation or gender identity?

8. Is there any complaints policy for students and teachers to bring about natural justice to students?

9. Do you feel that the curriculum addresses the issue of gender identity issues such as homophobia?

10. Does your libraries and resources reflect the commitment towards addressing gender issue?

11. Do the library and teaching resources reflect the school's commitment to affirm diverse sexualities and gender identities?

12. What are your ideologies related to same-sex relationships?

13. What are the struggles of a gender diverse student at your school? 
14. Do you feel everyone at school is made of the responsibilities of accepting gender diverse students?

\section{INTERVIEW SAMPLE QUESTIONS \\ FOR STUDENTS}
Age:
Ethnicity:
Gender:

Sexual orientation:

1. How would you explain gender diversity?

2. Do you support gender diversity among your peers at your school? Why or Why not?

3. What do you think are the struggles of you or your friends of being a gender diverse student?

4. How do you feel your school meeting the requirements of a safe physical environment for all students specially those who are struggling with their gender identity?

5. What policies are in place that tend to provide the support to all students at school especially those who have identity concerns?

6. Does the school has harassment, bullying and discrimination policies which includes gender identities and sexualities? Please explain these further.

7. Is there any clear procedures to support for those who are experiencing about sexual orientation or gender identity? Please explain.

8. What the complaints policy for students to bring about natural justice to students?

9. Do you feel that the curriculum addresses the issue of gender identity issues such as homophobia?

10. How does your libraries and resources reflect the commitment towards addressing gender issue?

11. How well do feel your library and teaching resources reflect the school's commitment to affirm diverse sexualities and gender identities?

12. What are your ideologies related to same-sex relationships?

13. What are the struggles as student you or friend faces being a gender diverse?

14. Do you feel everyone at school is made of the responsibilities of accepting gender diverse students? How is this achieved?

15. How do you feel your school is handling the issues related to gender diversity? 
Please provide any further suggestions that you feel your school should put in place to support gender diversity. 